Claremont Colleges

Scholarship@ Claremont

CGU Theses \& Dissertations

CGU Student Scholarship

2012

\title{
Stylizing, Commodifying, and Disciplining Real Bodies: An Examination of WWE Wrestling
}

Isamu Horiuchi

Claremont Graduate University

\section{Recommended Citation}

Horiuchi, Isamu. (2012). Stylizing, Commodifying, and Disciplining Real Bodies: An Examination of WWE Wrestling. CGU Theses \& Dissertations, 55. http://scholarship.claremont.edu/cgu_etd/55. doi: 10.5642/cguetd/55

This Open Access Dissertation is brought to you for free and open access by the CGU Student Scholarship at Scholarship @ Claremont. It has been accepted for inclusion in CGU Theses \& Dissertations by an authorized administrator of Scholarship @ Claremont. For more information, please contact scholarship@cuc.claremont.edu. 


\section{Stylizing, Commodifying, and Disciplining Real Bodies: An Examination of WWE Wrestling}

A dissertation submitted to the Faculty of Claremont Graduate University in partial fulfillment of the requirements for the degree of

Doctor of Philosophy in Cultural Studies

by

Isamu Horiuchi

Claremont Graduate University, 2012

(C) Copyright Isamu Horiuchi, 2012

All rights reserved. 


\title{
APPROVAL OF THE REVIEW COMMITTEE
}

This dissertation has been duly read, reviewed, and critiqued by the Committee listed below, which hereby approves the manuscript of Isamu Horiuchi as fulfilling the scope and quality requirements for meriting the degree of Doctor of Philosophy in Cultural Studies.

\author{
Henry Krips, Chair \\ Claremont Graduate University \\ Professor of Cultural Studies \\ Andrew W. Mellon All-Claremont Chair of Humanities
}

Alexandra Juhasz, Member
Pitzer College
Professor of Media Studies

Kathleen Fitzpatrick, Member

Pomona College

Professor of Media Studies 


\section{Abstract \\ Stylizing, Commodifying, and Disciplining Real Bodies: An Examination of WWE wrestling}

by

Isamu Horiuchi

Claremont Graduate University: 2012

This dissertation examines professional wrestling in the U.S., in particular, live and television shows produced by the World Wrestling Entertainment (WWE). Through the examination, it addresses complex issues of authenticity, audience, commodification, and discipline in contemporary popular culture and media.

I use three approaches in this study. First, I apply the theory of culture industry, developed by Theodor W. Adorno and Max Horkheimer, to understand WWE wrestling. I examine how the WWE thoroughly stylizes its products to attract fans and condition them to repeat the same calculable reactions. However, contemporary fans often refuse to react as the WWE wants them to. By analyzing the complex interplay between the WWE and fans, I update and re-contextualize Adorno and Horkheimer's idea that the culture industry exerts total control over consumers.

Second, I examine the recent rise of "nonfictional" narratives in professional wrestling, narratives that candidly acknowledge wrestling's scripted nature. I demonstrate how the WWE uses nonfictional narratives to present fans new ways of finding realness in wrestling and respecting wrestlers. I also point out that, by utilizing both fictional and nonfictional narratives, the WWE has developed clever ways of balancing between offering controversial products and transmitting conservative and respectable messages to enhance its populist appeal. 
Third, I look at the history of professional wrestling through theories of modernity and postmodernity. I grasp it as a dynamic process in which wrestling has expressed its challenge against and ambivalence towards dominant ideologies, values, and masculinities of modernity in multiple ways. I also examine the predominance of obsessed subjectivities in contemporary WWE wrestling as a unique form of postmodern expression. I argue that obsessively competitive and self-destructive performances of WWE wrestlers illuminate the contradiction of the construction of modern "disciplined" subjects described by Michel Foucault. They also reveal that in the culture where pain and destruction of human beings are among the most desired objects, the WWE has to endanger real live bodies of its wrestlers in order to survive and thrive. WWE is a rich, problematic, and compelling cultural phenomenon that illuminates issues and contradictions of itself, and the system it belongs to. 


\section{Acknowledgements}

I would like to thank my dissertation committee, Henry Krips, Alexandra Juhasz, and Kathleen Fitzpatrick for their guidance, support and encouragement. Every chapter of this dissertation has immensely benefitted from their invaluable suggestions and thoughtful critiques.

I would also like to thank Ranu Samantrai, who was a member of my qualifying examination committee. I am indebted to her kindness and willingness to work with me on the subject—Sport and Modern Society—which was outside her specialty, yet she engaged with zeal.

I also gratefully acknowledge the financial assistance provided by the Department of Cultural Studies at Claremont Graduate University, which helped me to write up this dissertation.

I am also very grateful to my wife Miki and my daughter Mito for always being by my side and supporting me. Their presence in my life gives me strength and courage to keep moving forward.

Finally and most importantly, I would like to thank my parents Nobuyuki and Noriko Horiuchi, without whose love, patience, and support I would have not been able to complete my graduate study in the U.S. This dissertation is dedicated to them. 


\section{Table of Contents}

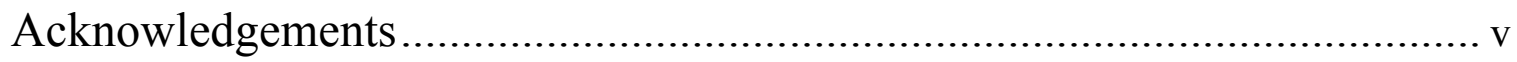

\section{Introduction}

The Wrestler, Professional Wrestling, and Contradictions of Contemporary Popular Culture ....................................... 1

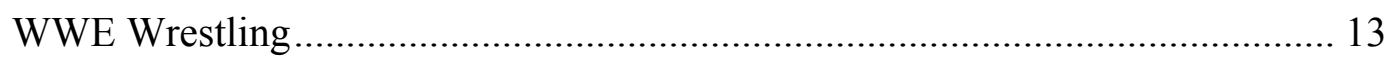

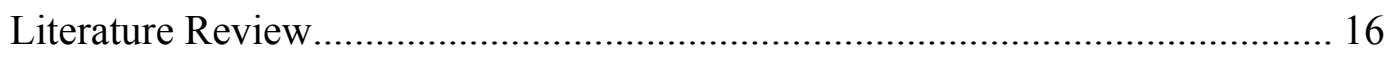

Examining Contemporary Professional Wrestling ....................................... 41

\section{Chapter 1: Contemporary WWE Wrestling through Culture Industry Theory}

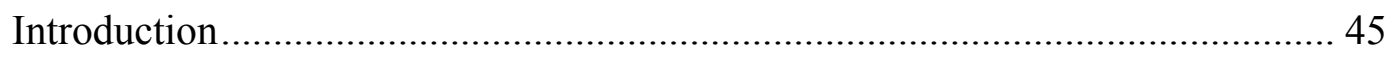

Section 1: The Theory of the Culture Industry ................................................ 49

Section 2: Stylistic Features of WWE Wrestling through Culture Industry Theory .................................................. 58

Section 3: The State of Total Control in the Ring ........................................... 77

Section 4: WWE Wrestling as a Failure of Enlightenment Rationality............... 93

\section{Chapter 2: Issues of Realism in Contemporary WWE Wrestling: The Promotion and Circulation of Nonfictional Narratives in the Late 1990s}

Introduction. 100

Section 1: Realism of Professional Wrestling:

When Insiders were Obliged to "Protect the Business".. 
Section 2: The Transformation since the Late 1990s:

The Dualization of Realism in WWE Wrestling ............................... 109

Section 3: Realism, or Making Sense of WWE Wrestling as Fiction ................ 118

Section 4: The Significance of the Increase of the Promotion of Nonfictional narratives ...................................... 132

Section 5: Nonfictional Narratives as a Channel of Political Discourse ............ 146

Section 6: Nonfictional Narratives as Repeatedly Appropriated Texts .............. 152

Chapter 3: The Modern, the Postmodern, and Obsession in Professional Wrestling

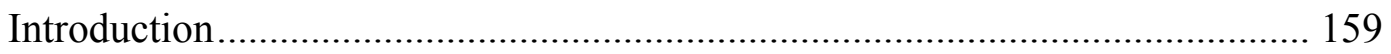

Section 1: Framing the Modern and the Postmodern........................................... 167

Section 2: Professional Wrestling as a Postmodern Phenomenon........................ 186

Section 3: The Aesthetic of Obsession

and Over-the-Top Matches in Contemporary WWE Wrestling ....... 207

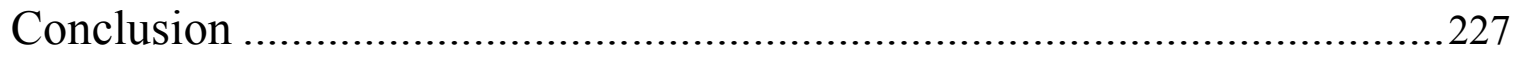

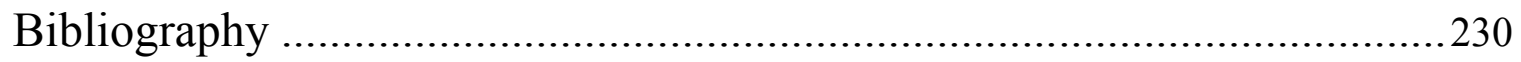




\section{Introduction}

The Wrestler, Professional Wrestling, and Contradictions of Contemporary Popular Culture

The highly successful and celebrated 2008 film The Wrestler, directed by Darren Aronofsky, glorifies but also interrogates contemporary professional wrestling. Unlike previous Hollywood wrestling movies, such as Paradise Alley (1978), No Holds Barred (1989), and Ready to Rumble (2000), The Wrestler openly acknowledges that professional wrestling matches are scripted performances; it provides a detailed description of backstage discussions among wrestlers choreographing their matches. In the film, Mickey Rourke portrays the aging and battered professional wrestler Randy “The Ram” Robinson. Randy, a big star in the 1980s, is now living alone in a seedy trailer park, working on weekdays at a supermarket under an odious boss. On weekends, he still performs wrestling matches in local shows for much less pay than the thousands of dollars he made during his heyday. Although he often cannot afford the rent for his trailer, he is willing to buy various illegal substances (e.g., steroids) from his gym mate to maintain huge muscles that look disproportionate at his age.

One day, Randy suffers a heart attack after performing a grueling hardcore-style match, and he decides to retire and have a normal life. But he eventually fails. He is unable to fix his relationship with his estranged daughter, and he can't stand dealing with his customers at the supermarket deli counter. Randy is determined to stage a comeback through a nostalgia rematch with The Ayatollah, the villain wrestler who performed a successful feud with Randy in their glory days. Before the match starts, Cassidy, a stripper who has been hesitant to pursue a relationship with Randy, shows up to his dressing room. She begs him not to perform the match, reminding him of his physician's warning not to wrestle anymore. But Randy quietly laughs it off and says, "The world don't give a shit about me." As Cassidy asks him to start a life with her, 
Randy's entrance music begins to play and the crowd is audibly excited. Randy tells her, "You hear them? This is where I belong." He enters to the ring, leaving her.

During the match, Randy has another heart attack and the agony shows on his face. Realizing the emergency, The Ayatollah whispers to Randy that he (Randy) should immediately pin him and finish the match. Randy refuses to listen and kicks The Ayatollah's head. The crowd is heated up and starts to chant the name of Randy's signature finishing move, the Ram Jam. The gasping Randy climbs up to the top of the ring corner. As he leaps from the top rope to execute the Ram Jam, the screen cuts to black and the film ends, implying his death.

The Wrestler inspired a great deal of response not only from film fans and critics but also from the wrestling industry. Former star wrestlers such as Mick Foley and Diamond Dallas Page gave rave reviews of the film, verifying the authenticity of its description of their profession. ${ }^{1}$ It is reported that "Rowdy" Roddy Piper, a superstar in the 1980s, broke down and cried in the arms of Rourke (who portrayed Randy) backstage at the film's screening because Piper was so moved by the film. ${ }^{2}$ However, there were less favorable reactions from wrestlers as well. A review by former world champion Bret "The Hitman" Hart was especially bitter. He insists that, unlike Randy, most former wrestlers, including himself, have not lost status in the world. For him, The Wrestler presents a "dark misinterpretation" of professional wrestling and "unbalanced

\footnotetext{
${ }^{1}$ Mick Foley, “The Wrestler is Good: A Three-time WWE Champion Explains What Darren Aronofksy's Pro-wrestling Movie Gets Right," 2008, http://www.slate.com/articles/news_and_politics/life_and_art/2008/12/the_wrestler_is_good.single.html (accessed April 1, 2012). Also, in the roundtable discussion among former wrestlers included in the blu ray version of The wrestler, Diamond Dallace Page endorsed the film as a faithful reflection of the business.

${ }^{2}$ Edward Douglas, "Mickey Rourke Piledrives The Wrestler," 2008, http://www.comingsoon.net/news/movienews.php?id=51289 (accessed April 1, 2012); Christopher Rivlin, “Aronofsky Looks over a Wrestler's shoulder for his Latest Endeavor," 2008, http://www.tuftsdaily.com/arts/aronofsky-looks-over-a-wrestler-s-shoulder-for-his-latest-endeavour-1.1048903 .T5JNxBxbx_U (accessed April 1, 2012).
} 
portrayal in which there's no respect for our art or our dignity." He worries that the film will give audiences the false impression that every retired wrester suffers the fate of Randy. ${ }^{3}$

Such polarized reactions from the wrestling industry show that, for better or worse, The Wrestler touches on deep and critical issues in contemporary professional wrestling. In fact, the film addresses and embodies several highly significant features of contemporary wrestling. These features interrelate and conflict with one another, making wrestling an extremely dreadful and harrowing, yet also alluring and compelling, entertainment spectacle. In this introduction, I explain four of the important features of contemporary wrestling illuminated by The Wrestlerthe features that this dissertation explores in depth.

First, The Wrestler attends to a horrifying aspect of the contemporary wrestling industry. That is, as we will see in detail in chapter 1, professional wrestlers have an abnormally high mortality rate. While maintaining inordinately muscular physiques, wrestlers regularly perform matches that are extremely physical and damaging. They are required to meet excessively severe standards. It is no secret that many wrestlers, like Randy, have abused various illegal substances, recreational drugs, and painkillers to keep up with professional expectations. As of 2012, organizations treat wrestlers as independent contractors rather than employees. In many cases, they are given neither medical benefits nor pension plans. Even a wrestler with superstar status could face Randy's predicament: left with a battered body and mind with no savings or special skills other than performing wrestling. ${ }^{4}$ It should be noted that The Wrestler does not blame this

\footnotetext{
${ }^{3}$ Bret Hart, “The Hitman versus 'The Wrestler,'” 2009, http://www2.macleans.ca/2009/02/16/the-hitmanversus-'the-wrestler'/ (accessed April 1, 2012).

${ }^{4}$ As will be mentioned later in this introduction, in recent years, The WWE has implemented and improved its Talent Wellness Program, which includes various medical and drug testings and referrals to health-care providers. It also began to offer rehabilitation assistance to its former talent and workshops regarding practical skills, personal financing, and health insurance to its current talent. However, these efforts were not enough to address all of the problems suffered by its former talent. In fact, there are several broken-down ex-superstars, such as Jake "The
} 
deadly structure of contemporary wrestling solely on the exploitative behavior of organizations and promoters. According to the film, wrestlers are also motivated to keep performing and abusing themselves in order to earn the admiration of the crowd and out of a sense of camaraderie with their peers. In that sense, The Wrestler points to a structural problem in the wrestling industry: promoters, wrestlers, and fans share responsibility for a pile of broken bodies and minds.

Second, by presenting Randy's suicidal performance in the ring, The Wrestler evokes one of the most prominent themes in the narrative of contemporary professional wrestling: an irrational and obsessive urge to keep going and to push one's body to the limit. Although he realizes that wrestling is wearing him down, Randy keeps performing in the ring. In the hardcore death match, he and his opponent - a cameo performance by Necro Butcher, an actual wrestler who is famous for his crazy action in the ring — openly encourage each other to actually hurt their bodies with various foreign objects. As the live crowd enthusiastically and religiously admires the two wrestlers' reckless efforts, a typical narrative and character division of wrestling — such as a hero fighting against a villainous opponent for the sake of justice-is rendered meaningless. Now, the theme of this match is the wrestlers pushing their own bodies to the limit. Randy's irrational drive to keep going culminates in the last scene of the movie. He is given an option to start more a humane, normal, and happy life, which he has been yearning for. Nevertheless, he chooses to perform in the ring to the death. Randy's performance in these matches can be called transcendental, since his action goes beyond the normal standards of conduct and value systems (in wrestling or in real life) and takes him beyond the breaking point of his body.

Snake" Roberts, Lex Ruger, and Randy "Macho Man" Savage, who critics and fans see as possible models for Randy's character. 
Contemporary wrestling frequently features such irrational and obsessive urges to keep on performing and to transcend normal values. Wrestlers perform increasing numbers of these grueling, over-the-top matches, where they exchange extremely high-risk moves, hurt each other with objects (ladders, tables, chairs, etc.) in spectacular ways, and refuse to stop fighting even after receiving each other's finishing move. These matches normally gain enthusiastic support from fans, who show "mad respect" to the wrestlers (or tag teams) in the ring regardless of whether they are playing "babyface" (hero) or "heel" (villain) in the storyline. Fans' overwhelmingly positive reaction has resulted in even more intense, exhausting, dangerous, yet incredibly awe-inspiring performances by wrestlers. Ironically, the contemporary wrestling industry represents its own severe structural problem — the high mortality rates of wrestlers - in a sophisticatedly aesthetic and affirmative form.

It should be noted that the escalation of over-the-top performance in the ring paralleled the intensification of business competition between wrestling organizations outside the ring. In particular, during the fierce television-ratings war between the WWE (World Wrestling Entertainment) $^{5}$ and the WCW (World Wrestling Championship) in the late 1990s, both organizations began to feature many extremely physical matches and all-out performances by wrestlers. ${ }^{6}$ Since then, these types of matches have become a staple of contemporary professional wrestling. ${ }^{7}$ Randy, the fallen superstar of the film, now only works for small local organizations

${ }^{5}$ The WWE was known as the WWF (World Wrestling Federation) until 2002. However, to avoid confusion, this dissertation uniformly uses $W W E$ to refer to this organization, even when I am addressing events before 2002.

${ }^{6}$ It is to be noted that these major organizations (the WWE and the WCW) did not originate such over-thetop matches. Small organizations such as Extreme Championship Wrestling (ECW) began to feature extreme matches and physically demanding, high-flying matches in the United States. They imported these types of matches from the Japanese and Mexican wrestling scenes, to create an alternative to the products of major organizations.

${ }^{7}$ One of many things that makes The Wrestler look authentic is that it successfully describes the transition 
that have little to do with large-scale capital flows. However, when put in the context of professional wrestling in the United States, his exhaustive performance in the 2008 film echoes the intensified competition between capitalist enterprises that attempt to attract viewers by destroying existing values and standards.

Third, by repeatedly emphasizing the contrast between the extraordinary world of professional wrestling to which Randy belongs and the real world that alienates him, The Wrestler highlights the marginalized status of the hypermasculine culture of professional wrestling in society. ${ }^{8}$ Also, by describing the frenzy of this marginalized site where wrestlers and the crowd closely communicate with each other, this film captures the moments in which people, with furor and a heightened sense of community, oppose dominant discourses of society—where professional wrestling is regarded as a form of "trash" culture or one of the "cultural bottom feeders." 9

While his exhaustive performance in the ring has an affinity with the intense competition between large-scale capitalist enterprises, Randy himself is deprived of capital. Randy's hypermasculine identity as a wrestler is neither respected nor legitimized in the real world; he is locked out from his trailer by the park's manager due to his failure to pay the rent, and his boss at

of wrestling narratives from the 1980 s to the 2000s. The film assumes that the legendary rivalry between Randy and The Ayatollah in the 1980s took on a patriotic, nationalist form with an American hero versus an Iranian villain, which was typical in the actual wrestling business during that time. This archetypal nationalist narrative in the past contrasts with today's all-out hardcore death match between Randy and Necro, where the character divisions are suspended and the audience admires both wrestlers' efforts.

${ }^{8}$ As I extensively explore in chapter 3 , since the late 1990 s, the expression of obsessive inner state of wrestlers has replaced hypermasculine surface appearance of wrestlers' bodies in the 1980s as a dominant form of masculine aesthetic in professional wrestling. Nevertheless, many popular professional wrestlers today are still equipped with extreme amounts of body muscles and definitely represent hypermasculinity. The old, yet still hypermasculine, body of Randy as a former superstar of 1980s, and his extreme and obsessive performance in the ring of 2000s attest that The Wrestler faithfully reflects this trend in American professional wrestling.

${ }^{9}$ Scott M. Beekman, Ringside: A History of Professional Wrestling in America (Westport, CT: Praeger Publishers, 2006), vii. 
the supermarket often derides the fact that he is a wrestler. His physician, representing a socially authorized discourse of medical science and health care, utterly negates the profession that has led Randy to use illegal substances and inflict heavy damage on his own body. Randy's estranged daughter decisively refuses to fix the relationship with her father when he indulges himself in a one-night stand with a female wrestling fan. ${ }^{10}$

Disheartened, Randy realizes that he is able to find peace only in the wrestling ring, performing in front of fans. Before the beginning of the last match, he grabs the microphone and appeals to the crowd, "As the time goes by, they say, 'he's washed up, he's finished, he's a loser, he's all through.' You know what, the only ones [sic] that's gonna tell me when I'm through doing my thing, is you people here." That is, Randy expresses his refusal of the dominant voice (what "they" say) in the real world and his loyalty to the voice of this marginalized culture.

The aforementioned hardcore death match between Randy and Necro earlier in the film includes a more intense moment of inversion — and also perversion—of normal values. As Necro uses a staple gun to drive staples into his own flesh as well as Randy's, the crowd repeatedly and joyfully chants "You sick fuck!" to Necro. This scene involves multiple levels of transgression and perversion. To begin with, a hardcore death match, where all objects are permissible as weapons, epitomizes professional wrestling's transgressive nature; in this match, the values of normal legitimate hand-to-hand combat sport are overtly ignored. Also, Necro's usage of a staple gun doubly perverts the usual objective of fighting — to defeat the opponent by using one's prowess and inflicting devastating physical damage to him—which is consistent with dominant constructions of masculinity. First, obviously, the insertion of small staples into the skin and

\footnotetext{
${ }^{10}$ It should be noted that this movie does not entirely victimize wrestlers' masculinity. It also includes a scene in which Randy quarrels with Cassidy and verbally abuses her, using explicitly misogynic language.
} 
flesh does not cause a lot of physical damage to the opponent; rather, it gives the opponent mental trauma. Second, Necro uses the staple gun not only to attack Randy but also to attack himself, thereby demonstrating his twisted form of manly endurance. Finally, the crowd's reaction to Necro celebrates, in a carnivalesque way, his pervasive performance by mimicking the voice of authority. They formally revile Necro and call him "sick fuck," as if they were judging him from common sense. However, it is obvious that they mean the opposite; with this chant, the crowd enthusiastically pays respect to Necro and affirms that they too are "sick fucks." The Wrestler convincingly presents professional wrestling as a site in which people collectively express their alienation and resentment, perverting and mimicking society's dominant ideas and sane voices. In the hypermasculine world of wrestling, the dominant construction of masculinity can also be an object of perversion.

The fourth feature of contemporary wrestling illustrated by The Wrestler concerns a recent change in the narrative form of wrestling. This film, despite the fact that it is a scripted fictional drama that belongs to mainstream culture, marks a development in what might be called the nonfictional turn in the genre of professional wrestling. As I show in chapter 2 , in the late 1990s, wrestling organizations began to produce and endorse what I call nonfictional narratives of professional wrestling, which offer viewers (and readers) access to the behind-the-scenes "truth" of wrestling performances, candidly acknowledging that wrestling matches are scripted. These nonfictional narratives can be considered the wrestling industry's response to viewers' increasing awareness of the scripted nature of professional wrestling. These narratives opened a new way of celebrating the wrestling business as well as telling viewers how to appreciate wrestlers' performances.

Like many nonfictional narratives of wrestling that have been produced since the late 
1990s, The Wrestler addresses the backstage camaraderie between wrestlers feuding in the ring and vividly describes how "real" the physical and mental damage caused by performing professional wrestling is. In fact, The Wrestler is heavily influenced by the 1999 wrestling documentary film Beyond the Mat, one of the landmark texts of the nonfictional turn in professional wrestling. In fact, some of the scenes and plots in The Wrestler are explicit retellings of those in Beyond the Mat. ${ }^{11}$ In this sense, The Wrestler should be considered the refictionalization of the nonfictional narratives of professional wrestling.

To make things even more complicated, The Wrestler was involved in an actual professional wrestling mega event. In the spring of 2009, shortly after the film was released, WWE superstar Chris Jericho issued an challenge to Mickey Rourke (who portrayed Randy in The Wrestler), saying Rourke may have been able to wrestle in the "fake" world of the movies but could not do anything in the "real" world of wrestling. This perverted challenge, where the WWE incorporated a successful film in the real mainstream scene into its fictional storyline - by calling its own products the "real" thing and the film version "fake" — was realized in the WWE's largest annual event WrestleMania on April 5, 2009. In the show, Rourke, who is a former token professional boxer, knocked Jericho down to please over 70,000 people in attendance. In addition to the form and content, the way that the film was involved in an actual wrestling show epitomized the complex intermingling of fiction and reality in contemporary professional wrestling. In fact, many successful shows in WWE wrestling demonstrate the fusion between the fictional and nonfictional.

\footnotetext{
${ }^{11}$ For example, Beyond the Mat features Jake "The Snake" Roberts, a broken-down former WWE superstar. In the film, Roberts, just like Randy, attempts to fix the relationship with his estranged daughter. However, his daughter, just like Randy's, fiercely blames her father for his long-time neglect of her and utterly rejects him.
} 
These four features of contemporary wrestling illuminated by The Wrestler - a high mortality rate among wresters, the prominent theme of obsessive urges, the marginalized status of hypermasculinity, and the genre's nonfictional turn - point to complex issues and contradictions in contemporary popular culture and media. The high mortality rate among professional wrestlers — individuals who are expected to be in peak physical shape — signals a contradiction in the intensified competition among cultural industries in late capitalist society. As both laborers and commodities, wrestlers are expected to build hypermasculine bodies and perform with exaggerated actions. The increasing demands for the innovation, sensationalization, and spectacularization of products as well as the constant production in wider areas have led many wrestlers to abuse their own bodies and minds to death. The demands that are based on rational calculation to increase profits have incurred the irrational self-destruction of wrestlers.

To further the contradiction, despite the fact that wrestling has caused so many actual deaths, in the ring wrestlers are still willing to give all-out performances to express an irrational and obsessive urge to go beyond the limit of their bodies. Producers encourage wrestlers to put on such exhausting performances by setting up special stages (ladder matches, street-fight matches, etc.) and scripting the matches. Fans enthusiastically embrace these over-the-top fights. In a sense, the wrestling industry thrives on staging and spectacularizing its own moment of contradiction where rationality turns into irrationality. ${ }^{12}$ The continuing popularity of such overthe-top matches in wrestling indicates a profound contradiction in contemporary popular culture: even the most deadly aspect of an industry can be turned into its most valuable commodity.

\footnotetext{
${ }^{12}$ It is arguable whether one can always view two forms of irrationality (the actual death of wrestlers as a result of abusing their bodies and the expression of pushing one's body over the limit in the ring) in the same light. However, The Wrestler clearly puts the two in parallel with each other: Randy (presumably) dies in the ring as a result of his all-out performance.
} 
The expressions of hypermasculinity and its alienated status in wrestling suggest that, in popular culture, reactionary and liberating aspects can be two sides of the same coin. Wrestlers predominantly rely on their abnormally bulked-up muscles to solve problems. In wrestling, justice and the restoration of moral order are always achieved by the exertion of physical violence against evil—as opposed to negotiation and mutual compromise. The constructions of good and evil characters are frequently consistent with dominant racial, ethnic, national, and gender stereotypes, giving storylines overtly nationalist, ethnocentrist, and sexist themes. However, wrestling also expresses an utter and collective rejection of political correctness, elitism, and so-called civilized tastes. It offers an opportunity for the audience members to confront and express their frustration, alienation, and resentment in society and to issue challenges to various discourses from the dominant. Moreover, wrestling often questions the dominant notions that it usually embodies. As stated, an all-out performance by wrestlers often takes the audience to a sort of transcendental state where the usual storylines of wrestling (e.g., good versus evil) are suspended. Also, remember the twisted and excessive form of manliness expressed by Necro when he uses a staple gun to hurt himself; his "sick fuck" performance laughs at the dominant construction of masculinity upon which wrestling usually relies. Wrestling urges us to read the complex interplay of various conflicting elements in popular culture without resorting to a reductionist view.

The proliferation of nonfictional narratives of wrestling in the late 1990s signals a significant shift in contemporary American media. This phenomenon parallels the recent proliferation of the commodification of nonfictional material as a spectacular entertainment (e.g., reality television). Both the nonfictional turn in wrestling and the dominance of reality programming in American television are considered responses to viewers' increasing awareness 
of and boredom with the constructed nature of dramatic fiction. Nonfictional programs provide such viewers with another form of entertainment that appears to be more authentic than the previously ubiquitous fictional dramas. Of course, contemporary viewers are not so naive to believe that these nonfictional materials offer unmediated access to reality; many reality television programs are willing to expose their own contrivance to cater to viewers' awareness of the programs' constructed nature. Nevertheless, as Mark Andrejevic argues, in contemporary reality television programs, viewers "demand more and more punishing contrivances in the hopes of squeezing out a bit of authenticity of real emotion."13 This trend corresponds to the nonfictional turn in professional wrestling. Many nonfictional narratives of professional wrestling emphasize the real pain, danger, and passion involved in the production of wrestling performances. The exhaustion of Randy's life in the ring in The Wrestler also caters to contemporary viewers' increasing demand for "real" pain and brutality. The change in the representation of wrestling reflects an important shift in the production and consumption of the real in contemporary American popular culture and media.

So far, by referring to The Wrestler, we have seen the various complicated and contradictory issues of contemporary professional wrestling, popular culture, and media that this dissertation sets out to explore. In the rest of the introduction, I give a concise introduction of the main object of this study in this dissertation: WWE wrestling. Then I review current literature in professional wrestling studies and contemporary popular culture studies to further specify the direction of this study. The introduction concludes with an overview of arguments in each of the following chapters of this dissertation. 207.

\footnotetext{
${ }^{13}$ Mark Andrejevic, Reality TV: The Work of Being Watched (Lanham MD: Rowman \& Littlefield, 2003),
} 


\section{WWE Wrestling}

This dissertation addresses complex and contradictory issues of representation, authenticity, desire, experience, and politics in contemporary popular culture and media by exploring professional wrestling produced by the WWE and the culture that surrounds it. The WWE is a publicly traded company and the largest professional wrestling organization in the United States as well as in the world. It holds more than three hundred live events per year and televises many of them. It currently produces two weekly cable-television programs, Raw and SmackDown (both two-hour shows), and more than twelve pay-per-view television programs a year. It also distributes the one-hour show WWE Superstars and a talent-scout program called $N X T$ (a one-hour show) on its own website. Raw, which broadcasts on USA Network at 9 p.m. EST every Monday, is considered the flagship show of the company. Originally launched as a one-hour program in January 1993, it is "among the most-watched regularly scheduled programs on primetime cable television." 14 These programs are broadcast not only in the United States but also in more than one hundred forty five countries and in thirty languages. ${ }^{15}$

The WWE (at the time, still the World Wrestling Federation, or WWF) and its chairman Vince McMahon were responsible for the drastic transformation of the professional wrestling industry during the 1980s. McMahon broke the tacit nonaggression pact between regional wrestling promoters, syndicated with television stations across the country, and expanded to other promoters' territories. Although professional wrestling has been a simulated sport or theatrical combat with predetermined results since the early twentieth century, it was McMahon

\footnotetext{
14 "Live and Televised Entertainment," WWE Corporate, http://corporate.wwe.com/company/events.jsp (accessed April 1, 2012).

15 “Company Overview," WWE Corporate, http://corporate.wwe.com/company/overview.jsp (accessed April 1, 2012).
} 
who made wrestling's secret (its scripted nature) widely known. He entirely abandoned a traditional way of presenting wrestling as if it were serious competition and began to feature obviously scripted storylines in which actors, musicians, and other celebrities were often involved. The WWE also cooperated with MTV, incorporating pop music into wrestling events, and drew the attention of a much wider range of audiences and media than before. McMahon eventually began to refer to his product as "sports entertainment" instead of legitimate sporting competition. Likewise, the WWE tends to refer to its talent as "superstars" rather than “wrestlers.” In 1985 at Madison Square Garden in New York City, the WWE launched what would be the company's largest annual show, WrestleMania, starring its top superstar, Hulk Hogan, and the actor Mr. T. ${ }^{16}$ The popularity of the WWE reached its pinnacle with WrestleMania III in 1987.

Since then, the WWE has continued to innovate in its products. For example, since 1997, McMahon has appeared in WWE's storylines, playing a character based on himself and thereby incorporating the business reality of the company into its fictional world. Due to the huge success of the feud between two innovative characters, McMahon, an abusive and dictatorial boss who is obsessed with his power, and "Stone Cold" Steve Austin, a bald-headed, beerdrinking tough guy who does not trust anybody but himself, and the emergence of new superstars such as The Rock and Mick Foley, the WWE eventually defeated its rival organization World Championship Wrestling (WCW) in the aforementioned head-to-head television ratings competition. In 2001, the WWE bought out the WCW and the Extreme Championship Wrestling (ECW), the largest independent wrestling organization at that time, to virtually monopolize the industry. Throughout the 2000s, the WWE maintained its dominance in the wrestling industry. In

\footnotetext{
${ }^{16}$ Both Hogan and Mr. T played major roles in an extremely popular 1982 movie Rocky III.
} 
recent years, however, buy rates of pay-per-view specials and television ratings have started to fall. ${ }^{17}$ The content of WWE programs has become more moderate than it was in the late 1990s and early 2000s, avoiding sensational violence and overt lewdness. Since 2008, all WWE wrestling programs have been rated PG by their network distributers. Now, the WWE takes pride in producing what it calls family-friendly entertainment. ${ }^{18}$

Besides live and televised wrestling programs, the WWE's major revenue sources include the production of films that feature their superstars, the sales of original merchandise (such as videos, DVDs, T-shirts, music CDs, books, and magazines), product licensing (in particular, that of video games and toys), and advertising on its website. The WWE has a subsidiary called WWE Studios, which has produced a number of theatrical films and straight-to-DVD movies starring various WWE superstars. Also, some of the popular WWE superstars and ex-superstars are treated as huge celebrities by entertainment media and appear in various nonwrestling television programs, magazines, newspapers, and even on the packaging of food sold in convenience stores.

In recent years, the WWE has engaged in various social activities and publicized its community service and nonprofit contributions. Since 2001, it has established an annual tradition of visiting U.S. troops in foreign countries such as Iraq and Afghanistan or domestic military bases for Christmas. The WWE has performed shows there to express gratitude to the solders, and they have been broadcast on major networks such as NBC. The WWE also works with the Make-A-Wish foundation, and WWE superstars frequently grant wishes to children with serious

\footnotetext{
${ }^{17}$ As one of the reasons for the decreasing numbers in the WWE business, the explosion of the popularity of the Ultimate Fighting Championship, the largest franchise of a new fighting sport mixed martial arts, cannot be ignored. In recent years, it has surpassed the WWE to become the most dominant force in the PPV television business.

18 “Overview,” WWE Parents, http://corporate.wwe.com/parents/overview.jsp (accessed April 1, 2012).
} 
medical conditions. It hosts social programs such as the WrestleMania Reading Challenge and Smackdown Your Vote! In April 2011, the company also cofounded with the Creative Coalition a "multi-platform anti-bullying initiative" called be a STAR (which stands for "Show Tolerance And Respect") and has had its superstars regularly visit schools and speak in front of students. Furthermore, responding to criticisms following the recent and frequent deaths of former and active professional wrestlers and WWE superstars, the WWE has developed programs such as the Talent Wellness Program, which provides various medical and drug tests and monitoring to its talents, the Former Talent Rehabilitation Assistance Program, and the Talent Life Skills Program to promote the welfare of its former and current talents. ${ }^{19}$

\section{Literature Review}

Contemporary professional wrestling has become an extremely complex site with various conflicting issues that reflect shifts in contemporary culture and media. In order to understand this intricate cultural phenomenon, researchers need to adopt several different theoretical perspectives, reconditioning each of them and carefully examining the interrelationships among them. Although professional wrestling has never been a popular subject for academic research, there are quite a few existing studies that help us address issues in contemporary wrestling. Also, several works from the Birmingham school of popular culture studies provide valuable empirical and theoretical insights. In the following literature review, I consider how discussions and theoretical approaches in current literature (of professional wrestling studies and cultural studies)

\footnotetext{
19 “Talent Wellness Program Summary,” WWE Corporate, http://corporate.wwe.com/company/wellness/talent_wellness.jsp (accessed April 1, 2012); "Former Talent Rehabilitation Assistance," WWE Corporate, http://corporate.wwe.com/news/rehabilitation/summary.jsp (accessed April 1, 2012); “Talent Life Skills,” WWE Corporate, http://corporate.wwe.com/company/talent_life_skills.jsp (accessed April 1, 2012).
} 
can be applied to contemporary WWE wrestling as a complex cultural phenomenon. I also

examine how these existing approaches should be renewed, updated, and complemented with

other approaches in order to keep up with the recent changes in the wrestling business.

\section{Ritual and Myth Approaches to Professional Wrestling}

American professional wrestling scholarship has frequently used what I call ritual-myth theory. ${ }^{20}$

This approach, which has developed mainly in the fields of sociology and anthropology,

considers wrestling matches ritual dramas that symbolically reenact conflicts among values and

positions in American society. The ritual drama in wrestling should also be called a myth, as it

helps the audience interpret the realities of everyday life and of contemporary American society

and suggests how they should live their lives. Here, wrestlers are considered mythical figures

who symbolize various positions and values in the social order.

For example, as early as 1974, Thomas Henricks analyzed wrestling matches by applying ritual-myth theory. According to Henricks, villains in wrestling represent a threat to the order of American society. The characters they play follow social stereotypes such as those of the "foreign menace" (German, Japanese, and Russian) or those of the "antagonist from within"

\footnotetext{
${ }^{20}$ Thomas Henricks, "Professional Wrestling as Moral Order," Sociological Inquiry 44, no. 3 (1974): 177188; Gerald W. Morton and George M. O’Brien, Wrestling to Rasslin: Ancient Sport to American Spectacle (Bowling Green: Bowling Green State University Popular Press, 1985), 156-165; Irene A. Webley, "Professional Wrestling: The world of Roland Barthes Revisited," Semiotica 58 (1986): 59-81; Brendan Maguire and John F. Wozniak, "Racial and Ethnic Stereotypes in Professional Wrestling," Social Justice Journal 24, no 3 (1987): 261273; Bruce Lincoln, Discourse and the Construction of Society (Oxford: Oxford University Press, 1989), 148-159; Michael R. Ball, Professional Wrestling as Ritual Drama in American Popular Culture (Lewiston: Edwin Mellon Press, 1990); Sam Migliore, "Professional Wrestling: Moral Commentary Through Ritual Metaphor," Journal of Ritual Studies 7 (1993): 65-84; Terry M. Saunders, "Play, Performance and Professional Wrestling: An Examination of a Modern Day Spectacle of Absurdity" (PhD diss., University of California, Los Angeles. 1998); Aaron D. Feigenbaum, "Professional Wrestling, Sports Entertainment, and the Liminal Experience in American Culture" (PhD diss., University of Florida. 2000); Charles S. Adams, "Myth and Ritual in Professional Wrestling," in From Season to Season: Sports as American Religion, ed. Joseph L Price (Macon: Mercer University Press, 2001), 203211; Mark Leverrette, Professional Wrestling, the Myth, the Mat, and American Popular Culture (Lewiston: Edwin Mellen Press, 2003).
} 
(schoolyard bullies, blowhards, and pretenders). Villains use dirty tactics to attack heroes in matches; they frequently ignore the referee's orders or take advantage of the referee's impotence. Heroes, many of whom are white Americans, at first try their best to observe the regulations and endure the illegal beatings by villains but finally decide to transgress legal limits and punish them with the support of the audience. For Henricks, this typical wrestling narrative is a ritual drama that symbolically reenacts the crisis and reestablishment of American social and moral order: "This setting things straight is the ritual creation of cosmos out of chaos; order is achieved where simple legality was impotent by an overwhelming force of moral righteousness. ${ }^{.21}$ Here, wrestlers are considered mythic figures whose (symbolic and simplified) struggles provide the audience with a preferred interpretation of the reality of American society.

After Henricks, many scholars of professional wrestling attempted a similarly straightforward application of ritual-myth theory. In particular, sociologist Michael Ball offers a most distinctive and assertive interpretation. By combining theories of ritual developed by Victor Turner, Erving Goffman, and Mary Jo Deegan, Ball considers wrestling a modern ritual form and an apparatus by which powerful elites maintain their dominance. Via wrestling, elites - as producers and manipulators of ritual settings and content—present a mass audience with a social drama where "the victory of the status quo demonstrates the superiority of existing social relations and institutional meanings. ${ }^{, 22}$ Wrestling serves to profit elites both ideologically and financially, oppressing and alienating ritual consumers.

If not as assertive as Ball's argument, many other works on wrestling by ritual-myth theorists share common traits. They focus on the storylines attached to wrestling performances

\footnotetext{
${ }^{21}$ Henricks, "Moral Order," 184.

${ }^{22}$ Ball, Ritual Drama, 158.
} 
and find in them the symbolic stabilization of society. Therefore, they consider wrestling a tool to spread conservative ideologies that are convenient for the maintenance of existing social order. At the end of their pioneering work on the history of professional wrestling, Morton and O’Brien write,

But what wrestling does as ritual that helps us through bad times is that it does prove that villains can be defeated, that heroes who embody good American ideals can win and that, whatever else, determination and dedication can and do triumph over deceit and treachery. ${ }^{23}$

For these ritual-myth theorists, most of whom examined wrestling before the late 1990s, the significance of wrestling lies in the ideological function of its narrative. Wrestling reenacts a drama that symbolizes various forms of social struggle. The final victory of justice and the reinstatement of existing moral order are always assured. Therefore, wrestling leads the audience to favor the maintenance of the dominant order and the construction of national unity.

Any viewers of American professional wrestling in the past fifteen years will agree that such interpretations of wrestling narratives are now outdated. During the late 1990s, professional wrestling storylines went through drastic changes. The apparently patriotic storyline in which righteous American heroes would defeat villainous foreign forces ceased to be the main plot of the show. Instead, wrestlers with bad attitudes began to be accepted as new heroes by fans, who supported their struggle against conniving economic elites. Given such changes in the narrative of professional wrestling, some recent scholarly works attempt to employ the ritual-myth approach in more differentiated ways. For example, in his 2000 dissertation on WWE wrestling, Aaron Feigenbaum disagrees with Michel Ball's aforementioned argument while using a framework of ritual-myth theory. Feigenbaum argues that contemporary WWE wrestling, as a

\footnotetext{
${ }^{23}$ Morton and O'Brien, Wrestling to Rasslin, 165.
} 
business enterprise, listens to "the people's" voice in order to make profits. Therefore, the WWE is more eager to embrace "the people's" values as opposed to elite values, regardless of whether they conform to existing social order. In that sense, WWE wrestling is a commercialized, and thus democratized, ritual that celebrates American society. ${ }^{24}$

To prove his point, Feigenbaum closely documents the process by which the WWE made "Stone Cold" Steve Austin—a tough guy with an attitude and unrefined manners — a fan favorite during 1998 and 1999. In the storyline, Austin has various struggles against his boss Vince McMahon, the billionaire owner of the WWE who despises Austin and attempts to subjugate him by abusing his power and money. Feigenbaum argues that Austin's battle against McMahon is a symbolic enactment of the audience's social and individual struggles in their everyday life, as both performers symbolize positions in the social order. They feel exploited by their bosses at work, and they feel that (self-proclaimed) intellectuals look down on their cultural taste. WWE wrestling is a ritual form that grants audience members the opportunity to express their alienation in life and experience the reconfiguration of the existing social order. He also points out that WWE wrestling is not entirely oppositional to American society. Austin embodies American values, such as drives of competitiveness and individual achievement that the audience embraces. ${ }^{25}$ Also, in the symbolic narrative of the WWE, it is not the political and economic system but a moral corruption of individual elites (such as McMahon) that alienates people. ${ }^{26}$ Compared to Feigenbaum, Marc Leverette's 2003 book, Professional Wrestling: The Myth, the Mat, and American Popular Culture, more faithfully follows the framework of

\footnotetext{
${ }^{24}$ Feigenbaum, "Liminal Experience," 28-29.

${ }^{25}$ Ibid., 274.

${ }^{26}$ Ibid.
} 
classical ritual-myth theory. He too outlines the rise of Steve Austin during 1998 and 1999 that is documented by Feigenbaum and argues that Austin's struggle and triumph is a myth of American society that symbolically represents the crisis and restoration of order. Like other ritual-myth theorists, Leverette considers that wrestling is a ritual and a form of "sociological propaganda" 27 that not only allows the audience to interpret the world but also tells them how to do so. However, unlike classical ritual-myth theorists of wrestling, he sees the shift in the contents of ideology that wrestling disseminates during the 1990s. He argues that patriotism and nationalism gave way to "possessive individualism",28 and consumerism. While staging and celebrating the triumph of Austin, a rugged individualist, the WWE continuously urges fans to make money and spend it to live the myth it offers them. ${ }^{29} \mathrm{He}$ also notes that in the beginning of the 2000s, the WWE began to incorporate the process of its own global expansion and media conglomeration into its own storylines. ${ }^{30}$

Both Feigenbaum and Leverette update the preceding ritual-myth perspectives on wrestling. Both recognize that the WWE storylines began to portray the WWE as a company led by an evil, exploitative boss. They suggest that the WWE has increasingly revealed its own profit-seeking nature as a commercial enterprise. Feigenbaum notes that the profit motive demands that WWE wrestling cater to "the people's" values. Leverette notes that the WWE overtly celebrates its own economic expansion, as well as instigating incessant consumption of its products by fans. Their observations illuminate the internal contradiction in the WWE's

\footnotetext{
${ }^{27}$ Leverrette, Myth, 112.

${ }^{28}$ Ibid., 176.

${ }^{29}$ Ibid., 117.

${ }^{30}$ Ibid., 175-6.
} 
narrative; now, WWE wrestling attracts fan support by exposing the fact that it is run by powerful elites who pursue their own interests. In that sense, Feigenbaum's and Leverette's works opened the possibility of complicating the idea of myth that wrestling storylines create.

However, in order to address the complexity of contemporary wrestling, existing ritualmyth approaches still need to be significantly revised and complemented with other perspectives. In fact, recent developments in wrestling challenge ritual-myth approach's particular way of reading wrestling storylines. Ritual-myth theory assumes that wrestlers are symbols of social positions and their characters represent social virtues and vices. However, as we saw in The Wrestler, in contemporary wrestling an extreme, exhausting, all-out performance of wrestlers often creates a state where formal storylines and character roles are suspended. Such an alternative state questions the validity of an orthodox symbolic reading of ritual-myth theory; now, whether a wrestler plays a good or bad character ceases to matter at all, and the audience praises efforts of both wrestlers. The audience primarily sees them not as characters but as human beings.

Trends in televised wrestling during the late 1990s should also be mentioned. In that era, wrestling television programs began creating surprises and increasing visual intensity week after week. The amount of information included in each program proliferated, and narratives developed more quickly. The moral order reinstated in one moment would be shockingly destroyed in the next. Viewers would momentarily consume all of the program contents and rapidly forget them. Therefore, contemporary wrestling programs repeatedly show the "recap" clips of what happened before. Also in that era, with the circulation of nonfictional narratives of wrestling, viewers' consciousness of the constructed nature of the spectacle increased. That is, viewers became more aware that contemporary wrestling needed to continue staging unexpected 
events and became increasingly interested in knowing and guessing backstage politics and decision-making processes (regarding who would be pushed or make a "turn" from a villain to a hero, etc.). These trends in wrestling cannot be approached from the symbolic reading of ritualmyth theory, which primarily deals with the meaning of fictional storylines and characters in wrestling. In fact, all of the existing ritual-myth approaches to wrestling, including those that were written after the mid 1990s, fail to address the emergence of nonfictional narratives in contemporary wrestling.

Despite these weaknesses, researchers of contemporary wrestling can benefit from the ritual-myth approach. Even though contemporary wrestling is open to many different ways of reading, characters in contemporary wrestling still represent exaggerated social (racial, ethnic, gender, sociological, pathological, etc.) stereotypes, and the battles among them always are always rich in social symbolism. Also, in order to look at the representational strategy of the contemporary WWE, ritual-myth theorists' critical view of wrestling as a tool for disseminating nationalist ideology is still relevant. As we saw, since the late 1990s, nationalism and patriotism's role as the main theme of WWE storylines has been lessened. However, this does not mean that the WWE has given up disseminating nationalist messages. During the same period, it began to use a newly introduced nonfictional narrative format to publicly announce how nationalist and patriotic the WWE was. In order to understand how the WWE distributes different types of ideological messages via two different forms of narrative (fictional and nonfictional), researchers should adopt, and also significantly upgrade, ideological critique made by ritual-myth theorists.

\section{Literary and Cultural Theories Applied to Professional Wrestling}

Several studies of wrestling that apply literary and cultural theories offer valuable perspectives 
for the understanding of contemporary wrestling. In particular, Roland Barthes's classical essay on professional wrestling in Paris in the 1950s provides an essential insight. Although the essay "The World of Wrestling" appears in his book titled Mythologies, his understanding of wrestling should be distinguished from those of the ritual-myth theorists cited above. ${ }^{31}$ Barthes does talk about moral and ideological contents of wrestling storylines. However, unlike ritual-myth theorists, he does not seem to assume that moral and ideological values are the most important trait of wrestling. The first sentence of the essay summarizes his view of wrestling: "The virtue of all-in wrestling is that it is the spectacle of excess. ${ }^{.32}$ For Barthes, what characterizes wrestling most is not the concrete meaning of the performance but excessiveness in the form of presentation.

In the rest of the essay, Barthes repeatedly emphasizes that the presentation of wrestling matches is penetrated with exaggeration and excessiveness. For example, Barthes describes the expression of suffering in wrestling matches as follows:

Wrestling presents man's suffering with all the amplification of tragic masks. The wrestler who suffers in a hold which is reputedly cruel (an arm-lock, a twisted leg) offers an excessive portrayal of Suffering; like a primitive Piatà, he exhibits for all to see his face, exaggeratedly contorted by an intolerable affliction. ${ }^{33}$

In wrestling matches, all of the objects, events, and actions (wrestlers' attire, physical existence, movements, and facial and verbal expressions) present such "excessive portrayals." Wrestling matches give a series of iconic moments, each of which has an extremely clear meaning that can be immediately understood by the audience. Therefore, wrestling is "like an algebra which

${ }^{31}$ Roland Barthes, “The World of Wrestling," in Mythologies, trans. Annette Lavers (New York: Hill and Wang, 1972), 15-25.

\footnotetext{
${ }^{32}$ Ibid., 15.

${ }^{33}$ Ibid., 19.
} 
instantaneously unveils the relationship between a cause and its represented effects. ${ }^{34}$ It presents an "ideal understanding of things" and the "euphoria of men" who are freed from the vagueness of their everyday life and experience extreme clarity and univocality of signs. ${ }^{35}$ In Barthes' view, the primary feature of wrestling performances lies in the form (signifier), not in the content (signified) of their messages.

It is striking to see that what Barthes observed more than fifty years ago still characterizes contemporary professional wrestling. As we will examine in detail in chapter 2, contemporary WWE wrestling is imbued with excessiveness and exaggeration, even more so than the wrestling shows described by Barthes. Wrestlers' physiques have become more pumped up with muscles and have put on less fat, exaggerating the ideal of the male body. Actions in the ring have become increasingly spectacular and more visually intense. Barthes observed, "the wrestlers' gesture needs no anecdote, no decor, in short, no transference in order to appear true. ${ }^{.36}$ In contemporary WWE television programs, wrestlers' already exaggerated performances are presented as part of excessively simple and hyperbolic narratives filled with absurd vignettes and decorated with various dazzling audio-visual and special effects.

It now seems ironic that Barthes stated that exaggeration and excessiveness in wrestling embodied the "euphoria of men." In contemporary wrestling, the acceleration of the degree of exaggeration and excessiveness has caused tragic deaths of wrestlers. As mentioned, many wrestlers have exhausted their bodies and minds to keep up with the increasingly unattainable standards in contemporary wrestling, resulting in an unusually high mortality rate. This does not

\footnotetext{
${ }^{34}$ Ibid.

${ }^{35}$ Ibid., 25.

${ }^{36}$ Ibid., 19.
} 
suggest that Barthes misunderstood the nature of professional wrestling, however. In fact, as

Barthes observed, contemporary wrestling television programs are filled with a heightened sense of euphoria reinforced by intense and glaring audiovisual effects. However, behind the glittering appearance lie a lot of dead and crippled bodies. Exaggeration and excessiveness, the fundamental formal conventions of wrestling, have aroused exultation and horror all at once.

Barthes correctly emphasizes the fact that exaggeration and excessiveness give extreme clarity to the meaning of wrestling performances. At the same time, it should be noted that exaggeration and excessiveness also furnish self-referentiality in wrestling performances. That is, an exaggerated and excessive performance inevitably suggests to viewers that what they are watching is unnatural and thus constructed. ${ }^{37}$ In wrestling, while the clarity of meaning enables viewers to immerse themselves in the fictional world as smoothly as possible, its selfreferentiality raises viewers' awareness of the constructedness of wrestling performances. Because of the exaggerated and excessive nature of wrestling performances, viewers are often forced to vacillate between two different modes of watching: immersion and awareness. As we will see in chapter 2, a unique tension between immersion and awareness produced by the combination of fictional and nonfictional representations characterizes the complex realism of contemporary wrestling. Barthes's account is of fundamental importance for researchers of

\footnotetext{
${ }^{37}$ In fact, Masayuki Kobayashi, in his thoughtful reading of "The World of Wrestling," argues that Barthes's text suggests the self-exposing effect of exaggeration in wrestling. Kobayashi draws attention to the following sentence that concludes Barthes's essay: "In the ring, and even in the depths of their voluntary ignominy, wrestlers remain gods because they are, for a few moments the key which opens Nature, the pure gesture which separates Good from Evil, and unveils the form of a Justice which is at last intelligible" (Barthes, "The World of Wrestling," 25). In Kobayashi's reading, the act of opening Nature (initiated by the exaggerated physical expression of wrestlers) includes the demystifying of its own ideological effects. Professional wrestling, while having the ideological effects of justice reenacted, at the same time debunks its own myth of signification. Therefore, Kobayashi stresses that Barthes, a fierce critique of ideological effects in various events and products, does not seem to be disgusted with professional wrestling (Masayuki Kobayashi, "Puroresu Shakaigaku he no Shoutai: Ideology and Texture [An Introduction to the Sociology of Professional Wrestling: Ideology and Texture]," Gendai Shiso [Modern Thought] 30-3 [2002]: 103-106).
} 
contemporary wrestling, as wrestling is still a "spectacle of excess." His essay had a great influence on John Fiske's seminal analysis of WWE wrestling in the 1980s, which will be discussed later.

In “"Never Trust a Snake': WWF Wrestling as Masculine Melodrama,” media scholar Henry Jenkins offers one of the most exquisite analyses of professional wrestling. He interprets WWE wrestling in the late 1980s and early 1990s as the reflection of complex and repressed emotions of a working-class, male audience and the contradiction of its members' masculinity. Drawing insights from sport sociology and drama studies, Jenkins argues that sports (a masculine site) and melodrama (a feminine site) are "gender specific spaces" ${ }^{38}$ for emotional release and repression that society has provided. Via playing and watching sports, men are expected to learn to repress their sentimentality and emotional vulnerability and sublimate them into physical aggressiveness. Melodrama translates women's affect in the form of domesticity, sentimentality, and vulnerability. ${ }^{39}$ In short, sports and melodrama are sites in which dominant expectations of masculinity and femininity are built and fulfilled. Then, Jenkins argues that WWE wrestling is a form of "masculine melodrama" that bridges the gap between sports and melodrama, reflecting the vulnerability of men via the expression of physical prowess.

He points out that WWE narratives have a "fascistic" nature: "ultimately, might makes right; moral authority is linked directly to the possession of physical strength, while evil operates through stealth or craftiness (mental rather than physical). ${ }^{40}$ Hence, the WWE repeatedly shows

\footnotetext{
${ }^{38}$ Henry Jenkins, “'Never Trust a Snake': WWE Wrestling as Masculine Melodrama," in Out of Bounds: Sports, Media and the Politics of Identity, ed. Aaron Baker and Todd Boyd (Bloomington: Indiana University Press, 1997), 53.

${ }^{39}$ Ibid.

${ }^{40}$ Ibid., 55.
} 
the struggle of honest and modest men who will never give up and do finally defeat their deceptive abusers. Reflecting the melodramatic tradition, this narrative is presented with excessive clarity. Such a performance appeals to a working-class audience whose masculinity suffers in the contradiction between social expectation and reality. The dominant construction of gender promises them an authority in patriarchy, but economic reality renders their physical strength subject to exploitation and subordination. Wrestling provides working-class males with a "fantasy of omnipresence" ${ }^{41}$ while making them confront their own emotional vulnerability and frustration. ${ }^{42}$ Jenkins further argues that such masculine melodrama of the WWE reflects the tradition of American populism. Like wrestling, populism presents a simple worldview based on the immediacy of everyday experience, seeing the virtue in hard physical labor and resenting conniving elites, bosses, and bureaucrats who are detached from the production process. It has provided a ground for workers and farmers to unite against the expansion of capitalism, dreaming of a utopia where "individuals recognized their common interests and respected their mutual responsibilities." ${ }^{43}$ Jenkins argues that when WWE heroes, many of whom play the role of honest Americans, unite together to defeat devious foreigners and enemies within, the populist narratives are activated. Here, the homosocial desire of vulnerable working-class males who desperately need each other is transferred into the urge for the populist communities. Populist rhetoric and male melodramatic imagination resonate together.

Jenkins's extremely rich and sensible account urges researchers to see the complexity and contradictory nature of WWE wrestling. Here, "fascistic" belief in physical strength,

\footnotetext{
${ }^{41}$ Ibid.

${ }^{42}$ Ibid., 56.

${ }^{43}$ Ibid., 70.
} 
homosociality, and xenophobia are mingled with authentic frustration against economic and political exploitation and the real yearning for better communities based on mutual dependence and faith. His essay also calls for the need to link WWE wrestling with traditions in other genres (in Jenkins's case, sports, melodrama, and political thought) to illuminate its ambivalent features. Furthermore, as we will see below, Jenkins's exploration of the link between WWE wrestling and American populism offers an excellent reference point for the analysis of the politics of more recent WWE wrestling.

Steel Chair to the Head, the 2005 anthology of professional wrestling studies, includes more recent accomplishments in this area. Some of the essays in this book offer beneficial insights into the recent development in wrestling. For example, in the introduction to this volume, Nicholas Sammond candidly explains the decline of moral significance in the narrative of contemporary professional wrestling programs:

Wrestling, of course, offers no such moral comfort. Week after week, it seems, no one learns anything from its excesses of violence, sexuality, and general moral turpitude. It has become, at the dawn of the twenty-first century, utterly, intentionally, and exuberantly gratuitous. ${ }^{44}$

Sammond's observation questions the validity of an approach that many scholars have adopted: the moral and ideological reading of wrestling storylines. When a vast amount of wrestling matches and narratives are produced and consumed each week, repetition becomes self-evident to viewers, and it becomes harder for them to emotionally engage in the narrative. Wrestling scholars need to acknowledge this postmodern trend (saturation of information in media, and the decline of the power of narrative) and examine how wrestling organizations cope with it to keep

\footnotetext{
${ }^{44}$ Nicholas Sammond, "Introduction: A Brief and Unnecessary Defense of Professional Wrestling," in Steel Chair to the Head: The Pleasure and Pain of Professional Wrestling, ed. Nicholas Sammond (Durham: Duke University Press, 2005), 3-4.
} 
attracting viewers.

Also in this volume, Douglas Battema and Phillip Sewell illuminate another form of the recent change in wrestling. ${ }^{45}$ They critically examine various representational strategies of the WWE during the late 1990s and early 2000s (e.g., the blurring of the boundaries between good and evil in storylines, the rise of Vince McMahon as a masculine entertainer-entrepreneur par excellence, and the WWE's public offering that encouraged fans to own its superstars). They argue that, during that period, the WWE went beyond what Jenkins called masculine melodrama for a working-class, male audience. The WWE reconstructed its masculine appeal around the celebration of market logic, monetary wealth, and entrepreneurial prowess. Also, instead of staying consistent with the tradition of American populism (another Jenkins' observation), the WWE began to display strong affinity with what Thomas Frank calls "market populism," which assumes markets' ability to provide consumers democratic choice and celebrates diversity and the radical nature of commodities produced by cultural industries. Following Jenkins' account, Battema and Sewell's analysis deftly illuminates the change in the ideological and political appeal of WWE wrestling. It also successfully situates the WWE's hypermasculine discourse in the broader context of U.S. culture, such as the rise of neoconservative ethos and the arrival of the so-called new economy. Such critical insight is important for examining the latest trends in WWE wrestling, as the WWE always employs ambivalent political-ideological strategies, appealing to radicalism and conservatism at the same time.

\section{The Birmingham School of Cultural Studies}

Departing from a traditionalist or elitist view that laments the "bad" effects of mass

\footnotetext{
${ }^{45}$ Douglas Battema and Philip Sewell, "Trading in Masculinity: Muscles, Money, and Market Discourse in the WWF," in Steel Chair to the Head, ed. Nicholas Sammond, 269-294.
} 
culture on helpless masses and from a classical Marxist view that considers culture only as the reflection of economic conditions, the Birmingham School of cultural studies stressed the importance of popular culture as a site of political and ideological struggle and negotiation. On the one hand, the Birmingham School scholars viewed popular culture as the apparatus of what Antonio Gramsci called "hegemonic" forces, which would not only forcefully impose dominant views and ideologies but also flexibly attempt to acquire consent from the dominated. On the other hand, the school also argued that the consumption of popular culture could be an act of resistance by people with fewer resources. Through the unique interpretation of the contents of popular media, people might express their resistance to dominant views. By consuming and using popular goods in ways that are not intended by producers, people might create their own new meanings, signs, and identities.

The basic idea of the theory of popular culture developed by the Birmingham School scholars can be found in Stuart Hall's paper "Encoding/decoding," written in the early 1970s. ${ }^{46}$ In this paper, Hall considers a process of communication through television programs as a series of relatively distinctive stages (production, circulation, distribution/consumption, and reproduction) where meanings are imposed, negotiated, and contested. He adopts the semiotic model where meanings of signs are produced via the operation of codes, that is, various sets of general and specific knowledge and interpretative conventions to make sense of signs. Producers encode meanings of televisual signs through dominant sets of codes in which hegemonic social and cultural orders are imprinted. However, viewers do not necessary decode the meanings of televisual signs in the same way that they are encoded. Hall hypothetically lists three different

\footnotetext{
${ }^{46}$ Stuart Hall, "Encoding/decoding," in Culture, Media, and Language: Working Papers in Cultural Studies 1972-1979, ed. Stuart Hall, Dorothy Hobson, Andrew Lowe, and Paul Wills, (London: Hutchinson, 1980), 128-39.
} 
positions that viewers take in decoding the messages: the dominant position, the negotiated position, and the oppositional position. When viewers take the dominant position, they decode the meanings of the text as they are encoded by producers. In the negotiated position, viewers adopt the dominant way of reading text on a general level. However, in specific contexts, they perform their own readings. In the oppositional position, viewers, while understanding the dominant way of interpreting the text, decode the message in a contrary way.

It should be noted that Hall's three different reading positions by no means suggest that there is an unlimited multiplicity or openness of interpretation (i.e., that "any meaning is possible"). He stresses that none of these three positions are immune from the dominant code's influence. Even viewers who take the oppositional position acknowledge that there is a dominant way of decoding the text, and they choose to take a different path referring to the dominant code. Hall also emphasizes the contextual nature of communication. That is, both encoding and decoding practices always occur within specific cultural, historical, and ideological contexts, and therefore "there is no 'purely denotative', and certainly no 'natural' representation." Furthermore, Hall does not consider decoding practices purely cognitive issues; they are events that would influence the construction of social reality: "at another determinant moment, the 'message', via its decodings, issues into the structure of social practice. ${ }^{, 48}$ In this encoding/decoding model, Hall suggests a nonreductionist way of understanding the production and consumption of television and other popular cultural media. In this view, popular media is a dynamic site where various meanings are contested and negotiated and where dominant ideologies, social realities, and identities are reproduced and challenged. Such contests and

\footnotetext{
${ }^{47}$ Ibid., 133.

${ }^{48}$ Ibid., 130.
} 
negotiations are embedded in specific contexts.

Hall's model influenced the new generation of scholars who would produce a series of seminal works on the consumption of popular television. Among them are Ien Ang's Watching Dallas and John Fiske's Television Culture. ${ }^{49}$ Both consider the consumption of popular culture an active practice, contesting the view developed by Theodor W. Adorno and Max Horkheimer, who assumed that consumers of mass-culture products are passive and powerless dupes. Some of the perspectives developed in Ang's and Fiske's books are highly relevant to the examination of activities and psychology of wrestling viewers.

Watching Dallas analyzes various letters to the author from Dutch viewers of the popular American soap opera Dallas and shows that they have complex and conflicting attitudes against dominant discourses. Ang points out that many Dutch Dallas viewers are aware of, and strongly influenced by, what she calls the "ideology of mass culture," a dominant view that regards many popular cultural products as cheap, "bad" objects produced exclusively for commercial purposes. They recognize that, from the viewpoint of this ideology, Dallas, which features repetitive stories and stereotypical characters with exaggerated emotions, is an unrealistic, despicable program that has a negative influence on viewers. The ways in which viewers react to this ideology, however, vary. Some viewers use the power of irony to justify themselves. Instead of emotionally engaged in the melodramatic world of Dallas, they enjoy the program by laughing at the foolishness and unrealistic nature of it. That is, they fully adopt the ideology of mass culture and use it to maintain an ironic distance from Dallas without being carried away by it. Other viewers cannot easily reconcile the ideology of mass culture with their love for the program.

\footnotetext{
${ }^{49}$ Ien Ang, Watching Dallas: Soap Opera and the Melodramatic Imagination (London: Methuen, 1985); John Fiske, Television Culture (London: Routledge, 1987).
} 
They recognize the cheapness of the program and are often angered and annoyed by its narrative and characters. Nevertheless, they are still fascinated by Dallas. Also, there are other viewers who try to construct an oppositional identity by rejecting the ideology of mass culture. They claim that they have a right to have their own taste. ${ }^{50}$ Ang's argument is in fact a very sophisticated response to Adorno and Horkheimer's assertion that mass-culture products are standardized and intellectually undemanding and are designed to deprive consumers of critical reflection and make them passive and docile. Ang, with much empirical evidence, shows that viewers of Dallas in fact acknowledge, internalize, negotiate with, and even challenge the view put forward by Adorno and Horkheimer.

It is not hard to find similarity between Dallas fans' complex attitudes and those of wrestling fans. Wrestling fans, too, feel strong pressure to internalize, negotiate with, challenge, and defend themselves against the ideology of mass culture. As we will see in chapter 1, hardcore wrestling fans are the most sensitive and incisive wrestling critics who adopt the ideology of mass culture. They are bored with numerous repetitions of similar patterns in wrestling matches and storylines. They are disgusted and devastated whenever wrestling organizations offer them distasteful products, and they fiercely criticize the profit-making incentives behind such products. They often sarcastically laugh at themselves because they cannot stop watching wrestling even after being disappointed by it numerous times. Also, as repeatedly described in The Wrestler, wrestling fans sometimes very fiercely express their oppositional attitudes toward dominant views that look down on them. It is important for researchers of contemporary wrestling to learn from Ang's analysis and to consider how wrestling fans are influenced by dominant ideas - as well as how they adopt, negotiate, and

\footnotetext{
${ }^{50}$ Ang, Watching Dallas, 86-116.
} 
contest these ideas through various forms of wrestling consumption.

Fiske's Television Culture in fact includes a captivating analysis of WWE wrestling programs in the 1980s. Referring to Barthes' account of wrestling and Mikhail Bakhtin's theory of carnival, Fiske views wrestling programs as a carnivalesque spectacle where norms and dominant values are challenged and inverted. In wrestling, the excessive physicality of wrestlers' bodies predominates and neutralizes dominant meanings, moral values, and laws that represent the rationality of society. It is a parody of sport; while taking the appearance of sport competition, it laughs at the norms and assumptions of sport, such as fair play, equality, and the authority of referees. In wrestling, not only wrestlers but also spectators join the spectacle through cursing, jeering, and cheering. For Fiske, wrestling television programs offer a site for celebrating the degradation of the hegemonic. ${ }^{51}$ Of course, the same view can be easily applied to live wrestling shows as well. As mentioned earlier, descriptions of live wrestling shows in The Wrestler confirm Fiske's view of wrestling as a form of oppositional culture. Also, his definition of WWE wrestling programs as a parody of sport is highly productive, as it suggests professional wrestling's affinity with the culture of postmodernity. As sport sociologists have shown, the emergence and development of sport competition since the eighteenth century can be considered a part of the West's modernization process or the project of modernity. ${ }^{52}$ Sport came to embody many "modern" values (the internalization and observation of codes and rules, self-discipline, the nurturing of healthy minds and bodies, group loyalty, the rational and economic division of space, etc.) that are often ridiculed by professional wrestling. In that sense, Fiske's argument

\footnotetext{
${ }^{51}$ Fiske, Television Culture, 243-250.

52 Allen Guttmann, From Ritual to Record: The Nature of Modern Sports (New York: Columbia University Press, 1978); Norbert Elias and Eric Dunning, Quest for Excitement: Sport and Leisure in the Civilizing Process
} (Oxford: Basil Blackwell, 1986). 
pioneers the examination of wrestling as a postmodern cultural product.

However, as critics have pointed out, Fiske's outright celebration of active and resisting audience in Television Culture is questionable. ${ }^{53}$ While Fiske acknowledges that the television text attempts to impose dominant ideologies and naturalize the status quo,${ }^{54}$ he repeatedly stresses that the television text is primarily characterized by polysemy (multiplicity of meaning) and openness to various interpretations. This liberating feature promises what he calls television's "semiotic democracy." ${ }^{, 55}$ According to him, the audience's ability to draw its own meanings and pleasure out of text will ultimately neutralize the text's power to construct and impose dominant ideologies. The problem is that he fails to give a convincing explanation of the reasons for semiotic democracy's triumph. He only gives very vague justifications, such as: "To be popular, the television text has to be read and enjoyed by a diversity of social groups, so its meanings must be capable of being inflected in a number of different ways. ${ }^{, 56}$ In short, Fiske's semiotic democracy (formed by the audience who is a priori active) is an ideal concept constructed in a purely semiotic world detached from economic, institutional, and industrial conditions. In that sense, Fiske's idea runs against Hall's stress on the context-bound nature of encoding and decoding practices.

The Politics and Poetics of Transgression, written by Peter Stallybrass and Allon White, a former student of Hall who died prematurely, helps us complement Fiske's optimism with

\footnotetext{
${ }^{53}$ Mike Budd, Robert M. Entman, and Clay Steinman, "The Affirmative Character of U.S. Cultural Studies." Critical Studies in Mass Communication 7, no. 2 (1990): 169-184.

${ }^{54}$ Fiske, Television Culture, 139-140.

${ }^{55}$ Ibid., 239.

${ }^{56}$ Ibid., 66.
} 
regard to the carnivalesque character of wrestling television programs ${ }^{57}$ Although they too are heavily inspired by Bakhtin's carnival theory, Stallybrass and White distance themselves from his concept of the carnivalesque as an ideal model that sees people as inverting all official values, norms, and hierarchies - a concept that Fiske entirely accepts. Citing various historical cases, Stallybrass and White argue that political dimensions of carnival are much more complex than Bakhtin's formulation. While in Germany, popular carnivals were important sites for the Reformation struggles against Catholicism: the ecclesiastical powers attempted to mobilize old aristocratic carnivals in order to repress regular carnivals of people in Rome in the early seventeenth century. ${ }^{58}$ Carnivals are neither inherently revolutionary nor reactionary. An explanation of the political implications of carnivals has to be accompanied with "a close historical examination of particular conjunctures. ${ }^{, 59}$

In a similar manner, Stallybrass and White contest Bakhtin's simplified view of the fair, a premier example of the carnivalesque. Bakhtin locates the fair in the popular domain that is entirely outside the official order. However, Stallybrass and White counter, the fair "is neither pure nor outside. ${ }^{, 60}$ They stress that the fair was more of a hybrid place-located in historical, economic, and political realities - where various commercial and cultural forces intersected. As much as vulgar pleasure and values of the popular were celebrated in the fair, it was also subject to regulation and the expansion of capital. The fair was a place where the traditional and local were often exposed to modernized forces and commodity from a new world. For Stallybrass and

\footnotetext{
${ }^{57}$ Peter Stallybrass and Allon White, The Politics and Poetics of Transgression (Ithaca: Cornell University Press, 1986).

${ }^{58}$ Ibid., 15.

${ }^{59}$ Ibid., 16.

${ }^{60}$ Ibid., 28.
} 
White, the carnivalesque is not a utopia of the popular where all types of official discourses are degraded. It has always been embedded in various social and historical contexts, often driven by economic and political imperatives. They consider the carnivalesque to be one of the instances of what they call the "economy of transgression," where the official and the popular, the classical and the grotesque, the modern and traditional, the native and the exotic merge with each other. In this meeting, the self finds the other, and condemns it, but also desires to incorporate it as an "underground self.","1

For researchers who attempt to view contemporary WWE wrestling as a carnivalesque site, Stallybrass and White's reformulation is crucial. Instead of romanticizing WWE wrestling's subversive elements, researchers need to examine various economic and political factors that influence its contents. For example, the toning down of WWE programs' content in recent years (that is, their becoming less carnivalesque) has possibly been a result of the combination of several economic and political factors, such as the need to attract more sponsors, the WWE's partnership with toy company Mattel, and Linda McMahon's (Vince's wife and the company's former CEO) 2010 Senate run in Connecticut. Also, it is important to view WWE wrestling as a hybrid site where various contested ideas merge and where the boundaries between the self and the other are transgressed but also reaffirmed. As Jenkins' essay shows, in WWE wrestling, the counterhegemonic and the reactionary coexist within the complex interplay of gender, class, ethnicity, and politics. Also, the recent WWE uses a complex strategy to incorporate stars of smaller organizations (the other) into its storylines (self). It presents a story where these "minorleague" stars become true WWE superstars by defeating several pompous and conceited WWE superstars who look down on and derail them. That is, by exaggerating its own elitist and puffed-

\footnotetext{
${ }^{61}$ Ibid., 5 .
} 
up aspects that will be overcome by the earnest other, the WWE nevertheless reaffirms its identity as the true authentic place where wrestlers who passionately devote themselves to competition will finally triumph.

On its surface, Paul Gilroy's The Black Atlantic, which calls for the rethinking of the Eurocentric view of the modern world by proposing a new transcultural or transnational concept the black Atlantic, seems to have a little to do with contemporary professional wrestling. However, this book offers a theoretical perspective that allows us to find a link between wrestling and modernity as well as postmodernity. ${ }^{62}$ In his second chapter, Gilroy proposes the rethinking of the dominant idea of modernity as an emancipatory project, an idea that is still supported by theorists such as Jürgen Habermas and Marshall Berman. Gilroy argues that these theorists substantially ignore the modern history of brutality and terror caused by slavery, and they therefore fail to see that there are variations and fractures in the experience of modernity. In order to show the neglected, and certainly darker, side of modernity, Gilroy cites two narratives of African American slaves: Frederick Douglass's autobiographical tale and the tragedy of Margaret Garner. In these narratives, slaves (Douglass and Garner) show their willingness to die rather than be continuously enslaved. In their determination, Gilroy sees an irrational "principle of negativity that is opposed to the formal logic and rational calculation characteristic of modern western thinking, ${ }^{, 63}$ as a rational and calculating mind will choose survival as a slave over death. $^{64}$

${ }^{62}$ Paul Gilroy, The Black Atlantic: Modernity and Double-Consciousness (Cambridge, MA.: Harvard University Press 1993).

${ }^{63}$ Ibid., 68.

${ }^{64}$ Here, for the sake of intelligibility, I greatly simplify Gilroy's much more complicated argument. In the original text, Gilroy gives detailed accounts of the narratives of Douglass and Garner. Then, he considers them the 
This irrational will to death was a product of the alternative side of modernity that many European theorists fail to grasp. For these theorists, modernity promotes the pursuit of freedom by rational means. However, in slaves' perspective, it is rather an irrational death wish that brings them freedom from the terror, brutality, and inhumanity prepared by modernity. For Gilroy, modernity is characterized by its compound and fractured nature, where rationality and irrationality, the central and the decentered, emancipation and bondage simultaneously exist.

Gilroy's radical reconsideration of the modern seems to suggest that issues in contemporary wrestling, too, have much to do with the contradictory nature of modernity. That is, aspects of contemporary wrestling can be considered the epitome of irrationality produced by the other side of modernity explored by Gilroy. As we will see in detail in chapter 1, wrestling is a product of rational calculation, which is a "characteristic of modern western thinking": in professional wrestling, unlike other sport competitions, results of the matches are made calculable in order to attract the audience and make maximum profits. However, in recent years, wrestling ended up facing ultimate irrationality: the abnormally high mortality rate among wrestlers. Here, it is possible to find homology between modern slavery and contemporary professional wrestling. Modern slavery produced slaves' irrational preference of death over the continuation of enslavement. Likewise, wrestling, which epitomizes the modern principle of rational calculation, has caused wrestlers to irrationally wear out their own bodies and minds. Of course, I have no intention of calling wrestling a contemporary form of slavery, as that would be a gross exaggeration: unlike slaves, wrestlers choose to become and continue to be wrestlers. However, slavery and wrestling have commonality on an abstract level; in both cases, the 
modern prepares a dreadful situation that makes human beings destroy, or wish to destroy, themselves. Gilroy's formulation of the contradictory nature of the modern leads us to consider wrestling as one of the dark consequences of modernity.

As already mentioned, several issues in contemporary wrestling (including the high mortality rate among wrestlers) are reflective of trends in postmodern, late capitalist society. However, Gilroy's account indicates that wrestling is also considered the product of modernity's fractured and compound nature. In fact, he suggests the affinity between the postmodern and aspects of modernity that have been neglected by many European theorists: "it can be argued that much of the supposed novelty of the postmodern evaporates when it is viewed in the unforgiving historical rights of the brutal encounters between Europeans and the rest of the world." ${ }^{95}$ Given Gilroy's thoughts, researchers should suspect that the apparently postmodern features of professional wrestling are in fact the result of modernity's contradictory aspects.

\section{Examining Contemporary Professional Wrestling}

As we have seen, the Birmingham School has given many valuable accounts for the researchers of professional wrestling. While many audience studies of the school provide insights for understanding the dynamic and complex relationship between the production and consumption of wrestling, Gilroy's work is helpful for considering and theorizing wrestling in relation to modernity as an inherently fractured project. However, researchers of contemporary wrestling now need to develop in-depth perspectives on the forms of presentation in wrestling. As Barthes's foundational work in this field suggests, they are among the most important features of professional wrestling.

\footnotetext{
${ }^{65}$ Ibid., 44.
} 
For this purpose, it is necessary for wrestling scholars to revisit what many of Birmingham-school works attempt to overcome: Adorno and Horkheimer's account of the culture industry. Although assertiveness and determinism in it need to be discounted, their theory of the culture industry is unparalleled in its ability to critically and thoroughly illuminate formal features of popular cultural products. ${ }^{66}$

Therefore, chapter 1 of this dissertation centers on culture industry theory developed by Adorno and Horkheimer. The argument of the chapter is threefold. First, by closely referring to culture industry theory, I extensively consider stylistic features, or forms of presentation, of WWE wrestling that have remained unexplored in current literature. In particular, I explore the ways in which the WWE thoroughly stylized its products to attract fans, and the company's production mechanisms and principles behind the stylization. Second, I attempt to recuperate the value of Adorno and Horkheimer's heavily contested idea that the culture industry exerts total control over consumers. Although the situation today is much more complex than Adorno and Horkheimer assumed in 1940s, their total-control thesis helps us grasp the complex interplay between the WWE, which always attempts to control fan reactions and emotions, and the fans, who have already seen enough of the company's deceitful practices but nevertheless desire to be in the palm of the WWE. Third, I look at the high mortality and injury rate of professional wrestlers from the perspective of Adorno and Horkheimer's dark thesis of Enlightenment, that "enlightened" human beings have paradoxically used their rationality to enslave themselves. In professional wrestling, rational calculation of effects and the stylization of the product have led wrestlers to irrational self-destruction of their bodies and minds.

\footnotetext{
${ }^{66}$ Max Horkheimer and Theodor W. Adorno, Dialectic of Enlightenment: Philosophical Fragments, ed. Gunzelin Schmid Noerr, trans. Edmund Jephcott (Stanford: Stanford University Press, 2002), 94-136.
} 
Chapter 2 opens another unexplored field in contemporary wrestling studies. It examines the emergence of nonfictional narratives in WWE wrestling since the late 1990s. The advent of this new form of narrative presentation has transformed realism in WWE wrestling into a "dualized" state. Now the fans are encouraged to experience WWE wrestling in two different fashions: to immerse themselves in the fictional story-world and to find the nonfictional truth behind the production of the fictional world. The advent of nonfictional narrative has also allowed the WWE to demonstrate conservative political and ideological messages and publicize its social significance, while continuing to produce outrageous and sensational entertainment. I also argue that this nonfictional turn in WWE wrestling is to be understood as a process in which a culture industry has incorporated minor, unofficial discourses that used to escape from its control.

Chapter 3 offers a new perspective on the history of professional wrestling. That is, instead of giving a series of factual description, it aims to contextualize the development of American professional wrestling as a dynamic postmodern phenomenon. I argue that professional wrestling contained the seed of the postmodern at its birth, when it parted ways with serious modern sport and established its identity as a devious entertainment form. I then examine how professional wrestling has developed, renewed, and intensified postmodern aesthetics and sensibilities, paying attention to alternative, unconventional forms of masculinity demonstrated by the genre. The chapter concludes with the examination of "obsessive" performance and matches that are predominant in contemporary WWE wrestling. I argue that expressions of obsession in WWE wrestling are a new form of postmodern texts that address the process in which modern "disciplined" subjects destroy themselves in an intensified competition. The proliferation of over-the-top matches, where wrestlers keep competing until they are exhausted- 
just like the final sequence of The Wrestler-epitomizes the predominance of obsession in the WWE. Obsessive performances, while offering viewers the intense experience of pain, emotion, and realness, illuminate the contradictions of the WWE, a company that thrives by commodifying the destruction of its laborers' bodies and minds, and of the capitalist society it belongs to. 


\section{Chapter 1}

\section{Contemporary WWE Wrestling through Culture Industry Theory}

\section{Introduction}

In 1945, KTLA in Los Angles launched the first weekly professional wrestling television program, which would trigger the nationwide television wrestling boom. This was a year after Theodor W. Adorno and Max Horkheimer, who had been working together in Los Angels for several years, published the first edition of their famous essay on the culture industry, "The Culture Industry: Enlightenment as Mass Deception" as the fourth chapter of Dialectic of Enlightenment. Adorno and Horkheimer's critical radar had never caught professional wrestling while they were working on the essay. It had no word on wrestling.

Probably reflecting the lack of mention of wrestling in the essay, no extant studies of American professional wrestling have made substantial efforts to apply the culture industry theory developed in the essay to their subject. The unpopularity of the work of Adorno and Horkheimer among the researchers of contemporary popular culture does not help the situation. Culture industry theory indeed has significant shortcomings. Its assumption is overtly elitist and its argument extremely one-sided. The theory, formulated in defense of high art, utterly despises mass culture products and refuses to recognize any progressive traits in them. It also depicts consumers of mass culture as helpless victims who are deprived of the ability to put up resistance against the ruling class. Therefore, for scholars who like to explore liberating aspects of popular culture and the complex interplay between consumers and producers, culture industry theory is an object to criticize and overcome, or simply an outdated and ignorable matter of past scholarship. In fact, scholars who have examined liberating and/or intricate aspects of wrestling 
have been either explicitly critical or utterly indifferent to culture industry theory. ${ }^{67}$

In this chapter, I stand against the neglect of Adorno and Horkheimer in wrestling studies, and demonstrate that an in-depth application of culture industry theory to contemporary wrestling makes valuable contributions to the field and illuminates significant issues in the studies of popular culture. The theory reveals some of the important features of commercially successful wrestling organizations such as the WWE, features that are yet to be covered in the extant scholarship of this popular spectacle. Nowadays, the interaction between the WWE and the fans are certainly much more dynamic and convoluted than culture industry theory depicts. However, I do not see the dynamism and convolution involved in WWE wrestling as the indication of the irrelevance of the theory to WWE wrestling. Rather, I regard them as cases that allow us to update and complicate culture industry theory and to redefine its contemporary relevance to the study of wrestling and popular culture.

The argument of this chapter is threefold. First, I apply culture industry theory to extensively consider the stylistic features of contemporary WWE wrestling. ${ }^{68}$ In particular, I examine how thoroughly WWE wrestling has stylized its products, how these stylized products

${ }^{67}$ Fiske, Television Culture, 243-250; Jenkins, "Never Trust a Snake”; Sharon Mazer, Professional Wrestling: Sports and Spectacle (Jackson: University Press of Mississippi, 1998); Feigenbaum, "Liminal Experience.”

${ }^{68}$ Henry Krips' discussion of Adorno's theory of ideology helps and influences my reading of the culture industry essay. According to Krips, Adorno suggests that mass media encode "ideological lies" mainly through the technique or form of presentation, rather than through its message contents. For example, popular television programs and advertisements adopt a very personal form of address, engaging the audience as if the stars spoke to each and every one of the audience. In Adorno's view, it is through such a form or technique of address, rather than the contents of what announcers or casts say, that mass media presentations exert influence over the audience (Henry Krips, “A Mass Media Cure for Auschwitz: Adorno, Kafka and Žižek," International Journal of Žižek Studies 1, no. 4 (2007): 1-21). Krips' above reading of Adorno is highly applicable to the culture industry essay, which Adorno co-authored with Horkheimer. In the essay, Adorno and Horkheimer extensively discuss forms and styles of presentation of mass culture products, while giving only sporadic (and weak) analyses of specific messages contents of culture industry products. As I reveal in this chapter, their discussion of the forms and styles of mass culture accurately points out the stylistic features of contemporary WWE wrestling. 
attract WWE fans, and what kind of production mechanism and principles constantly demand the product stylization. ${ }^{69}$ These are among the most important questions in considering the uniqueness and attraction of professional wrestling as popular entertainment. As Roland Barthes suggests in his essay on professional wrestling in Paris in the 1940s, the distinctive feature of wrestling lies in its excessive and exaggerated forms or styles of presentation, not in the social or moralistic meanings of its narrative content. ${ }^{70}$ Contemporary WWE wrestling, while rigorously adhering to the stylistic convention of excessiveness and exaggeration, has advanced further stylization of its products. In doing so, it has succeeded in attracting both a hardcore and a casual audience and has become the largest wrestling organization in the world.

However, since Barthes' foundational insight, there has not yet been an academic discussion of the stylistic features of professional wrestling. Instead, as discussed in the introduction of this dissertation, most of the extant studies of wrestling focus on the social meanings (ideologies) and symbolism of wrestling narratives and characters. Culture industry theory will be the present guide for the unexplored field in wrestling studies, helping us to situate contemporary WWE wrestling in the history of the transformation of wrestling styles and of presentation styles in wrestling television. The theory points out with striking accuracy the mechanism and dynamics that have driven the history of professional wrestling and its stylization from the beginning.

Second, I demonstrate that Adorno and Horkheimer's much-contested idea that the culture industry exerts total control over consumers is very relevant to WWE wrestling. Both live

\footnotetext{
${ }^{69}$ To stylize or stylization refers to the act of deforming things to make them conform to certain styles, patterns, and formulas to be repeated.

${ }^{70}$ Barthes, "The World of Wrestling."
} 
and television shows of the WWE constantly attempt to realize the state of total control—where wrestlers control the crowd's emotion at will — in the most spectacular fashion by making the crowd react as loud and enthusiastically as possible. Of course, the WWE does not always succeed in exerting perfect control over consumers as suggested by culture industry theory. Fans, who have seen enough of the WWE's deceptive practices and preposterous fictional narratives, often vocally refuse to react as the company wants them to. Nevertheless, when the WWE masterly presents a new form of narrative by blurring the boundary between the fictional and the nonfictional, many fans temporarily allow themselves to succumb to the pleasure of being controlled. Through the examination of the complex interplay between the WWE and fans, and that between the fictional and the nonfictional, I attempt to update and re-contextualize the idea of total control in the age in which such a control increasingly appears to be implausible. I also demonstrate that the unique significance of WWE wrestling lies in the place where culture industry theory and other prominent cultural theories intersect.

Third, I go beyond the scope of culture industry theory and argue that the entire book of Dialectic of Enlightenment predicts a major problem of the wrestling business today, which is dominated by the WWE. Throughout the book, Adorno and Horkheimer present a dark thesis of Enlightenment, the thesis that "enlightened" human beings have come to use their rationality to enslave and ruin themselves. Contemporary professional wrestling, which sells a spectacle of live human bodies, epitomizes the process of rationality-turned-into-irrationality in a different way than all of the mass culture products depicted by Adorno and Horkheimer. In the wrestling business, a highly advanced and calculated production mechanism demands wrestlers to incessantly abuse their bodies and minds to an irrational degree; professional wrestlers have an abnormally high mortality rate. WWE wrestling reenacts the irrational self-destruction of human 
beings at the level of fiction, too. In its big matches, the company frequently features exhausting, over-the-top matches where wrestlers convey their unexplainable desire to push themselves to the limit.

In the first section I summarize important points of culture industry theory and other related theories, the points that provide effective perspectives from which to understand contemporary WWE wrestling. Then, in the following sections I explore various features of WWE wrestling and their significance in contemporary popular culture.

\section{Section 1}

\section{The Theory of the Culture Industry}

\section{Dialectic of Enlightenment}

As noted earlier, the culture industry essay of Adorno and Horkheimer is a chapter of Dialectic of Enlightenment. In this book, the authors attempt to explain the process in which Enlightenment has regressed into "mythology." The technological innovations and rationalization of social and political institutions only have resulted in the rise of totalitarian regimes and economic monopolization that exploit and debase masses. A rational project of Enlightenment, which was originally meant to lead the emancipation of human beings, eventually began to force everything to "conform to the standard of calculability and utility" and turned into ultimate irrationality.

The culture industry essay is presented as a concrete account of one of the dark consequences of Enlightenment. According to the authors, the culture industry, of which main products are various forms of entertainment such as feature films, television and radio programs,

\footnotetext{
${ }^{71}$ Horkheimer and Adorno, Dialectic of Enlightenment, 3.
} 
novels, magazines, and popular music, has barbarized people, entirely depriving them of humanity and their ability to seek and appreciate "true" happiness. In the essay, Adorno and Horkheimer provide a minute and in-depth examination of the features of culture industry products, and of the process in which the industry brings consumers under control and turns them into submissive masses.

\section{Product Stylization and the Presentation of the Unexpected}

Adorno and Horkheimer find the distinctive feature of culture industry products in its thoroughly stylized form of presentation. ${ }^{72}$ The stylization goes along with what they call the "schematism" of production. That is, the culture industry classifies all of the consumers into certain types and stylizes its products in line with the classification. Therefore, all of the products are composed of stereotypes, jargons, and clichés, which are designed to attract each of these types of consumers. Now, every detail of the products falls into a certain formula or preestablished pattern.

Adorno and Horkheimer also suggest that there is a seemingly opposing tendency in the culture industry. The industry, while persistently stylizing products, also constantly and obsessively seeks to add novel elements to the products, attempting to give consumers an impression that established styles or patterns are often broken. However, the authors assert, there is no substantial conflict between the drive for stylization and the urge to present the unexpected, since producers never really attempt to create something that "falls outside the idiom.",73 Orson Welles' unconventional approaches in making films are in fact "calculated rudeness" that only

${ }^{72}$ Although Adorno and Horkheimer also use the word standardization to refer to the same phenomena, I prefer stylization; unlike standardization, stylization does not imply that there is a fixed standard form that is shared by the majority.

\footnotetext{
${ }^{73}$ Ibid., 102.
} 
conform to the existing system. ${ }^{74}$ The novelty and unexpected elements added to culture industry products ultimately fall into the same old formulas, jargons, and clichés. The culture industry is under the "permanent compulsion to produce new effects which yet remain bound to the old schema." ${ }^{.75}$ For Adorno and Horkheimer, culture industry products never challenge existing stylistic conventions and therefore represent absolute boredom.

\section{Calculated Signals, Calculated Reactions}

Despite their argument that the culture industry stylizes products in line with various classified traits of consumers, Adorno and Horkheimer assert that there is no "true" diversity resulting from the product stylization. All of the products are ultimately the same, even though they are made of different stereotypes, jargons, and clichés that target multiple consumer types. Adorno and Horkheimer explain the sameness of culture industry products by comparing them with what they consider truly valuable works of art.

In these works of art, details have produced meaningful conflicts as they have posed a radical challenge to the whole structure. ${ }^{76}$ However, in culture industry products, all of the details bear no relationship with the whole. They are only designed to give consumers instant sensory stimulations, and to draw immediate and knee-jerk response from consumers.

Adorno and Horkheimer use the words "signals" and "reactions" to describe the instant and impoverished nature of the communication caused by culture industry products: "The spectator must need no thoughts of his own: the product prescribes each reaction, not through any actual coherence — which collapses once exposed to thought—but through signals. Any

\footnotetext{
${ }^{74}$ Ibid.

${ }^{75}$ Ibid., 101.

${ }^{76}$ Ibid., 99.
} 
logical connection presupposing mental capacity is scrupulously avoided." ${ }^{, 77}$ As soon as they find a signal attached to the entertainment products, consumers automatically give a reaction as if somebody pressed a switch button without giving any thought to the products. It is noteworthy that the authors state that these reactions are "prescribed" in the products; immediate reactions from consumers are pre-calculated in the production process. For Adorno and Horkheimer, the fundamental production mechanism of the culture industry lies in this low-end form of "calculation of effects. ${ }^{78}$ This raises a question: What makes the industry assume that it can precalculate consumers' reaction? A look at the contemporary WWE wrestling leads us to recognize that the key lies in the repetitive presentation of stylized contents.

In criticizing the signal-reaction exchange that is pre-calculated and planned by the culture industry, Adorno and Horkheimer care less about the specifics of exchanged messages. Regardless of the contents of signals and reactions, all of these exchanges are equally of no value, as long as they are calculated results prescribed by the industry. Therefore, for Adorno and Horkheimer, the details of the products are all interchangeable with each other, unlike those in works of art. Such details give only "pseudo individuality" to the products. Adorno and Horkheimer even go so far as to imply that the production system that the culture industry operates on is no different from the assembly line production system in factories. According to them, "automated sequence of standardized tasks" are imprinted in culture industry products. ${ }^{79}$ The details added to culture industry products correspond to mass-produced interchangeable parts of the assembly line products.

\footnotetext{
${ }^{77}$ Ibid., 109.

${ }^{78}$ Ibid., xviii.

${ }^{79}$ Ibid., 109.
} 
Indistinguishability between Advertisement and Contents

Adorno and Horkheimer also give an important insight regarding the relationship between the culture industry and advertisement. They stress that in culture industry products main contents and advertisements are tightly fused together. For them, the editorial section of American magazines such as Life and Fortune are at first glance indistinguishable from advertisements. ${ }^{80}$ Film trailers and feature films are also indiscernible: "Every film is a preview of a next, which promises yet again to unite the same heroic couple under the same exotic sun: anyone arriving late cannot tell whether he is watching the trailer or the real thing." ${ }^{.81}$ All of the contents of culture industry products are in fact advertisements, and advertisements are virtually the main contents of culture industry products.

This view complements Adorno and Horkheimer's contention that all of the culture industry products are essentially the same in the sense that they are all manufactured under the same mechanism - the calculation of immediate effects on consumers. In Adorno and Horkheimer's view, culture industry products, while drawing immediate reactions from consumers, also seek to inflict another form of immediate effect as advertisements. That is, they endeavor to instantly direct consumers' attention to what comes next and to have them keep consuming. Likewise, advertisements do not only lead consumers to keep consuming, but also, like entertainment products, show various calculated signals to draw consumers' immediate reactions.

Total Control over Consumers

\footnotetext{
${ }^{80}$ Ibid., 132.

${ }^{81}$ Ibid.
} 
From the observations of the features of the culture industry summarized above, Adorno and Horkheimer draw a very bold conclusion. That is, through the presentation of its products, the culture industry exerts total control over consumers who are by definition passive and helpless. In the state of total control, consumers behave as producers wish them to and are "magically" attracted to the products. The state demonstrates the perfect harmony between producers' intensions and the consumers' reactions.

The most important condition for the industry to attain the total control over the behavior of consumers is to deprive them of the ability and willingness to think critically and act. The signal-reaction exchange explained earlier is the prime example of the deprivation, as stimulating "signals" give consumers no time to contemplate on the products. Adorno and Horkheimer argue that, in adding such signals to entertainment products, "(a)ny logical connection presupposing mental capacity is scrupulously avoided.. ${ }^{, 82}$ The signal-reaction exchange reduces consumers into passive masses, who are willing to forsake their "mental capacity" to critically examine the products and voice their opinions.

Adorno and Horkheimer also argue that such deprivation of "mental capacity" ultimately leads consumers to be subjugated to and captivated by the culture industry. They explain it by relating the signal-reaction exchange to their unique view of a linguistic transformation in modern society. They claim that there has been a deterioration in the quality of language; now language "hardens to a formula." ${ }^{, 83}$ That is, language has lost its substantial meaning that it used to carry, and only designates objects. Paradoxically, this emptying or the formalization of

\footnotetext{
${ }^{82}$ Ibid., 109.

${ }^{83}$ Ibid., 133.
} 
language "reverts to magic." ${ }^{84}$ That is, it renders language an occult power to enchant people.

The enchanted people would only give immediate and expected reactions to the emptied and formalized language. In particular, names of things become the objects of worship, as the magic "most readily attaches" $" 85$ to names. The culture industry effectively manipulates this magical power of formalized language as it gives the products empty names and catchphrases. By repeating the names and catchphrases of the products, and also by having consumers repeat these names and phrases, the culture industry succeeds in creating enchanted, tame, and subjugated consumers. ${ }^{86}$

The subjection of consumers through the occult enchantment means the homogenization of consumers. As explained, the culture industry classifies all consumers into stereotypical categories, and manufactures the products that are targeted to each of the categories. The enchanted consumers willingly fall into the category assigned to each of them: "Everyone is supposed to behave spontaneously according to a 'level' determined by indices." ${ }^{, 87}$ In this way, the industry realizes the perfect harmony between producers' intentions and consumers' reactions; consumers are willing to react to all the signals that they are supposed to react. Here,

${ }^{84}$ Ibid.

${ }^{85}$ Ibid., 134.

${ }^{86}$ The authors' account of the emptying (in their word, "demythologizing") and reenchantment of language is, of course, the extension of the Marxist notions of reification and commodity fetishism. Adorno's application of these notions is not limited to language; in his criticism of popular music, Adorno suggests that various elements on music, which include conductors, instruments, performative techniques and arrangements, are fetishized (Theodor W. Adorno, "On the Fetish Character in Music and the Regression of Listening," in The Culture Industry: Selected Essays on Mass Culture, ed. J.M. Berstein [London: Routledge, 2001], 29-60). Habermas (1984) critically points out that Adorno and Horkheimer over-expanded the notion of reification, by detaching it from the specific historical context of the emergence of capitalism and the problem of human relations caused by capitalism (Jürgen Habermas, The Theory of Communicative Action, Volume 1: Reason and the Rationalization of Society [Boston: Beacon Press, 1985], 378-380).

\footnotetext{
${ }^{87}$ Horkheimer and Adorno, Dialectic of Enlightenment, 97.
} 
consumers' "varied" responses ultimately turn into sameness and only affirm the industry's continual reign and total control over them.

Adorno and Horkheimer further argue that in controlling the act of consumers, the industry implants in their mind the idea that the capitalist rule permanently continues. Through endless repetition of unfulfilling contents, which are essentially previews or advertisements of what comes next, the industry eventually disciplines consumers. It makes them believe that the same thing will be repeated forever, that there is no way to change, and therefore that they should be permanently satisfied with being unsatisfied consumers. The way in which entertainment is produced signals the dead end of capitalism, too. Consumers/workers, while enjoying mass entertainment in search of retreat, repeatedly find that entertainment is produced through the same "mechanical labor process" $\$ 8$ that they want to escape.

\section{Problems and Different Theories}

As noted earlier, culture industry theory contains many problems. For one thing, Adorno and Horkheimer make various negative judgments on the value of popular entertainment-i.e., all of the products are boring, of no value, and only wear pseudo-individuality-in comparison to what they consider to be true works of art. Therefore, unless one shares his or her standpoint as well as his or her conception of what true works of art should be, it is hard to find validity in their dismissal of mass culture products. Also, Adorno and Horkheimer's equation of the production system of the culture industry with the assembly line system is unconvincing. It is unlikely that all of the tasks required in the culture industry, which involve the constant creation and presentation of entertainment contents, are entirely "automated" or "standardized."

\footnotetext{
${ }^{88}$ Ibid., 109.
} 
Larger problems lie in Adorno and Horkheimer's description of how the culture industry exerts total control over consumers. The authors assume that mass culture products only express capitalist ideology and interest, which consumers unconditionally accept. In other words, culture industry theory fails to recognize any complexity and conflict in the relationship between producers and consumers of popular culture.

As described in detail in the introduction of this dissertation, scholars of the Birmingham School of cultural studies oppose Adorno and Horkheimer's description of consumers as homogeneous and passive "dupes." They stress the active side of the consumption of mass culture. Consumers may interpret messages decoded in mass culture products in varied ways, resisting the "dominant" way of reading that producers attempt to impose on them. ${ }^{89}$ The resistance is not limited to the level of interpretation, but may be materialized in actual practices. Henry Jenkins, being inspired by the Birmingham-school works, describes the "poaching" activity of television fans, who rewrite the narratives of their favorite television programs in order to serve desires of their own. ${ }^{90}$

In opposition to these cultural studies works, Slavoj Žižek is in agreement with Adorno and Horkheimer in emphasizing the power of the ruling culture to exert ideological effects on the masses. ${ }^{91}$ However, unlike Adorno and Horkheimer, Žižek does not assume that consumers unconditionally believe the dominant ideology expressed in mass culture products. Adorno and Horkheimer's idea is, however sophisticated, still mired in the classical concept of ideology as "false consciousness." They assume that masses believe in the false promise and erroneous

\footnotetext{
${ }^{89}$ Hall, "Encoding/decoding"; Ang, Watching Dallas; Fiske, Television Culture.

${ }^{90}$ Henry Jenkins, "Star Trek Rerun, Reread, Rewritten: Fan Writing as Textual Poaching," in Fans, Bloggers, and Gamers: Exploring Participatory Culture, (New York: New York University Press, 2006), 37-60.

${ }^{91}$ Slavoj Žižek, The Sublime Object of Ideology (London: Verso, 1989), 28-33.
} 
world-view presented by the dominant ideology. Žižek argues that this classical concept cannot be applied to today's world. Presently, what Peter Sloterdijk calls cynicism has replaced false consciousness as the dominant mode of ideological function. Cynical subjects recognize lies and wrongs included in the dominant ideology. They know that the dominant ideology serves the interests of the powerful, and that there is a gap between what it promises and the social reality. Nevertheless, cynical subjects still find some reason to maintain the social order and follow the ideology as if they did not realize its true color. Despite their knowledge, they act as if they didn’t know anything. Therefore, Žižek states, ideology does not guide or misguide people at the level of knowledge (as assumed by Adorno and Horkheimer) anymore. It does that at the level of action.

\section{Section 2}

\section{Stylistic Features of WWE Wrestling through Culture Industry Theory}

Raw, SmackDown, and PPV Specials: The WWE's Main Products

Before beginning the examination of the features of WWE wrestling with close reference to culture industry theory summarized in the last section, a brief explanation of the WWE's main products may be in order. Although contemporary WWE wrestling uses multiple media platforms, such as DVDs, magazines, web broadcasting, website updates, and social media platforms such as Twitter and Facebook, it provides virtually all of the on-going narratives through television. In particular, the company's two two-hour weekly programs, Raw (Monday on USA network) and SmackDown (Friday on Syfy channel) are the main sites where most of the "feuds" (rivalries between wrestlers) are created and developed, new characters are introduced and recognized by fans. Even though many wrestlers appear in both shows, each program has its 
own separate roster of wrestlers, general manager as an on-screen character to run the show, and championship.

Raw and SmackDown adopt similar stylistic and structural formats of presentation, although the former is live broadcasting from the venue whereas the latter features pre-taped events. In both shows, an approximately two-hour episode is composed not only of wrestling matches, most of which are preceded by spectacular entrances of wrestlers, but also other small segments, include several in-ring skits, quarrels, scuffles, and "promos" (verbal performances) performed by wrestlers and other talents such as referees, managers, authority figures, and many other guest performers. Also inserted in programs are numerous "recap" and "hype" video clips that summarize past storyline developments and advertises upcoming matches, and various pretaped vignettes performed by wrestlers and performers, all of which are shown to live crowds on a huge screen called the "Titantron" that is set above the center stage.

In the patchwork of numerous segments, multiple feuds among wrestlers are created, developed and often blatantly dropped. Large-scale stunts and spectacular ceremonies (e.g., car action stunts, brawls outside the arena, weddings between performers) are often featured in Raw and SmackDown to enhance the attraction of narratives and matches. Many of the feuds are geared for showdowns in Pay-Per-View (PPV) special programs, which are presented on a monthly basis and use a much larger portion of time in showing wrestling matches than Raw and SmackDown. However, Raw and SmackDown also frequently feature "PPV level" big matches and title matches. PPV specials would solve some of the problems, but leave others unsolved and create new ones that will be developed in Raw and/or SmackDown. The cycle of creation, development, cancellation, closure, and recreation of narratives continues as long as the popularity of these programs stays healthy. 


\section{Dynamics between Product Stylization and the Production of the Unexpected}

In order to understand the form or style of presentation in WWE wrestling, Adorno and Horkheimer's observation on the product stylization and the constant addition of new effects in the culture industry is crucial. Both of the elements that characterize the production of the culture industry - the drive for stylization and the obsession to present the new and unexpectedpenetrate the production of WWE wrestling, too. ${ }^{92}$ I argue that both have been essential factors in the evolution of American professional wrestling since its beginning stage. Professional wrestling as we know it today was the product of stylization, that is, the act of deforming unscripted (therefore "legitimate") fighting contests into a scripted and stylized form. ${ }^{93}$ At the same time, in order to differentiate itself from other (unscripted) sports, professional wrestling has added and refined numerous new narrative forms, characters, moves, and catchphrases to surprise and excite the audience. WWE wrestling today, which attracts more people than any other wrestling products in the world, is to be considered the most successful result of the dual movement of stylization and the constant production of the new and the unexpected. The presentation of its products, in particular of $R A W$ and SmackDown, is thoroughly stylized, while

\footnotetext{
${ }^{92}$ I am not suggesting that Adorno and Horkheimer's negative view about the stylized nature of the culture industry products are entirely applicable to contemporary WWE wrestling. I find unconvincing their assertion that, however hard the culture industry attempts to present new elements, its products are boring since they are always "bound to an old style." WWE wrestling often succeeds in introducing new elements and making "bored" fans excited and immerse themselves in the story. I don't call such successful cases boring. Here, I agree with Jenkins who states that popular culture makes us "wow" when it twists or transforms repeated formulas into "something marvelous and unexpected" (Henry Jenkins, The Wow Climax: Tracing the Emotional Impact of Popular Culture [New York: New York University Press, 2007]), 3.

${ }^{93}$ One of the most obvious examples of the stylized movement in professional wrestling is the convention of "hitting the ropes." That is, professional wrestlers are almost always willing to run towards the ring ropes, hit them with the back, bounce back, and run towards the opponent to perform some move with him. This practice, an extremely unnatural one by the standard of legitimate fighting contest, is one of the established norms in professional wrestling all over the world. For a more detailed examination of this practice, see chapter 2 of this dissertation.
} 
these programs constantly and compulsively demonstrate new and unpredictable elements. The conspicuousness of the dynamics between stylization and compulsive production of the unexpected characterizes WWE wrestling. In the following pages, I will explore how the dynamics has influenced and regulated 1) wrestlers" "gimmicks" (characters), 2) the ways in which wrestler build and perform matches, and 3) the presentation of storylines in WWE wrestling.

\section{Gimmicks}

Since the beginning stage of professional wrestling, wrestlers have stylized their movements, behaviors, and appearances by performing their own gimmicks. All of the gimmicks are classified as either "babyfaces" (wrestlers who are supposed to be cheered by fans) or "heels" (who are supposed to be jeered by fans). Gimmicks have to be over-the-top and therefore extremely easy for anyone to understand. Many of them are "schematically" produced and have targeted audiences in line with the classification made by promoters; these gimmicks explicitly exploit social, racial, ethnic, and gender stereotypes to please or provoke certain group of crowds. ${ }^{94}$ WWE wrestling still preserves such basic features of wrestling gimmicks.

At the same time, WWE wrestling has advanced the stylization of wrestlers by constantly fine-tuning gimmicks. Gimmicks of contemporary WWE wrestlers are much more elaborate and more rigorously restrict wrestlers' performance and appearance than in the past. WWE wrestlers are required to make their gimmicks familiar to the audience in every aspect of their presence and to maintain the familiarity. All of the popular WWE wrestlers now have their own catch

\footnotetext{
${ }^{94}$ Wresting historian Scott Beekman states that as early as the 1920s, wrestling promoters applied "(often false) ethnic identifications to wrestling to generate the interest of the same ethnic group." They pitted Greeks against Italians or Jews against Catholics to provoke racial tensions (Beekman, Ringside, 65).
} 
phrases to repeat every time they address the audience. They have the same signature faces and gestures to repeat as well. In the ring, each has his/her own usual set of performative sequences and "finishers" (finishing moves). Such stringent constraints did not exist in wrestling in the 1970s, when wrestlers were more at liberty to perform and improvise their gimmicks. ${ }^{95}$ Also, the physiques of contemporary wrestlers are obviously more rigorously stylized than in the past.

Broadly speaking, the stylization of male wrestlers' bodies has proceeded in two steps. Most of the wrestlers until the mid 80s looked very loose and "natural" by today's standard; they carried a considerable amount of body fat with them, and few had body-builder body types. During the late 1980s, WWE wrestlers' bodies became noticeably more muscular than before, and many turned themselves into "muscle freaks." 96 The tendency eased as the demands for athleticism increased in the 1990s. ${ }^{97}$ However, wrestlers still have to be in great shape as part of their gimmicks; today, most WWE wrestlers have much fitter bodies with clearer cut muscles than wrestlers before the mid-1980s. The demand to stylize one's appearance is even more blatant in the case of female wrestlers of the WWE ("WWE divas"), most of whom are thin and have implanted breasts and model-type faces.

While strictly regulating wrestlers' performance and appearance through gimmicks, the

${ }^{95}$ Although wrestlers' gimmicks in the past were less strictly stylized than what they are now, the demands to keep performing their gimmicks were much stronger in the past. Unlike current wrestlers, past wrestlers were always required not to drop their gimmicks even when they were off duty as long as someone else was present. Until the mid 90s, wrestling organizations attempted to conceal the fact that their products were scripted in order to "protect the business." For a more extensive discussion of the efforts to maintain the "realism" of professional wrestling, see chapter 2 of this dissertation.

96 Top wrestlers of that era such as Hulk Hogan, Ultimate Warrior, the Road Warriors (Legion of Doom) epitomized this trend.

97 The transformation was paralleled to the change in the postmodern features of WWE wrestling in the late 1990s. During that time, slow, relatively safe, and not-so athletic battles between "muscle freaks" of the 1980s, ceased to be the main attraction of the WWE. Instead, long, high-risk, and over-the-top matches between obsessed wrestlers who would keep fighting until their bodies exhausted became the prominent product of the company. See chapter 3 of this dissertation for more details. 
WWE has added more repertories of refined gimmicks by constantly coming up with new ones.

These new gimmicks, while breaking some established notions, still observe the fundamental conventions of wrestling gimmicks; they are always over-the-top, extremely easy to understand, and should be either on the babyface or heel side. To cite a few notable examples, in the late 1990s, instead of conventional idea of virtuous and patriotic babyfaces, the WWE featured a more arrogant type of guys — exemplified by Stone Cold Steve Austin — as its main babyfaces. During the same period, Vince McMahon, the untrained-in-wrestling owner of the company, stepped up to become Austin's rival, performing a character based on his real-life persona. ${ }^{98}$ In the late 2000s, Chris Jericho reinvented himself with a new heel gimmick to a great success. Instead of adopting archetypal concepts of wrestling heel, such as foreign menace, barbarian, or abusive millionaire, he became a suit-wearing, cold-blooded, and self-righteous heel who called others hypocrites and claimed that he always told the truth. The most successful elements of these gimmicks will certainly be re-adopted in the future to further stylize the performance of wrestlers. ${ }^{99}$ In WWE wrestling, the dual movement of stylization and the urge to present the new always co-exists, as success of a new gimmick always adds further archetype of performance styles to the existent repertories.

\section{Building and Performing Matches}

The stylization of wrestling performance can be observed not only in terms of individual dissertation.

${ }^{98}$ For a more detailed observation of the feud between Austin and McMahon, see chapter 3 of this

${ }^{99}$ The breakthrough of Austin was followed by the emergence of other non-virtuous babyfaces such as The Rock and The-Degeneration X, and as the most current example Randy Orton. After the success of Vince McMahon, his real-life families and the executives of the company-his son Shane, his daughter Stephaney, and his wife Linda-involved in WWE storylines one after another, all performing themselves. Chris Jericho's coldblooded, self-righteous heel gimmick was later inherited by C.M. Punk. 
wrestlers or individual gimmicks, but also in more collective (regional and organizational) terms; wrestlers and fans often talk about the differences among North American, European, Mexican, and Japanese styles of performing professional wrestling, or among wrestling styles of different organizations. The multiplicity of wrestling styles in this sense is among the most intriguing topics for hardcore wrestling fans to discuss, although it has rarely received attention from the extant scholarship of professional wrestling. ${ }^{100}$ Adorno and Horkheimer's account of the dynamics between the stylization and the compulsion to produce the new provides an effective perspective for understanding the wrestling style featured in the WWE.

Contemporary WWE wrestling matches, in particular those in Raw and SmackDown are more rigorously stylized than in the past. Matches in Raw and SmackDown demonstrate much more crisp, spectacular, and refined movements, which are to be repeated in different matches. In comparison, matches in the WWE from the 1960s to the early 1980s were much slower-paced, less spectacular, and much more laxly structured. ${ }^{101}$ In fact, fans and wrestlers often note that the contemporary WWE has its own style of performing wrestling that is quite distinct from wrestling styles performed in many other contemporary organizations. ${ }^{102}$ The so-called "WWE

\footnotetext{
${ }^{100}$ For example, see Chris Jericho and Peter T. Fornatale, Undisputed: How to Become the World Champion in 1372 Easy Steps (New York: Grand Central Publishing, 2011), 18 and "What is 'WWE style,"” in Pro Wrestling: WWE LurKerFAQs, 2011, http://www.lurkerfaqs.com/posts/view/222733 (accessed April 1, 2012).

${ }^{101}$ At that time, most of the moves used in wrestling matches were much lower-impact than now, and highflying and acrobatic moves were rare. Wrestlers before the mid 1980s used to improvise the actions except the predetermined finish. In contrast, in Raw and SmackDown, wrestlers work together before the match and determine all of the spots (spectacular moves) they are going to perform, and let directors know what they will do before the match. WWE wrestler Chris Jericho states that the best way to perform the match is to predetermine the beginning, the middle, and the finish, and call the rest on the fly However, when he worked against inexperienced wrestlers, he needed to work everything together before the match (Jericho and Fornatale, Undisputed, 55-56).

${ }^{102}$ For example, as discussed in detail later in this chapter, Jericho explains the difference between the "WWE style" and styles that are prevalent in other organizations and countries. Jericho also writes that HHH, one of the most popular WWE wrestlers, told him that the WWE wrestlers have a "different way of doing things." (Jericho and Fornatale, Undisputed, 47) Here, the "WWE style" or the WWE "way of doing things" should only be understood as a set of dominant but not exclusive tendencies of performing wrestling in the WWE. Nothing is absolutely unique about the wrestling performance in the WWE; many former WWE superstars would perform in a
} 
style" of wrestling, which is best exemplified by matches in Raw and SmackDown, is known for limiting the number of moves used by each wrestler. ${ }^{103}$ While some other North American organizations, most notably the Ring of Honor, tend to allow a diversity of moves, the WWE style is characterized by the heavy reliance of the repetition of signature sets moves and finishers that are familiar to audience. Fans often sarcastically talk about the "five moves of doom" by John Cena, the most popular wrestler of the WWE, suggesting that he always uses the same five moves in the same order to beat the opponent in the finishing sequence of the match. Also, wrestling featured in the WWE tends to place stronger emphasis on high-impact moves such as punches and slams, as opposed to exchanges of submission holds on the ground.

In the WWE, not only individual moves of the wrestlers, but also the larger structure of the match is heavily patterned. When the company tries to "push," or promote the popularity of a certain wrestler, he/she will be matched up with an obvious "jobber," or underdog. Such a bout is called a "squash" match. In order to maximize its intended effect, the match is given only a few minutes to follow a formula; it ends after a "pushed" wrestler dominates opponents, goes through his/her usual set of moves, and uses his/her signature finisher. In fact, the formula of squash matches is shared by many wrestling organizations throughout the world.

In the WWE, many of non-squash matches have common established structural flows. In a typical 5 to 10 minute match, after some initial actions, a heel wrestler eventually gains the

similar style in other organizations. Also, some of the matches in the WWE are closers to styles that are typical in smaller organizations than others. Many WWE wrestlers have wrestled in different organizations and countries, and often attempt to evolve their performances by adopting various new essences. In fact, some wrestlers deny that there is a WWE style. Former WWE wrestler Sean Waltman claims its is not WWE style but "main event style" that are performed by the major matches in the WWE. Likewise, Lance Storm, another former superstar, argues that what is performed in the WWE is only a basic style of professional wrestling and there is nothing peculiar to the wrestling featured by the WWE (Sean Waltman, "When Jericho Came to the WWF, He Didn't Get it Yet," interview by Wade Keller, Pro Wrestling Torch, 726 [2002], 9-12).

${ }^{103}$ For a discussion of the style of wrestling adopted by the WWE, see Waltman, "When Jericho Came to the WWF" and Jericho and Fornatale, Undisputed. 
upper hand over a babyface in order to frustrate the crowd. After taking a beating for several minutes, the battered babyface starts to fight back. Following several failed attempts, he/she ${ }^{104}$ finally makes a "comeback" by breaking the heel's offense. The comeback sequence is heavily stylized. Typically, while the heel opponent catches him/her with some type of submission hold, such as headlock, sleeper hold or hammerlock, the babyface begins to express signs of life by bringing his/her arms up and making a fist tight. As the crowd becomes excited and cheers for the babyface increase, he/she finally breaks the hold, and retaliates with a fury of "explosive" offensive maneuvers to please the crowd. After these routinized actions, the match goes on to its ending sequence.

A similar match structure is prevalent in tag-team matches. Here wrestlers use "hot-tag" sequences as an equivalent of "comebacks" in single matches. After one member of a babyface team is isolated from his partner and dominated by a heel team for a while, he/she begins his desperate attempt to escape and tag his partner. As his/her partner extends the arm to encourage $\mathrm{him} /$ her to come back to their corner to make a tag, the crowd begins to cheer him/her. The battered member of the babyface team finally succeeds in tagging his/her fresh partner, who then jumps into the ring and attacks both of the heel team members one after another with explosive maneuvers to excite the crowd. Almost every Raw and SmackDown features either the "comeback" or "hot tag" pattern at least one time.

Finally, almost all of the match endings in Raw and SmackDown fall in established patterns. As a logical consequence of the fixation of finishers of wrestlers, most of the matches will end when one wrestler successfully executes his/her signature finisher. When the WWE

\footnotetext{
${ }^{104}$ Although I use "he/she" in this context, in actuality matches of female wrestlers are rarely given more than five minutes. Also, female wrestlers do not have a lot of opportunities to perform "comeback" or "hot-tag" sequences explained in this section.
} 
wants to avoid a "clean" finish to postpone the "feud" between a babyface and a heel, the company often has the heel apply an illegal method (e.g., the use of a weapon, the intervention by his cornerman) to win the match or disqualify himself/herself. Or, the company may give the babyface clean or legitimate victory, and then have the loser/heel attack him/her from behind to develop the hatred between the two. Both patterns are repeated on a weekly basis on Raw and SmackDown.

As in the case of gimmicks, the obsession to present the unexpected frequently affects the flow and structure of WWE wrestling matches. The obsession becomes particularly visible in big matches between top wrestlers, in which both of them should be presented as tough fighters that cannot be easily defeated. ${ }^{105}$ In such matches, the two wrestlers may cancel out each other's finishers with countermoves, or "kick out" the opponent's pin-fall attempts following their finishers, raising their shoulders before the three count to avoid the defeat, to betray the expectation of the crowd that the finishers are unbeatable, and to incite their excitement.

Such efforts to produce the unexpected ultimately increase the numbers of formula and rather reinforce the stylized nature of matches; a long exchange of counters against each others' finishers and a series of "near pin falls" or "false finishes" are now established patterns that are constantly repeated in WWE wrestling. In fact, due to the incessant urge to present the unexpected, contemporary WWE wrestling often features much prolonged, physically damaging, all-out performances of the wrestlers. Such over-the-top matches now constitute a typical style that everyone expects in a big match between two mega stars. Therefore, the escalation into a more extreme performance style inevitably imposes a severe burden on wrestlers, an issue that will be discussed later. At this moment, it is suffice to say that in the WWE, even the urge to

\footnotetext{
${ }^{105}$ In the WWE, such a match is almost exclusively among male wrestlers.
} 
present the unexpected leads to the further stylization of matches.

\section{Presentation of Storylines, “Angles,” and Surprises}

The similar dynamics between stylization and the urge to present the unexpected can be observed in the proliferation and intensification of "angles," or staged incidents and storylines that are designed to develop rivalries among wresters, and other special events such as title changes. Contemporary WWE wrestling products, in particular Raw and SmackDown, are blatantly obsessed with surprising viewers all the time. Of course, from its beginning, professional wrestling as a scripted performance has given audience shocks and surprises to attract audience. However, between past and present wrestling, there are huge gaps in the scale, quality, and frequency of the presentation of shocking and surprising elements. From the 1960s to the early 1980s, the WWE would only occasionally stage accidents and surprises. As one of these rare angles, in 1983, then-champion Bob Backlund was attacked by his heel rivals while he was twirling clubs. The clubs were supposed to fall on Backlund's neck to inflict significant damage on him. However, when he fell down, the clubs landed on the floor and were far from his neck. Backland grabbed one of the clubs on the ground, brought it to his neck, made an agonized look, and screamed in pain. Meltzer writes that Backlund's performance "looked preposterous" by today's standard. However, it was still aired on television since "in these days, angles were so rare that they almost always worked." ${ }^{106}$ In contrast, contemporary Raw and SmackDown produce much more spectacular and refined angles and surprises week after week. Wrestlers frequently perform large-scale stunts, going outside the building and throwing an opponent into the river, hitting the opponent with a car at the parking lot wrestlers with a car, or

\footnotetext{
${ }^{106}$ Dave Meltzer, Wrestling Observer Newsletter, March 24, 2003, 10.
} 
jumping off from more than 10 feet high to fall to the opponent who was lying on the table, destroying himself, the opponent, and the table. Now, the abundance of sensational events and surprises has become the norm, and therefore a typical style of WWE wrestling narratives. ${ }^{107}$ Staged surprises in the fictional world of the WWE hardly surprise fans, as they have been numerously repeated and are always expected. As will be examined in detail below, such a condition often encourages the WWE to transgress the boundaries between the fictional and the nonfictional.

The dynamics between stylization and the compulsion to produce the unexpected regulates every aspect of the presentation of WWE wrestling. WWE wrestling, while incessantly fitting its products into styles that are to be repeated, is also blatantly obsessed with breaking the styles to surprise fans. The obsession itself has become its predominant style. Why, or under what principle and mechanism have such dynamics developed? How do the dynamics influence the manners in which fans consume WWE wrestling? Culture industry theory provides a framework in which to answer these questions.

\section{Calculated "Signal-Reaction" Exchanges and Stylization of Performance}

Adorno and Horkheimer's description of "signal-reaction" exchanges between producers and consumers is very useful in understanding how WWE wrestling is to be consumed. In fact,

\footnotetext{
${ }^{107}$ The similar contrast between the past and the present of the WWE can also be also observed in the change in the frequency of championship title changes. Bruno Sammartino, the most popular champion in the early WWE retained his world championship belt for more than seven years since he captured it for the first time in 1963. The fans saw the same dominant champion always winning the match during the period. It is reported that when he lost his title to villain Ivan Koloff, the audience was entirely stunned for a moment, and the "dead silence" was followed by cries from women and men in tears (Meltzer, Wrestling Observer Newsletter, March 17, 2003, 6). At that time, a title change was a huge surprise to an unimaginable degree for today's wrestling fans.

In contrast, nowadays most of championship title changes are very ordinary events that are expected in any PPV events. In fact, in 2009 the WWE featured nine changes of the same WWE championship, along with eight changes of the world heavyweight championship, which was created as the equivalent of the WWE championship for SmackDown brand when the WWE divided the roasters into Raw and SmackDown. 2010 saw six WWE title changes and five world heavyweight title changes.
} 
WWE wrestlers, with their heavily stylized movements, restlessly attempt to trigger signalreaction exchanges throughout the match. They exchange big punches, chops, and kicks to draw instant "ooh" and "ahh" reactions from the crowd. Wrestlers frequently make their usual passionate faces or smile at the crowd to draw responses. Each popular wrestler has his/her own special patterned sequences in which audiences' immediate reactions are granted. They need to keep receiving these reactions and maintain the heat of the match, or the match is considered "dead." Successful live and televised WWE wrestling shows need to be filled with empty exchanges between signals and immediate reactions.

WWE wrestling matches feature many pattered and conventional performative sequences in which wrestlers and the crowd are supposed to exchange signals and reactions. For example, if a wrestler who is taking the offensive has his/her opponent's back lean on the corner posts of the ring, climbs up to the second ring rope, and looks down the opponent whose body is stuck between the offensive wrestler and the corner, it is a signal that he/she will execute a series of fists to the opponents' head. The crowd, who know their roles in this conventional sequence, will react by collectively counting one, two, three, as the offensive wrestler repeatedly throws his/her fists down with unnaturally large follow-through motions. "Comeback" and "hot-tag" spots explained earlier are other shared conventional patterns to create signal-reaction exchanges; many in the crowd cheer to support the battered babyface when he/she begins to show signs of life and will to fight back. They sigh when he/she fails and get dominated again, and explode when he/she (or his/her fresh partner) retaliates against the opponent(s) with a fury of explosive moves.

Not only in their wrestling performances, but also in their "promos" (verbal performances), WWE wrestlers present many signals for the crowd to react, as if they were 
pressing switch buttons. Heels routinely speak ill of the local city of the venue to induce almost automatic boos and jeers from the live crowd. In contrast, babyfaces positively mention the name of the cities to receive "pops" (positive and immediate reactions). Many popular wrestlers have established their own catch phrases and gestures that generate big collective and reflex reactions. The Rock, one of the most popular wrestlers in the WWE during the late 1990s and early 2000s, always ended his promo with the famous "If you smell what The Rock is cooking!" line. As soon as he started the phrase, many in the crowd chant it with him. ${ }^{108}$ Then, The Rock, in a slow, and excessively formalized fashion that was reminiscent of Japanese Noh play, would raise one of his "people's eyebrows" to trigger another joyful reaction from the audience. His promo is the epitome of finely stylized performance where audience's big and immediate reactions are guaranteed.

Here, to repeat the same performance, or to engage in the stylization of performance, is the key in making the immediate reaction supposedly guaranteed. A regular repetition of the same stylized move makes the audience familiar with it. The regularity and familiarity of a particular performance develops a fixed expectation for the performance among the audience (e.g., "after he makes this gesture, he is going to execute his finisher," "this move should inflict a devastating damage to the opponent"). A fixed expectation for a particular performance conditions the audience to react in similar fashion whenever wrestlers do the performance, and therefore the expectation is fulfilled. ${ }^{109}$ Now, wrestlers can also calculatedly surprise the

\footnotetext{
${ }^{108}$ He often playfully pauses after "The Rock," making the chanting audience slip and go ahead of him. Then, he waits for a while to receive all of the attention once again, and slowly and ecstatically finishes the phrase, demonstrating a perfect control of the crowd as parrots.

${ }^{109}$ Many of fixed reactions in WWE wrestling have a lot to do with the formalization and re-enchantment of language described by Adorno and Horkheimer. This point will be revisited later when we extensively discuss the concept of total control in WWE wrestling.
} 
audience by betraying the expectation (e.g., wrestler A defends the finisher of wrestler B when audience expects that the wrestler B is winning with the finisher) and draw even bigger reactions. That is, as long as wrestlers have stylized one of their performances (moves, gestures, etc.), audience's reaction to it can be counted regardless of whether they fulfill or betray audience's expectation.

The answer to the question of what makes the culture industry assume that it can precalculate consumers' reaction; by stylizing the presentation of the products (and thus repeating the same presentation), the industry conditions consumers to react in a fixed way, and therefore makes the reaction supposedly pre-calculable. In general terms, we can assume that the more thoroughly the products are stylized, the more detailed calculation becomes possible.

Therefore, the demand to manufacture meticulously calculated products has driven the comprehensive stylization of WWE wrestling products. In particular, the presentation of Raw and SmackDown is minutely planned. For each episode, a team of writers prepares a detailed script and production notes of the entire show; these notes cover all of the segments. ${ }^{110}$ Each segment has a pre-set goal to achieve, and its duration is strictly determined according to a time schedule. Here, the stylization of each performance is a necessary condition for formulating and achieving such a detailed plan. As we have seen, by stylizing their performances, wrestlers are able to condition the audience to react in expected ways. ${ }^{111}$

Theoretically, the history of professional wrestling as theatrical combat began when

\footnotetext{
${ }^{110}$ For a detailed account of the production process of Raw and SmackDown, see the interview of former WWE script writer John Piermarini (John Piermarini, "TORCH TALK with John Piermarini Part 2: Detailed Account of Writing for Vince McMahon, Working under Brian Gewirtz, Why He Left WWE," interview by Wade Keller, Pro Wrestling Torch 1191 [2011], 1, 13-14).

111 Therefore, there are noticeable stylistic difference of performance between WWE "house" (nontelevised) shows and televised show such as Raw and SmackDown. In house shows, where no detailed plans are needed, wrestlers are more relaxed, look less mechanical, and more often performs outside their signature moves.
} 
calculation led to the act of stylization. That is, this form of performing art was born when wrestlers and promoters began to make the results of contests calculable to please and attract crowds without inflicting injury on the participants. ${ }^{112}$ In doing so, wrestlers deformed the movements of legitimate fighting contests into certain styles to make their performance spectacular and easy to understand. In this sense, Raw and SmackDown, minutely calculated wrestling programs that feature highly stylized performances, demonstrate the necessary consequences of the evolution of this popular performing art. Culture industry theory illuminates the mechanism and dynamics that have penetrated the history of the development of professional wrestling.

\section{The Deep Fusion between Advertisement and Contents in WWE Television}

Raw and SmackDown epitomize the fusion between content and advertisement that culture industry theory describes. In these "wrestling" programs, it is uncertain whether wrestling matches are to be called the main contents. Live and taped skits among wrestlers, wrestlers' interviews, or "promos", which are technically advertisements of wrestling matches, are often more prominently featured than wrestling actions. Between the presentation of such skits and wrestling matches, numerous promotional videos of wrestlers and "hype" and "recap" clips of ongoing storylines are inserted. Also, Raw and SmackDown incorporate many advertisements of various WWE merchandise and other sponsor products into program content. In almost all of the episodes, these skits and promotional segments occupy more than a half of the total running time.

\footnotetext{
${ }^{112}$ In the late nineteenth and the early twentieth century, many famous "professional" wrestlers were champions of legitimate wrestling contests. These champions often engaged in fixed fights to deceive the audience to make money (Beekman, Ringside, 13-50).
} 
More importantly, in these programs almost all of the matches are virtually advertisements for future developments; they are presented as parts of ongoing feuds and leave some of the problems unsolved. Therefore, the matches are always openly future-oriented. In fact, "How well did they build for the future?" is one of the predominant criteria for many fans to evaluate the matches in Raw and SmackDown. Even in PPV events, which occur roughly once a month and where some of the narratives developed in Raw and SmackDown are expected to find closure, many of the featured matches function as blatant advertisements for the next Raw or SmackDown. Throughout the year, the WWE keeps going forward by developing multiple narratives via the matches, vignettes and other forms of presentation. In the ceaseless progress of narratives, which also contain numerous repetitions of the same styles of performance and angles, everything becomes a main content and also a preview. In this sense, WWE wrestling products, Raw and SmackDown in particular, faithfully follow the mechanism of calculating rationality in the culture industry; it constantly stimulate the audience and direct their attention for further consumption, while attempting to draw immediate reaction from them.

Raw and SmackDown are the epitomes the total fusion between content and advertisement not only in terms of their fragmented segments, but also in the historical context of the development of wrestling television in the U.S. The fusion was already observable in WWE weekly wrestling programs started in the mid 1980s such as Prime Time Wresting (1985), Superstars of Wrestling (1986), and Wrestling Challenges (1986), in which main contents (wrestling matches) were reduced to advertisements. ${ }^{113}$ At that time, weekly wrestling programs were lesser products that were designed to promote bigger events, such as live shows at major

\footnotetext{
${ }^{113}$ As I mention in chapter 3, the usage of television wrestling matches as advertisements for live shows originated in the $1950 \mathrm{~s}$.
} 
venues or PPV shows. In these programs, wrestling matches were essentially pre-taped advertisements for the showdown on the bigger shows; many of these matches are "squash" matches where stars featured in bigger events easily beat mediocre opponents.

Raw was a revolutionary wrestling program when it was launched in 1993, and advanced a further fusion between contents and advertisements from the opposite direction. This program presented a live, well-constructed wrestling show, featuring important matches between stars. It also featured noteworthy storyline developments, including various spectacular stunts and theatrical acts by wrestlers, which became major attractions of the show. That is, Raw revitalized wrestling matches in weekly programs, which had long been diminished to be advertisements, as the main attraction. At the same time, it upgraded various storyline development segments, originally advertisements for forthcoming wrestling matches, as another main contents.

The success of Raw eventually led to the emergence of its competition Monday Nitro (1995), another Monday night wrestling show produced by World Championship Wrestling (WCW). The competition between the two programs made the production of weekly wrestling programs as prime-time premier shows a standard practice in the business. SmackDown joined Raw in 1999 to become another major weekly programs of the company and helped the WWE to defeat the WCW. Since then, Raw and SmackDown have been the representatives of weekly wrestling television programs in North America. The history of the development of wrestling television programs in North America and the dominance of Raw and SmackDown convincingly demonstrate the validity of Adorno and Horkheimer's observation that main content and advertisements amalgamate in mass culture products. This history is also the process in which wrestling programs have become non-stop, forward moving wheels that nevertheless repeat the same stylized contents. 


\section{Culture Industry Theory Exaggerated}

So far, I have stressed that the performance style and presentation form of WWE wrestling exemplify features of the culture industry described by Adorno and Horkheimer. However, this does not indicate that WWE wrestling is a very typical and ordinary culture industry product. On the contrary, the style and form of WWE wrestling are extraordinary in the sense that they are all of excessive and full of exaggerations. After the years of incessant stylization and innovation, WWE wrestling is still faithful to the definition of professional wrestling given by Roland Barthes in the 1940s: the "spectacle of excess."

Of course, exaggerated presentations are to be found in many other forms of popular entertainment; for example, action movies exaggerate actions and soap operas exaggerate emotions. However, in the WWE virtually everything is embellished. When a wrestler throws his/her usual punches, chops or kicks he/she throws them with extremely large motions, which cause the opponent to overreact in expressing agony. Wrestlers build magnificent bodies, always demonstrate over-the-top gestures, overstate on everything whenever they speak, and attempt to humiliate their opponents in the most spectacular fashion possible both inside and outside the ring. Even the live crowd follows the tradition; their reactions are always very simple, clear and loud. They shake the venue with their big, collective cheers, jeers and chanting of wrestlers' names.

That is, the exaggerated performance style and the presentation form of the WWE embody the features of the culture industry as described by Adorno and Horkheimer in the most blatant fashion. This embodiment suggests that the WWE can be seen a magnifier of culture

\footnotetext{
${ }^{114}$ Barthes, "The World of Wrestling."
} 
industry theory in two contrasting ways. On the one hand, the WWE can be the best representation of the theory, as it vividly and intelligibly exemplifies the logics and mechanisms of the industry formulated by the theory. On the other hand, the WWE can also be a crude caricature of the theory when it demonstrates issues that the theory did not assume. In such cases, the WWE's exaggerated style and form may relentlessly expose the shortcomings the theory. This ambivalence will be highlighted the following discussion regarding the WWE and the state of total control.

\section{Section 3}

\section{The State of Total Control in the Ring}

The Art of Controlling Fans and Its Difficulty

As noted above, Adorno and Horkheimer's description of the state of total control, is highly problematic as it failed to recognize any complication and conflict between producers and consumers of popular culture products. Nevertheless, if one understands the state of total control not as a realistic notion but rather as a model, their explanation becomes very relevant to contemporary WWE wrestling. For the WWE, the state is an ideal that its products should express in the most visible and audible fashion; wrestlers try their best to have the live crowd in the palm of their hands, keep the crowd excited, and continually draw big reactions. If wrestlers succeed in doing that, the show becomes a grand spectacle that epitomizes the perfect harmony between the producers' intension and consumers' reaction.

In WWE wrestling, as indicated by culture industry theory, giving consumers no scope for contemplation is the key for establishing total control over them. Therefore, all of the contents featured by the WWE-over the top gimmicks of wrestlers, various spectacular and 
high-impact moves, large-scale stunts, and shocking "angles"- are to give fans immediate stimulation without demanding their "mental capacity." These stimuli are supposed to draw instant, knee-jerk responses from fans.

However, a random presentation of these stimuli rarely makes fans abandon themselves. That is, wrestlers need to master the art of building wrestling matches to control fans, the art that is closely related with the stylization of performance discussed earlier. In order to understand this point, the insights of former WWE wrestler Sean "X-Pac" Waltman are highly suggestive. He states that top wrestlers need to create a situation where fans can smoothly immerse themselves in a wrestling match and exert the control over fans as if they (wrestlers) were taking them (fans) through a "roller coaster ride." In order to attain such a goal, Waltman agues, wrestlers need to make their performances as articulate and easy-to-follow as possible. WWE main event wrestlers do not have to be able to do "a million different phenomenal moves," as they should not "complicate things." ${ }^{115}$ His view is in accord with the way in which the WWE stylizes wrestlers' moves by making them repeat limited numbers of signature moves. It should also be noted that many of these moves of WWE wrestlers, including all of their finishers, are given original names, which announcers and wrestlers numerously repeat. Following Adorno and Horkheimer's explanation, one can understand the naming practice of familiar moves as a devise to create magical and fetish attraction to them. ${ }^{116}$

Waltman further explains that there is another important skill set for top wrestlers to master. In WWE main event matches, all of the moves and gestures have to "flow forward

${ }^{115}$ Waltman, "When Jericho Came to the WWF."

${ }^{116}$ Likewise, the WWE's practice to trademark its wrestlers' ringnames can be understood as a way to monopolize and control the fetish attraction attached to the names, which can be used for various merchandise. 
smoothly": "When something isn't gone in the right place, subconsciously the fans are taken out of the match." Here, wrestlers have to "be able to know what the people want or how they're going to react to certain things at a certain time." How is a wrestler able to acquire such ability? Waltman leaves us a hint by stating that one of his colleagues in the WWE had a problem mastering it: "When Chris Jericho came to the WWF (WWE), he didn't get it yet. He didn't even realize that he didn't get it, and it was very frustrating them."

Chris Jericho's offers a description of his own trouble. He confesses that, at that time, “One of the biggest problems was that I still hadn't learned how to be a WWE style heel." His difficulty concerned the flow of typical WWE "non-squash" matches mentioned earlier. In such matches, Jericho explains, a heel at first has to demonstrate a "strong beatdown of the babyface" during the early to middle part of the match. Then when the babyface performs his "comeback" sequence later, the heel has to "jump up and down as fast as you could" to successively "sell" the babyface's offense to excite the crowd. However, because of his lack of experience in the WWE, Jericho had not become proficient in performing this pattern. He used to show weaker offence in the earlier half of the match. Then, when the opponent was trying make the comeback, he would only lie on the mat. Consequently, he had hard time in pleasing and exciting the WWE crowd. ${ }^{118}$ Jericho's explanation clarifies one of the keys to master what Waltman considers the essential skill for wrestlers: how to give fans a smooth flow by doing proper moves at proper moments. That is, a wrestler needs to know and internalize patterns of the sequence of moves, with which fans are familiar, such as the one described by Jericho. These patterned sequences have been numerously repeated and therefore been naturalized among fans, who have been

\footnotetext{
${ }^{117}$ Ibid.

${ }^{118}$ Jericho and Fornatale, Undisputed, 18.
} 
conditioned to give automatic reactions to the moves. When wrestlers follow one of these patterns, established familiarity of moves and the naturalness of flow enable fans to "smoothly" immerse themselves into the match, without having stumbling blocks. In this way, wrestlers are able to gives fans easy-to-follow products without offering them an opportunity to stop and think critically about the products.

Therefore, both of Waltman's points - the needs to restrict the variation of moves and to know when to perform certain moves - concern the familiarity created by the stylization of wrestling performance. Extensive and detailed stylization of wrestling performance enables WWE wrestlers to give familiar moves (most of which are spectacular and high-impact) according to familiar patterns of the flow. Stylization of performance is a necessary procedure for WWE wrestlers to establish close control over fans' behavior.

Of course, in WWE wrestling the state of total control cannot be secretly and quietly attained. The state should be clearly demonstrated in the form of loud, excited, and collective reaction form the live crowd. When wrestlers perform a superb match complemented by a compelling story, the majority of the crowd is willing to play the role of the controlled consumers, as if they were confirming the validity of culture industry theory. They instantly and loudly react to every moves, cheer and support babyfaces, and jeer and boo heel wrestlers as they are supposed to do. While giving deafening reactions, the fans voluntarily immerse themselves in the uniformity or "sameness." 119 The language the crowd uses attests further relevance of culture industry theory to WWE wrestling. In expressing their appreciation to and enthusiasm for a

\footnotetext{
${ }^{119}$ Precisely speaking, to create the grand spectacle of total control, matches do not always have to be between a babyface and a heel. Even when live crowds are divided into supporting two different wrestlers, as far as they keep on giving enthusiastic reactions to performance in the ring, they are equally in the palm of the hands of the wrestlers. In such a case, as culture industry theory indicates, all of the fans are considered to be the same "good" consumers even when they support different products. In fact, in a large-scale shows, WWE often features a match between two popular babyfaces, expecting some fans cheers one and others cheers another.
} 
particular wrestler, they chant the names of the wrestlers. This simplest and the most formulaic expression — repetition of a word — epitomizes the magical, enchanting power attached to the names of culture industry products. When thunderous reactions from the crowd follow the route mapped out by culture industry theory, WWE wrestling is able to attain the state of total control and put together an ideal, "hot" wrestling show.

WWE television programs try their best to transmit the excitement of the live crowd in the venue. In doing so, the WWE constantly makes the point that the company and the crowd have established the state of total control (or perfect harmony) all together. Therefore, the WWE injected canned audience reaction when the company taped Raw in Japan, where audiences were significantly more silent than in North America. ${ }^{120}$ The WWE frequently does the same practice for SmackDown, which basically features pre-taped shows. In WWE television, commentators always yell and scream to wrestlers' moves and other performances, giving the impression that the products are compelling enough to excite the crowd.

Unlike live shows, WWE television programs do not need viewers' vocal and loud reactions. Nevertheless, these programs make further efforts in discouraging viewers from deliberating over the products through various televisual tools and technologies. During the matches, commentators, who are either on a neutral side or biased side constantly tell viewers how to interpret the events and who they, the viewers, are supposed to cheer or jeer. Neutral commentators praise wrestlers honest efforts and criticize despicable acts, while biased commentators are doing the opposite to provoke viewers. And they do it with excessive enthusiasm. Unlike regular sports television, the goal of the WWE commentators is not to help viewers understand the technical subtlety of the competition. They focus on further clarifying the

\footnotetext{
${ }^{120}$ Jericho and Fornatale, Undisputed, 299.
} 
meanings of performance, which have already been made too clear, and magnifying the effects of performances, which have already been exaggerated.

Also, as noted, Raw and SmackDown contain numerous "hype" and "recap" clips inserted between matches and skits. Throughout the episode, significant events are frequently replayed, summarized, and recapitulated by these clips, so that even viewers with short memory can keep up with the storyline. These clips are decorated with glittering visual effects, flashing computergenerated images, and a heavy metal music and high impact sounds. The aesthetic style of these clips is resonant with the WWE's high-impact wrestling actions and sensational angles, and incessantly gives viewers instant stimulation.

WWE live shows and WWE television programs, in different ways, aim to express the state of total control in the form of spectacle. Ideally, both the live crowd and television viewers are deprived of their own thoughts by the dazzling and skillfully presented products. The live crowd gives huge reaction whenever they are supposed to react, and the television viewers are mesmerized by the spectacular sight of the unity between wrestlers and the crowd. In the most successful cases, WWE wrestling exemplifies the way in which the culture industry exerts total control over consumers.

However, things do not always go so well. As a below case study will highlight, fans are not always uniform admirers of the products. As much as they aspire to be in the palm of the wrestlers' hands, and be immersed in the enthusiastic sameness, fans may only give silence and indifference when storylines or gimmicks do not click or the performance in the ring is uncompelling. They often even appropriate the form of collective chant to express their boredom (“Boring!"), mock wrestlers ("You Fucked Up!"), give protest (“We Want XX [the name of an absent wrestler]" or "XX [the name of the featured babyface] Sucks!"), and show critical 
distance towards the products (“Same Old Shit!” or "You Can't Wrestle!”). ${ }^{121}$ The outbreak of such disobedient chants from the crowd demonstrates the WWE's failure to exert total control as defined by Adorno and Horkheimer over fans. Here, fans see through the artifice of the WWE, refuse to obey its dictations, laugh at its products, and criticize the products' quality and predictability. In doing so, fans express displeasure or create a twisted pleasure of their own. These chants, in the most audible fashion, indicate a fault in culture industry theory. Fans do not always forsake their "mental capacity" or critical attitude towards the products, even when the forms of presentation in WWE wrestling constantly seduce them to do so. ${ }^{122}$ Although they love to abandon themselves and be in the palm of the wrestlers' hands, they choose not to do so, and in doing so, to think for themselves.

Contemporary WWE wrestling provides an interesting case for researchers to renew, update, and complicate the notion of total control over consumers that is advocated in culture industry theory. Both the company and fans aspire to create and experience the state in the most spectacular, enthusiastic fashion. However, today's fans have also learned a variety of ways not to be cooperative with the company, and often find pleasure in being insubordinate. What kind of countermeasures does the WWE employ to regain the state of total control when fans behave disobediently (despite their own aspiration to experience the state)? How effective are such counteractions against the fans who have already developed critical awareness to the WWE's

\footnotetext{
${ }^{121}$ In the late 1990s, as the North American wrestling industry experienced a huge boom and the fans gained more access to various forms of inside information about wrestling, the outbreak of these disobedient chants became more frequent.

${ }^{122}$ Here, Walter Benjamin, Adorno and Horkheimer's fellow critic at the Frankfurt School, gives a more convincing idea regarding the effects of popular entertainment. Benjamin is in agreement with Adorno and Horkheimer in stating that popular entertainment forms such as films demand viewers to adopt a new "distracted" mode of reception. However, unlike Adorno and Horkheimer, Benjamin argues that this new relaxed form of reception gives viewers scope for contemplation and consciousness raising and therefore has liberating effects (Walter Benjamin, "The Work of Art in the Age of Mechanical Reproduction," in Illuminations: Essays and Reflections, ed. Hannah Ardent, trans. Harry Zohn [New York: Schocken Books, 1969], 239-240).
} 
artifice? In such cases, what kind of complex interplay between consumers and producers can be observed? An episode of Raw in November 2010 featuring John Cena, arguably the most popular professional wrestler today, provides an intriguing case to consider these questions. This case helps us to shed a new light on the producer-consumer relationship and the concept of total control in contemporary popular culture.

\section{Case Study: John Cena's "Seemingly Nonfictional" Farewell}

In the 22 November 2010 episode of Raw, Cena gave a "farewell address" to the crowd and the millions of television viewers watching the live broadcast. He was "fired" from the WWE at the Survivor Series Pay-Per-View (PPV) event held on the previous night, where he appeared as the special referee of the WWE title match between the favored champion Randy Orton and the cunning villain Wade Barrett. According to the storyline, Cena had to carry out any command from Barrett in order to keep his job in the company. However, in the climax of the big PPV show, Cena refused to obey Barrett's order to connive with him and make him a WWE champion; when Orton pinned Barrett's shoulders to the mat, Cena justly counted three and declared Orton's victory, knowing that it would cost him his job.

At Raw on the next day, Cena delivered in a unique way what was advertised as his final speech. He did not make it an obvious stage act, by cursing Barrett whose shabby order forced him to give up his career, as WWE wrestlers always do. Instead, Cena, showing a genuine appreciation in his face, presented himself as if it were a non-storyline sincere final message. When Cena, in a tearful voice, announced that he was finally able to attend his mother's birthday for the first time in ten years, the live crowd began to chant his name. Then he made a final request to them. He asked them to give him the "dueling chant" that he had been receiving for years: "If I'm walking out here, one more time, I just wanna hear... I want every woman and 
every child to say 'Let's go Cena!' And I want every guy over the age of 18 to say 'Cena sucks!' Is that alright?"

Cena's dueling chant originated in mid-2005 and was a product of disobedient reactions from fans. At that time, a large portion of fans began to express their resentment against the WWE's portrayal of Cena's character as a heroic "street tough." In matches that involved Cena, jeers against him as well as cheers for his villainous opponents became increasingly audible. This also triggered reactions from Cena fans, or those who were more willing to accept the WWE's direction regarding whom they should cheer for. Eventually, during Cena's matches, the live crowd started a dueling chant. Whenever Cena fans started chanting "Let's go Cena!," dissenters would counter by chanting back "Cena sucks!” This unplanned development—originating from unexpected dissent - made Cena a unique wrestler in that he would generate both loyalty and disdain among the live crowd by merely appearing in the ring, regardless of who his opponent was.

However, there was no unexpected dissent or tension in the same dueling chant at his farewell ceremony in November 2010. The crowd was more than willing to grant his request. Under Cena's baton, they loudly alternated "Let's go Cena!" and "Cena sucks!" while he was listening with an emotional smile. Here, Cena turned the "Cena sucks!" chant from dissent into the ultimate praise from fans. ${ }^{123}$ About an hour after this touching moment, however, Cena returned to the WWE ring to attack Barrett. He then kept coming back in the following weeks until he was finally "rehired" in the next month, making the "farewell" utter (but usual) nonsense. In fact, the "John Cena firing angle (storyline)" was ranked 4th in the "Most

\footnotetext{
${ }^{123}$ Dave Meltzer of Wrestling Observer Newsletter calls Cena's request for the dueling chant "a brilliant move" because "(i)n a sense, he made, because he likes the chant, "Cena sucks" from being a protest chant to being a babyface trademark chant” (Dave Meltzer, Wrestling Observer Newsletter, Nov. 29, 2010, 17).
} 
Disgusting Promotional Tactics" category of 2010 Wrestling Observer Newsletter Awards, contributing to the ongoing slow decline of the popularity of WWE wrestling. ${ }^{124}$ Nevertheless, the farewell address itself made an impressive scene in which fans, who were usually divided into anti-Cena and pro-Cena, became united to pay respect to him.

Cena's farewell ceremony demonstrates how the WWE attempts to regain the state of total control — a perfect harmony between producers' intentions and consumers' reactionswhile realizing the difficulty of maintaining such a state. The ceremony commenced in front of many anti-Cena fans, who, unlike the fully obedient consumers of the culture industry described by Adorno and Horkheimer, would love to express their refusal to accept the producers' intention; at their choosing, they would start "Cena-sucks!" chant to resist the WWE's attempt to present Cena as its most favored hero. ${ }^{125}$ However, at the ceremony, the WWE came up with a clever artifice to tame anti-Cena fans and make them react in the way it wanted them to. Since the late 1990s, the WWE had occasionally adopted a "nonfictional" mode of address to make serious announcements, suspending its usual fictional narratives. As chapter 2 of this dissertation extensively argues, this new mode of address had become important outlet for the WWE to

\footnotetext{
${ }^{124}$ Dave Meltzer, Wrestling Observer Newsletter, Jan. 31, 2011, 9.

${ }^{125}$ It is possible (in fact, correct) to argue that these anti-Cena fans were already under the WWE's control; after the breakout of the dueling chant to Cena in 2005, the WWE intentionally made Cena's heroic character stronger to provoke anti-Cena fans into chanting even lauder. By allowing anti-Cena fans to loudly voice their dissent, the company successfully made Cena a "controversial superstar" whose appearance would automatically cause excitement and tensions among the crowd. From this perspective, "Cena sucks!" chant is another form of audience responses that are already prescribed by the WWE. However, from another perspective, the WWE's flexible action is also a proof that the contemporary WWE cannot exert an omnipotent power over consumers as the culture industry theory indicates. Being confronted with unexpected dissent from fans, the WWE was forced to transform Cena from everyone's favorite (which the company originally wanted) to a controversial figure. Although both perspectives are valid, the latter more accurately reflects the fact that the popularity of the WWE has been slowly but consistently declining. Therefore, in the present analysis of Cena's farewell, I adopt the latter perspective and regard "Cena-sucks" chant as a form of dissent rather than a form of submission to the dictation from the WWE. In doing so, I intend to highlight the difference that the WWE created between the usual dueling chant and that in
} this ceremony. 
present a new form of realism that complemented the realism of its utterly fictional narratives.

Whenever the WWE used this serious mode of address, fans would stop seeing wrestlers as heroic or villainous characters, and would instead treat them respectfully as human beings. At Cena's farewell, the WWE smartly manipulated this established convention; the company made Cena use a seemingly nonfictional mode of address and speak to the crowd as if it were a nostoryline, real retirement speech, and he delivered it excellently. As a result, the WWE succeeded in making the crowd do what it wished them to do: loudly chant the name of company's premier product, Cena. In that moment, the WWE, in the most visible and audible form, regained the total control of consumers as defined by culture industry theory.

In fact, this particular farewell ceremony beautifully traced the artifice of the culture industry that the theory draws. Two points can be made. First, Cena's address to the crowd and their response to it replicated what Adorno and Horkheimer call the "schematism" of production in the culture industry, which classifies consumers yet ultimately renders them into sameness. Cena requested the dueling chant assuming that everyone was going to behave according to a simple binary classification he applied to the audience; "every woman and child" would cheer, and "every guy over the age of 18 " would jeer his name. ${ }^{126}$ The majority of the audience was willing to fall into the binary. However, this binary essentially constituted a unified force to celebrate and pay respect to Cena and his career. As the chant echoed throughout the house, the opposition between the two voices "Let's go Cena!” and "Cena sucks!" dissolved and fell into the "prescribed sameness" that praised the premier product of the WWE.

\footnotetext{
${ }^{126}$ In fact, since the breakout of the dueling chant, it has often been unofficially speculated by media and fans that many females and children chant the "Let's go Cena!" part, while the "Cena sucks!" mainly consists of male adults. However, the binary classification of the dueling chants is officially acknowledged in the WWE ring for the first time in Cena's farewell.
} 
Second, the dueling chant in Cena's farewell epitomized the occult power of the emptied language explained by Adorno and Horkheimer. The chant had completely lost its original meaning - the conflict between pro- and anti-Cena fans - and became merely a formulaic repetition of the phrase that has been chanted for more than five years. However, this empty repetition possessed the magical power; the resounding chant became a proof that all of the fans were enchanted by "Cena," the name of the WWE's premier product. By repeating empty phrases that had been stripped of their original meaning, fans behaved exactly as culture industry theory dictates. Cena's ceremony was one of the contemporary examples into which Adorno and Horkheimer's total control thesis gave penetrating insights.

However, Cena's ceremony had complexity that culture industry theory did not expect. Three points are to be made. First, the very presence of anti-Cena fans suggested that the WWE's usual fictional narrative could not demonstrate the complete dominance over the consumers anymore. Their "Cena sucks!" chant was a form of protest against the way in which the WWE attempted to dictate their reactions. In order to create a perfect harmony between producers' intensions and consumers' reactions, the WWE needed to rely on Cena's seemingly "nonfictional" speech, since its usual fictional narrative could not create such a harmony. Second, Cena's "retirement," which served to unify both pro- and anti-Cena fans, only lasted about an hour. As mentioned, the WWE disposed of the nonfictional narrative of Cena's retirement in the same night by making Cena return to the ring and rejoin the fictional storyline. Consequently, the anti-Cena crowd resumed their "Cena sucks!" chant to express their dissatisfaction with the product, and the ongoing slow decline of the popularity of the WWE continued. The WWE could not make any substantial efforts to permanently maintain the state of total control that Cena's seemingly nonfictional speech created. After all, narratives of WWE 
wrestling needed to be based primarily on the logic of utter fiction, as opposed to that of nonfiction even though the former could not entirely dictate and control fans' reactions.

The third point suggests a complicated state of mind of fans, who are neither entirely “dupes" nor fully "rebels." Even during Cena's ceremony, it appears that many fans were not entirely tricked by his seemingly nonfictional speech; discourses of fans and wrestling writers suggest that many of the fans - regardless of whether they usually cheer or jeer Cena-were aware that his retirement, as well as his nonfictional mode of address, were only make-believe. For example, in reviewing the Survivor Series PPV where Cena was fired at the end, Dave Meltzer of Wrestling Observer Newsletter states, "even though the crowd liked him, you could tell nobody was buying it."127 The following comment from a fan reviewing Cena's ceremony on Raw next night corresponds with Meltzer's observation: “Concerning Cena, he gave a good promo for this going away, but it's too bad everyone knew he wasn't going anywhere."128 That is, quite a few fans found it difficult to take the WWE's promise about Cena's retirement seriously; they have seen enough that the WWE has repeatedly made similar kind of match

\footnotetext{
${ }^{127}$ Dave Meltzer, Wrestling Observer Newsletter, Nov. 29, 2010, 17. Bruce Mitchell of Pro Wrestling Torch agrees with Meltzer. In reviewing the same PPV, he writes: "I don't know if fans know how to react at the end, since everyone knows at the end of the day John Cena isn't going anywhere" (Bruce Mitchell, "PPV Roundtable." Pro Wrestling Torch 1179 (2010), 14). Also, a comment from a reader of the Torch reviewing the same show indicates that he/she was also sure that Cena was not retiring but battling against Barrette: "The fact that Cena didn't get his hand s of Barrette telegraphs the next stage in the saga, of course" "'Survivor Series PPV Reax \#1: 'I Enjoyed the Three-hour Old School Raw More than Tonight's PPV,'” PWTORCH VIP Website [Membership Website], 2010, http://www.pwtorch.com/members/artman/publish/Torch_Feedback_14/article_47470.shtml [accessed April 1, 2012]).

128 "WWE Raw Reax \#1: The Miz Cashing in MITB, John Cena's Acting, TLC Look-ahead, Creative Hitting their Stride?," PWTORCH VIP Website [Membership Website], 2010, http://www.pwtorch.com/members/artman/publish/Torch_Feedback_14/article_47500.shtml (accessed April 1, 2012). Another fan suggested that Cena's powerful speech nearly affected his belief that Cena was not retiring; "John Cena gave a promo that had me almost convinced he was gone for a bit" ("WWE Raw Reax \#2: Strong Opinions for \& against Miz Becoming New WWE Champion, Review of King of the Ring Qualifying Matches," PWTORCH VIP Website [Membership Website], 2010, http://www.pwtorch.com/members/artman/publish/Torch_Feedback_14/article_47504.shtml [accessed April 1, 2012]).
} 
stipulations (i.e., "loser leaves the company") for the sake of suspense and later disregarded them. ${ }^{129}$ Nevertheless, in Cena's farewell ceremony, many in the crowd dared to grant Cena's request and celebrated him as if they had believed his retirement. The ceremony even turned anti-Cena fans, who usually refused to follow the company's direction regarding who fans should cheer, into his supporters.

The contradictory actions of "Cena sucks!" chanters demand researchers to complicate significant theories of culture as well as culture industry theory. Their actions, while representing elements of several different theories, add a twist of their own. On the one hand, their usual "Cena sucks!" chant exemplified an activated, resisting or "poaching" audience identified by the work in popular cultural studies. ${ }^{130}$ These anti-Cena fans recognized the producers' expectation to them, betrayed it, and came up with their own way of consuming the product. On the other hand, the same disobedient fans dared to participate in the ceremony to praise the company's poster boy that they usually hate, while being well aware of the WWE's deceptive intensions. The mentality of "Cena sucks!" chanters (and any fans who participated in the dueling chant while realizing that Cena was not really retiring) in the ceremony apparently leans towards cynicism described by Žižek. ${ }^{131}$ There are gaps in their knowledge and actions; they recognized the WWE's insincerity, and knew that Cena would never retire. Nevertheless they acted as if they had known nothing; they chose to be united together to celebrate the WWE's premier

\footnotetext{
${ }^{129}$ Meltzer criticizes the WWE for presenting Cena's retirement storyline that fans did not believe, "how could you expect anything different given what has happened for years and years. This was a lesson that dates back to the $60 \mathrm{~s}$ and $70 \mathrm{~s}$ in company after company that when you screw your fan base based on paying off stips, eventually, you screw yourself in the long run" (Dave Meltzer, Wrestling Observer Newsletter, Dec. 6, 2010, 13). Not only the WWE, but also other wrestling companies have historically repeated the same form of "screwing."

${ }^{130}$ Fiske, Television Culture; Jenkins, “Textual Poaching.”

${ }^{131}$ Žižek, The Sublime Object, 28-33.
} 
product. It was cynical subjects' action—not their knowledge - that supported the WWE's control.

However, there is a significant difference between the situation described by Žižek and that in Cena's ceremony. In the former, the ruling culture maintains its total control over the masses, who, in spite of everything, continue to behave as the ruling culture expect them to behave. In contrast, in the latter, the state of total control lasted only for a moment and gave out, as the company reinstated Cena's fictional character as a heroic babyface who would provoke opposition from fans. In this sense, Cena's ceremony demonstrated a twisted, negative form of cynicism; the WWE and fans joined forces in creating the state of total control, while realizing that the state will only last for a moment. As explained, quite a few fans expected that Cena would be eventually reinstated, and the current dull state of the company would continue. That is, they knew that the seemingly nonfictional narrative of his retirement would be broken, and usual fictional narrative of the WWE, where quite a few fans loved to betray the company's expectation to them, would revive. Nevertheless, in the ceremony the fans dared to act as if they hadn't known the transience of the state of total control. They obeyed the company's expectation and celebrated Cena, just to momentarily experience the intense sense of total unity. The same "negative" cynicism possessed the WWE as well. It called the fans to be united by setting up the seemingly nonfictional mode of address, while planning to break it in an hour later.

In contemporary WWE wrestling, the state of total control often exists in contradiction where the fictional and the nonfictional intersect. It has become increasingly difficult for its usual fictional mode of address to be compelling enough to attain the state. Fans, who know too well about the artifice of fiction, cannot be entirely obedient to its order even though they aspire to be so. Here, the state of total control is the object of intense desire but also of resistance. When 
the WWE introduces nonfictional mode of address, the fans allow themselves to be entirely controlled by the WWE and to experience the sheer sense of unity. However, the unity does not last as long as professional wrestling is inherently a fictional spectacle. This time, the state of total control emerges as transient utopia. Fans aspire to experience and live in it, even though they know that the experience lasts only for a moment. Through Cena's farewell ceremony, WWE wrestling suggests the demise of the existent order, or the order of the fictional world, that regulates and maintains the much-desired unity between the producers and consumers, and the difficulty of the creation of the new order, or the order of the nonfictional. ${ }^{132}$ The ceremony also testifies that there are cynical yet hard efforts to join the new order and experience the sense of unity, no matter how transient the order is. WWE wrestling demonstrates a difficult and fleeting

\footnotetext{
${ }^{132}$ The huge success of the WWE Money in the Bank PPV in July 2011, which featured the main event between C.M. Punk and John Cena is another example where seemingly nonfictional narrative is temporarily but urgently wanted by fans to cover the declining attraction of fictional narratives. In the storyline leading to that PPV, Punk, while performing an outsider who challenged the authority of the WWE, masterly incorporated nonfictional elements in his verbal performance. Three week before the PPV, Punk predicted he would do the unprecedented by beating WWE champion Cena and walk away from the WWE with the title, as his contract with the WWE would expire in that day. At that time, it was reported by various media (including mainstream ones and insider newsletters) that his contract was really expiring and that many in the company assumed that he was leaving the company. In the following week, Punk's verbal performance went outside the normal range of WWE storyline; he criticized Cena that Cena was good at kissing Vince McMahon's ass and that was why Cena was the champion, despite the fact that in the WWE storyline, Cena was a virtuous babyface who despised the words and deeds of McMahon, an egotistical owner. Here, Punk alluded a nonfictional truth (that Cena was just a faithful employee of McMahon), breaking the fictional image of Cena as an anti-establishment hero. Punk continued his transgressive performance by bringing the fact of the company that had not been used in the WWE storyline: the fact that McMahon's daughter Stephanie and her real-life husband and WWE wrestler HHH were going to take over the WWE in the future. Punk stated that the WWE would become worse after McMahon died, since his daughter Stephanie and HHH were even more impotent. His microphone was cut off as Punk attempted to reveal more untold truth about McMahon. The staged "sudden" invasion of the nonfictional into the usual fictional storyline aroused fans' interest, and the title match between Cena and Punk became a huge success. During the match, the wildly excited crowd kept on reacting to every single move of the two wrestlers. That is, the (staged) nonfictional narrative helped the WWE to create the much-coveted state of total control, which the fans rarely experience inside the usual fictional narrative. The power of the nonfictional culminated when Punk won the match and walked away the WWE as champion. The invasion of the nonfictional only lasted a week though; a week later, Punk came back to the WWE and to be reincorporated into the world of fiction. Like Cena's farewell extensively discussed in this chapter, the excitement and the state of total control attained by the nonfictional can only be short-lived in the WWE. After all, WWE wrestling is essentially a fictional product.
} 
status of the concept of total control in the age where people see through the deceptive artifice of culture industries, while guaranteeing the concept's relevance.

\section{Section 4}

\section{WWE Wrestling as a Failure of Enlightenment Rationality}

I demonstrated earlier that culture industry theory was extremely helpful in understanding the logics and dynamics that underlay the stylization of performance in WWE wrestling. However, the stylization in the WWE involves a significant issue that is not addressed by the theory. That is, the essential attraction of the WWE lies in the fact that it stylizes and commercializes live human bodies; fans appreciate wresters' larger-than life characters and performance because they (fans) know that they (wrestlers) are humans who are willing to put their bodies on the line "for real." This point escapes the scope of culture industry theory, which does not give specific attention to the distinction between human and non-human cultural

products. Paradoxically, this point — the fact that wrestling needs to stylize and commodify live human bodies - makes WWE wrestling a distinct representation of the thesis of Dialectic of Enlightenment.

In contemporary professional wrestling, the indispensability of real, live, and mortal human bodies has caused severe problems. In WWE wrestling, accidental injuries of featured wrestlers happen on an almost-monthly basis. More critically, mortality rate of contemporary professional wrestlers is extremely high. The double murder and suicide committed by thenactive WWE wrestler Chris Benoit, who had consistently performed an extremely high-impact, 
physically-intense style of wrestling, in 2007 brought the seriousness of the issue to light. ${ }^{133}$ In reporting this incident, Dave Meltzer stated that, from 1997 to 2007, among the wrestlers who had working experience in major organizations, a total of 65 wrestlers died before turning 50. According to Meltzer, this number equals to 435 of NFL experienced players or 186 major league baseball players passing away under 50 in ten years. Of those 65 wrestlers, 37 (including Benoit) were known to be regular steroid users and 37 were known to have serious issues with either painkillers or recreational drugs. Although the direct causes of these deaths vary, overintakes of substances have heavily affected many of the deceased wrestlers. ${ }^{134}$

Obviously, one of the direct causes for this horrendous phenomenon has been the constant, extensive and extreme stylization and commercialization of wrestlers' bodies in contemporary wrestling. As explained, in order to make themselves marketable, wrestlers are required to stylize their bodily appearance much more severely than before; they are supposed to wear a large amount of muscle with less body fat to look like "wrestlers." Likewise, contemporary WWE wrestlers are also obliged to perform contemporary "WWE style" matches that primarily consist of high impact moves, which are inevitably damaging to their bodies. Also, most popular wrestlers need to perform in several shows a week. In his autobiography, former WWE champion Bret Hart testifies that in the late 1980s, a combination of the three requirements listed above — sternly stylizing one's bodily appearance, performing an intense style of matches, and meeting a severe schedule_-wore out wrestlers' bodies and minds and led

${ }^{133}$ During June 22nd to 24th 2007, Benoit, who was actively performing as one of top WWE superstars, killed his wife and son, and hanged himself. The incident draws a huge attention from mainstream media, and led news reporters, commentators, and critics to investigate. It was revealed that Benoit had been regularly taking, in fact, abusing, a large amounts of steroid for the testosterone replacement therapy, and that he has sustained a severe brain damage. However, the direct cause of the incident is still unknown.

${ }^{134}$ Dave Meltzer, Wrestling Observer Newsletter, July 19, 2007. 5. 
them to abuse drugs and illegal substances such as steroids:

The schedule had became merciless... My life was a whirlwind of airports, second-rate hotels, gyms and dressing rooms... Every morning I'd feel all those head-snapping turnbuckles I'd now become famous for, and my knees were permanently stiff from jumping off the middle rope... Tom (Billington, known as Dynamite Kid) and so many others tossed a couple of Percocets (a narcotic pain reliever) into their mouths before every match, and all too frequently I'd begun to do the same. I hurt... Some of the WWF wrestlers now looked so freakish from steroids it appeared they might explode. ${ }^{135}$

Hart later became a multiple time world champion, and one of the highest-paid wrestlers in the world. However, in 1999, he suffered a severe concussion after being kicked hard in the head in the ring, and was eventually force to retire. The brain damage has given him great torments in his after-wrestling life. Two years before Hart's injury, Tom Billington, who is mentioned in the quote above, was forced to spend the rest of his life on a wheelchair due to the years of performing extremely intense style of wrestling and abusing all kinds of drugs and steroids. Nowadays, situations have been much improved from that worst period; the road schedule is not as severe as before and the WWE has implemented its "wellness policy"-including mandatory drug tests - to its wrestlers. Nevertheless, the continual news of injury and mortality of wrestlers and former wrestlers keep revealing how deadly this entertainment spectacle became.

The frequent collapse of wrestlers' bodies and minds does not fit to the portrayal of the culture industry described by Adorno and Horkheimer: the culture industry that always ends up acquiring calculated results and profits. In wrestling, sudden injuries and deaths of wrestlers inevitably undermine the value of products, since the business always relies heavily on the charisma of individual talents, to whom fans are "magically" attracted. In extreme cases, the outbreak of steroid scandal among WWE wrestlers in the early 1990s and the Benoit incident in

\footnotetext{
${ }^{135}$ Bret Hart, Hitman: My Real Life in the Cartoon World of Wrestling (New York: Grand Central Publishing, 2007), 216-217.
} 
2007 jeopardized the company, forcing the entire wrestling industry to be under the federal investigation and at the receiving end of criticisms and attacks. As noted, Adorno and Horkheimer argue that entertainment products made by the culture industry reproduce and sustain labor in capitalist system. However, the opposite happens in the contemporary entertainment called professional wrestling; the intensification of entertainment contents often causes sudden breakdown of wrestlers, who are labors and commodities all at the same time. While advancing the extreme stylization and commodification of live human bodies, wrestling organizations such as the WWE have failed to calculate the breaking points of these bodies as well as the minds that manage them. The numerous wrestling tragedies question the all-powerful image of the culture industry.

However, in this very regard, the WWE, as well as the entire North American professional wrestling industry, embodies a larger scheme of Dialectic of Enlightenment, the schema that Enlightenment rationality has turned into irrational violence towards human beings. A thoroughly and intensely stylized nature of WWE wrestling is a result of advanced rationality that treats wrestlers' bodies according to the "standard of calculability and utility." As explained, the refinement of the art of the calculation of effects has called for the further stylization of wrestlers' performance. However, this "rational" demand to stylize wrestlers' bodies has turned into sheer irrationality and has led them abuse various substances, as the thesis of Dialectic of Enlightenment suggests.

Adorno and Horkheimer do not regard the violence toward humanity merely as a result of the oppression by the ruling class. For the authors, the biggest mystery is that many people in fact support the conditions that abuse them. They call this enigma the "mysterious willingness of 
the technologically educated masses to fall under the spell of any despotism."136 A similar enigma revolves around the WWE and other wrestling organizations. Although there is unbalance of power between companies and wrestlers that limits the latter's choice, there also are factors that make wrestlers willing to continue this dangerous profession while abusing substance. Hart remembers that the excitement and cheers from fans greatly encouraged wrestlers to keep going. ${ }^{137}$ Billington states that, even while abusing his body and mind, he enjoyed his life working for the WWE because of the decent salary and the camaraderie with fellow wrestlers: "I was in good company, because the majority of wrestlers all shared more or less the same lifestyle. And I enjoyed that life style. I can't lie about that. I did. Once you got used to it and you were making good money.",138

These reflections from wrestlers indicate that companies, wrestlers, and fans all have chosen to be involved in the escalation of dangerous performance in contemporary wrestling. Companies pay "good money" to wrestlers, and fans have given them enthusiastic supports so that they, wrestlers, keep abusing their bodies until they crumble. Wrestlers themselves have formed a culture of camaraderie to encourage each other in the path towards self-destruction. Companies, wrestlers, and fans all have demonstrated the "mysterious willingness" to "fall under the spell" of this entertainment spectacle of the clash of human bodies without being seriously reflective of the risk involved. As one of the deadliest entertainment spectacle, contemporary wrestling business, which the WWE dominates, attests to Adorno and Horkheimer's bleak assessment of enlightenment in a different way than many other entertainment products,

${ }^{136}$ Horkheimer and Adorno, Dialectic of Enlightenment, xvi.

${ }^{137}$ Hart, Hitman, 217.

${ }^{138}$ Tom Billington, Pure Dynamite: The Price You Pay for Wrestling Stardom (Ontario: Winding Stair Press, 2001), 121. 
including all of those examined by the authors. In other words, even before professional wrestling became a nationwide phenomenon, Dialectic of Entertainment already prescribed the tragic path that this entertainment spectacle would take.

There is a further twist to the dialectic of enlightenment in the WWE. Now, the WWE prominently features the irrational, "mysterious willingness" for the self-destruction in its fictional world. In important events, WWE wrestlers frequently perform long, grueling, over-thetop matches to express their unexplainable urge to keep fighting beyond the margin of safety. If performed masterly, these exhausting matches receive enthusiastic praise from fans. Of course, such matches are meticulously pre-planned by scriptwriters and wrestlers, and are carefully embedded in highly calculated program structures and storylines. Here, again, Adorno and Horkheimer's formulation takes on a new relevance at the place where the nonfictional and the fictional intersect in contemporary WWE wrestling. At the level of nonfictional reality, calculating rationality turns into irrational force that pushes wrestlers keep going forward on the path to real self-destruction. However, at the level of fiction, the same irrational force is reincorporated into a highly rational/calculating practice to make profit. Chapter 3 of this dissertation extensively considers the irrational force expressed in the exhausting performance of WWE wrestlers. Dialectic of Enlightenment haunts WWE wrestling as both fictional entertainment and real-life business.

In this chapter, I have examined features of contemporary WWE wrestling with close reference to Adorno and Horkheimer's theoretical formulations, in particular culture industry theory. As a result, I have demonstrated that their theories take on new relevance when fictional and nonfictional elements of WWE wrestling cross over each other. The WWE and the fans embrace nonfictional narratives in place of the usual fictional narratives in order to revive and 
experience the state of total control even for a moment. The irrational force of self-destruction triggered by Enlightenment rationality, may greatly damage the WWE at the level of nonfictional reality. However, at the level of fiction, WWE wrestling turns the irrational force into its greatest commodity, re-incorporating it into the system of advanced and minute calculation of effects. These arguments suggest that, in order to further understand the unique attraction, pleasure, and problems of contemporary WWE wrestling, one needs to examine the complex interplay between the fictional and the nonfictional it demonstrates. This is the direction that the next chapter is set to take as it explores various forms of realism in WWE wrestling. 


\section{Chapter 2}

\section{Issues of Realism in Contemporary WWE Wrestling: The Promotion and Circulation of Nonfictional Narratives in the Late 1990s}

\section{Introduction}

Realism has always been central to the discussion of professional wrestling. In the past, when insiders (promoters, matchmakers, and wrestlers) were supposed to "protect the business" by behaving in public as if wrestling matches were serious contests, "real or fake" arguments were ubiquitous. Those who disliked wrestling frequently pointed out that wrestling matches were not "real" contests, and wondered why so many grown-ups were easily duped by such an obvious fraud. Some wrestling fans were willing to believe in the legitimacy of contests at least to some degree, while other fans were entirely convinced that wrestling was a scripted performance and loved it as it was.

Nowadays, the simple "real or fake" argument seems to be entirely gone, as wrestling organizations openly acknowledge the scripted nature of their products. Nevertheless, the more complex concerns around the idea of realism still are focal points in many discussions of professional wrestling. Non-fans keep on using the word "fake" to describe wrestling and continue to ask the similar question: why does such fakery fascinate so many people (who even acknowledge the fakeness)? Fans, who are now fully aware of wrestling's scripted nature and constructedness, are nonetheless very sensitive to the moment in which its realism is broken; they are quick to express their disappointment whenever wrestling's constructedness is too overtly exposed by poorly performed moves or excessively nonsensical plots written by storywriters. Also, as Sharon Mazer observes, "Hard-core fans are explicitly obsessed with 
reading live and televised wrestling performance for the signs of the real and the fake."139

In fact, one of the unique features of contemporary WWE wrestling lies in its new structure of realism. In the late 1990s, the WWE, while accelerating the pace of the development of its usual absurd storylines, started to aggressively commercialize, promote, and circulate a different form of narrative, which I refer to as nonfictional narratives, that took viewers behindthe-scenes of the production of professional wrestling without concealing the scripted nature of wrestling matches and storylines. Via the diffusion of nonfictional narratives, WWE wrestling explicitly invited viewers to see through the "truth" behind its fictional products, while they also continued to enjoy the scripted fiction. Hence WWE wrestling now manifestly encourages viewers to make sense of it, or find verisimilitude in it in using two different ways of viewing: to immerse oneself in the world of fiction just like watching Hollywood movies, or (and at the same time) to find the "truth" behind the production of the fiction. The realism of WWE wrestling possesses a dual structure, which is officially endorsed by the WWE.

This chapter centers on issues of realism in WWE wrestling, in particular, the significance of the promotion of nonfictional narratives by the WWE. In the first section, I will consider the nature of realism in professional wrestling in the past, that is, when the wrestling industry tried its best to conceal its product's scripted nature from the public. I argue that wrestling in the past exhibited a contradictory attitude of hinting at and concealing its true nature, and that the contradiction stimulated people's desire to "expose" wrestling and was also one of the reasons for the marginalization of wrestling in "modern" society. The second section gives an overview of the process of transformation of realism in WWE wrestling during the 1990s into an officially-endorsed “dualized” state. Here, by applying Bill Nichols' thoughts on realism in

\footnotetext{
${ }^{139}$ Mazer, Professional Wrestling: Sports and Spectacle, 163.
} 
fiction and documentary, I theoretically define two different forms of realism, and argue that the diffusion of nonfictional narratives by the WWE (and other organizations) in the late 1990s promoted the formation and reification of the dual (fictional and nonfictional) realism structure of wrestling matches and performances. In the third section, I will examine mechanisms of one half of the dual realism, realism of WWE wrestling as fiction. Referring to Jonathan Culler's linguistic/structuralist understanding of literature, I consider unique and complicated mechanisms and conditions that enable viewers to make sense of and immerse themselves in the fictional world of wrestling. This will be my attempt to give a partial answer to the age-old question; why does such obvious fakery attract so many followers?

After that, in the rest of the chapter, I will extensively discuss the significance and various influences of the commercial promotion and circulation of nonfictional narratives by the WWE. Although we have rarely seen lengthy analyses of this issue, I contend that the increased circulation of nonfictional narratives endorsed by the major promotions such as the WWE deserves scholarly attention. As I will show in the fourth section, nonfictional narratives work on the redefinition of the values and significance of WWE wrestling. Those narratives attempt to tell viewers how to interpret wrestling, how to find "truth" behind the production of fictional matches and storylines, and how to respect wrestling. At the same time, nonfictional narratives construct the wrestling industry as a mesmerizing place, an object to be desired. Also, as the fifth section will explain, the production of nonfictional narratives offered the WWE another mode of discourse, and allowed it to make controversial and righteous ideological appeals in more flexible ways than before. Therefore the promotion of nonfictional narratives enabled the WWE to have a unique and strategic cultural and political positioning and to exert a version of populist politics. Finally, as the sixth section argues, the promotion and circulation of nonfictional 
narratives by the WWE are to be considered a process in which a culture industry has incorporated minor, unofficial discourses that used to escape from its control. This phenomenon was a result of a series of appropriation and reappropriation of texts between the wrestling industry and fans.

\section{Section 1}

\section{Realism of Professional Wrestling:} When Insiders were Obliged to "Protect the Business"

\section{A Wide Range of Interpretation and Imagination}

In their study of professional wrestling's theatrical conventions in the early 70 s, Gerald Craven and Richard Moseley argue that wrestling fans have a variety of attitudes towards wrestling. There are fans who are quite aware of wrestling's theatricality and enjoy it as a "camp." ${ }^{140}$ Also, there are fans who truly believe in the legitimacy of the wrestling match as a contest. Then, Craven and Moseley asserts that the majority of wrestling fans fall between these extremes; they are willing to suspend their disbelief and enjoy wrestling by applying the convention of viewing theaters rather than that of viewing sports. Hence their assertion that wrestling fans, "at some conscious level of expectation" experience wrestling as they do pure theater. ${ }^{141}$ However, at the same time, as the above quote suggests, Craven and Moseley realize that in fact the matter is a little more complex. They note that a wrestling fan, who appears to enjoy a wrestling match as he does theater, also speaks of the wrestling match as a sport. ${ }^{142}$ The

\footnotetext{
${ }^{140}$ Gerald Craven, and Richard Moseley, "Actors on the Canvas Stage: The Dramatic Conventions of Professional Wrestling," Journal of Popular Culture 4 (1972): 326-336.

${ }^{141}$ Ibid., 327.

${ }^{142}$ Ibid., 326.
} 
authors also acknowledge that the wrestling fan "would appear to be less aware of the purely theatrical aspects of the effects than the viewer of the melodrama."143 These remarks seem to indicate that professional wrestling at that time somehow prevented many fans from being fully conscious about its manufactured nature.

In his sociological study of professional wrestling as ritual and morality play also in the early 70s, Thomas Henricks, based on his survey, argues that "knowledge that wrestling is a simulation of the agon and not real contest extends as well to most wrestling fans."144 This quote sounds like most fans at that time were entirely aware of the scripted nature of wrestling contests. However, again, the matter is not that simple as seen in Henricks argument about wrestling fans' reaction towards people who call wrestling "fake." According to him, a "typical response" goes, "I know it's not a fake. - tell some of those people to get into the ring with one of them - what account can you give for the blood, broken arms, and legs?"145 This "typical" fan in the early 70s, while he may have acknowledged the theatricality of wrestling matches, believed in wrestlers' legitimate fighting skills, and placed values on his conviction that wrestling performances involved realness in terms of wrestlers' fighting ability.

Gerald W. Morton and George M. O’Brien find the same kind of ambiguous attitude in a wrestling fan at a wrestling show in 1978. Earlier in the event, this fan made bitter comments on two immature wrestlers, which clearly indicated that he knew the scripted nature of wrestling matches. However, later, the same fan started to talk about how dangerous a tag title match of the night would become, showing his desire to believe in the realness of the contest "even if only a

\footnotetext{
${ }^{143}$ Ibid., 328-329.

${ }^{144}$ Henricks, "Moral Order," 184.

${ }^{145}$ Ibid., 185.
} 
few hours. ${ }^{" 146}$ Michael R. Ball, in his sociological study of professional wrestling, based on his interviews, also remarks on the vagueness in fans' belief in the authenticity of wrestling contests. $\mathrm{He}$ "found people willing to believe portions while remaining skeptical of other portions. None fell into a simple belief vs. non-belief dichotomy." ${ }^{, 147}$ One of his informants said, "I think most of it is real. They fake some of it... you can tell that sometimes they miss by a long ways... but most of it is real. ${ }^{.148}$

These observations of wrestling fans in past studies indicate that professional wrestling used to allow a wide range of interpretation and imagination regarding its fidelity as contest. ${ }^{149}$ Most viewers acknowledged its manufactured nature or the showmanship involved in it, and knew that wrestling was usually not covered as sports by major newspapers and television news programs. Nevertheless, wrestling somehow aroused many fan's desire to find some authenticity in it, and to refuse the charge of fakery made by non-fans. Some even choose to believe it as an entirely legitimate competition, while others, in order to refute the charge of fakery, attempted to shift the meaning of fakery from the illegitimacy of the contest to that of wrestlers' fighting skills. This flexibility of interpretation and imagination for wrestling in the past were the products of the contradiction in the presentation of wrestling. That is, wrestling used to hint at

\footnotetext{
${ }^{146}$ Morton and O’Brien, Wrestling to Rasslin, 103-104.

${ }^{147}$ Ball, Ritual Drama, 122.

${ }^{148}$ Ibid., 122.

${ }^{149}$ Almost all of the scholars of professional wrestling assume that wrestling matches are scripted
} performance as opposed to genuine contest. However, as a rare exception, Nonini and Teraoka, in their critical examination of the attitude of middle class intellectuals, insist that wrestling matches are legitimate contests. According to them, heel (villain) wrestler's "backing into the corner while begging one's opponent for mercy" is a pure strategy to deceive the opponent and win the match (Donald M. Nonini and Akiko Arlene Teraoka, "Class Struggle in the Squared Circle: Professional Wrestling as a Working-Class Sport," in The Politics of Culture and Creativity: A Critique of Civilization, ed. Christine Ward Gailey [Gainsville: University of Florida Press, 1992], 155-156). 
and hide its "true" nature at the same time.

\section{Contradiction: Hiding and Hinting at its Own True Colors}

The fact that many fans as well as the general public acknowledged wrestling's scripted nature indicates that wrestling performances involved a large degree of self-referentiality; the style of performance revealed its own unnaturalness or manufactured nature to viewers. As discussed in the introduction of this dissertation, wrestling's self-referentiality came from the most basic stylistic convention of wrestling performance that Barthes points out: exaggeration and excessiveness. ${ }^{150}$ In wrestling, all of the movements are shown with exaggeration, and thus their meanings gain extreme clarity. When signs are presented with excessiveness, they inevitably suggest their own "unnatural" state to viewers, since their excessiveness makes viewers wonder if a serious competition also looks like that. That is, the excessiveness of signifying practices, which is the fundamental stylistic convention of wrestling, implicitly communicates professional wrestling's strangeness as a serious competition to viewers. Hence the disregard of wrestling in sports media coverage.

Nevertheless, wrestling used to try its best to avoid making its self-referentiality explicit; the industry deliberately chose to keep it in an implicit state. It was considered essential for insiders to "protect the business," that is, never to acknowledge in public the scripted nature of wrestling matches. ${ }^{151}$ Otherwise, many in the business believed the wrestling industry would decline. Bret "Hitman" Hart, one of the most famous wrestlers in the 1990s, describes the mindset of wrestlers in the mid 1980s, "It was a time when old schoolers still went to great

${ }^{150}$ Barthes, "The World of Wrestling."

${ }^{151}$ This practice is called a "kayfabe" of "kayfabing" in the professional wrestling jargon. It is said to have an origin in the language of carnival, where the word "fake" was inverted. 
lengths to 'protect the business,' living our characters not just in the ring but whenever the public — the marks — were around." 152 He continues:

In fact, as late as the mid-'90s the storyline had Owen [Owen Hart: Bret's real-life brother and one of the top professional wrestlers at that time] and I feuding, so for the sake of realism, as much as we would have enjoyed traveling together on the road, we instead avoided each other and wouldn't even sit together on numerous long plane rides back to Calgary. ${ }^{153}$

To use a crude binary, insiders tried to protect the "fantasy" world from the intrusion of "reality" by acting as if the fantasy world were continuous to the real-life world, even if the way that the fantasy world was presented always implied its unnaturalness. The internal code of "protecting the business" could certainly be called dogmatic and even arrogant, since it was practiced under the assumption that viewers were basically dupes who believed in the authenticity of wrestling, looking away from the fact that almost all of the viewers recognized the unnaturalness of wrestling to certain degrees. At the same time, the code could also be justifiable, considering the fact that there were quite a few fans who were willing to (and wanted to) believe in the authenticity of professional wrestling to some extent. The fantasy world of wrestling (which, paradoxically, was significantly supported by the physical reality and presence of wrestlers' bodies) had power to convince those fans to refuse or ignore the intrusion of reality, even at the moment when they were not watching wrestling live. In other words, the fantasy world of wrestling possessed its own reality effects and fascination that made quite a few viewers want no major interference from the outside real world. By following a code of "protecting the business," insiders of the industry also protected viewers' wish to find realness in professional wrestling.

\footnotetext{
${ }^{152}$ Bret Hart, Forward to Tributes II: Remembering More of the World's Greatest Professional Wrestlers by Dave Meltzer (Champaign, IL: Sports Publishing L.L.C., 2004), vii.

${ }^{153}$ Ibid.
} 
Realism in wrestling (in this context, realism in terms of its authenticity as contest) existed in contradiction; the wrestling industry prohibited insiders from revealing to the public wrestling's manufactured nature, at the same time wrestling's most basic stylistic convention displayed its artificiality. This ambivalence allowed a variety of perceptions and interpretations on the part of viewers noted above. It also made wrestling an easy target for "sensational" exposés. Since the early 20 th century, there had been many attempts to reveal the "secret" of professional wrestling. ${ }^{154}$ However, contrary to many insiders' concerns, such exposés never became fatal blows for the wrestling industry, at least in the United States. ${ }^{155}$ After all, they only told what wrestling's stylistic convention had already (and always) told. Nevertheless, the need for the exposé did not disappear, and people (both fans and non-fans) kept on wondering and talking about what professional wrestling "really" was. In a sense, by taking an ambivalent attitude of concealing and hinting at its own true colors at the same time, wrestling constructed itself as a slippery object of desire: a desire for peeping, knowing, and revealing. The excessiveness of presentation always alluded to its true nature, but since wrestling refused to admit its scripted nature in public, the desire was never entirely fulfilled.

Professional wrestling's refusal to submit itself to a society's system of knowledge should have been a frustration for people who believed in the enlightenment rationality, that is, those who have no doubt in the power of human knowledge to master and regulate all things in

\footnotetext{
${ }^{154}$ The most famous early attempt to such disclosure would be Marcus Griffin, Fall Guys: The Barnums of Bounce, Top Quality Wrestling, http://tqw.comeze.com/Fall\%20Guys.pdf (accessed April 1, 2012), which was originally published in 1937. After entering into the television age, ABC's 20/20 (1985) attempted to expose various tricks of professional wrestling. Several other exposé programs followed it.

${ }^{155}$ The case was a little different in Japan, where fans took the authenticity of professional wrestling contests much more seriously than in the United States. In the 1990s, along with the publishing of books that revealed the inner working of the business, the emergence of Mixed Martial Arts severely damaged the authenticity of wrestling contest, and lead to the decline of wrestling in Japan.
} 
this world. This is part of the reason that wrestling never received favorable recognition from "modern" society; it was recognized neither as a legitimate sport nor healthy (that is, identified) entertainment, and resided in the fringe of American culture. However, Vince McMahon, the chairman of the WWE, eventually decided to make the "truth" of professional wrestling public knowledge. As we will see in the following sections, this move, beyond his initial intention, triggered a significant transformation of the structure of realism in wrestling, and allowed wrestling to claim its public value as one of the most "American" forms of entertainment.

\section{Section 2}

\section{The Transformation since the Late 1990s: The Dualization of Realism in WWE Wrestling}

Contemporary professional wrestling does not exhibit the ambivalent attitude that it used to exhibit. It has resolved its ambivalence by revealing its own manufactured nature. It even encourages viewers to know more about behind-the-scenes happenings. Realism in wrestling has a different structure and quality than what it used to have.

The transformation was triggered by Vince McMahon's decision to end the 100-year old tradition of "protecting the business" for the convenience of his company. In 1989, McMahon admitted in front of the New Jersey State Athletic Commission that what he produced was a scripted performance and not a legitimate contest. ${ }^{156}$ That is, the WWE revealed its "true" nature to public institutions and submit itself to the system of knowledge. It is reported that McMahon's motivation was purely to avoid paying state tax for holding athletic Pay-Per-View events, and

\footnotetext{
${ }^{156}$ Peter Kerr, "Now It Can Be Told: Pro Wrestlers Are Just Having Fun: It's Out Now: Wrestling Is All in Fun," New York Times (1923-Current file), Feb. 10, 1989, http://search.proquest.com/docview/110196575?accountid=10141
} 
not to change the nature of wrestling products or public perception of them. ${ }^{157}$ In fact, although this act received some newspaper coverage, subsequently, the WWE and other wrestling organizations kept presenting their wrestling products as usual, and no immediate change was observed. However, as things turned out, McMahon's admission eventually altered the business in many significant ways.

The more obvious change came in the later half of the 1990s. On September 1995, the WCW (World Championship Wrestling), the organization owned by the media mogul Ted Turner, launched their weekly television program Monday Nitro in the same time slot as the WWE's flagship program Raw (which was also called Monday Night Raw), and started the socalled Monday Night Wars. As both programs presented innovative and creative products one after another, ${ }^{158}$ the popularity of wrestling skyrocketed and it became one of the "cool" products in popular culture.

As one of many creative efforts to win the competition, both organizations increasingly commercialized "real-life" elements by incorporating them into their storylines. The WWE, following the actual assault on Shawn Michaels, staged his sudden collapse in November 1995, which led many viewers to believe it was a non-staged "real" accident. Also the development of the "Mr. McMahon" character, an evil and dictatorial boss played by Vince McMahon himself, was trigged by the famous "Montreal Screwjob," where McMahon as a real-life chairman of the

${ }^{157}$ Dave Meltzer, Wrestling Observer Newsletter, Feb. 20, 1989, 1-2.

${ }^{158}$ To be precise, as we will see later, those "innovative" and "creative" products of the WWE and the WCW were in fact inspired by the products of the ECW, a Philadelphia-based small independent organization that gained enthusiastic supports from hardcore wrestling fans. 
WWE devised an actual trick to strip Bret Hart's championship title without his consensus. ${ }^{159}$ Both the WWE and the WCW did not hesitate to make their "real-life" business competition clearly visible to viewers. They rather used this head-to-head television competition as a resource for storylines that increased ratings; both sides began to frequently mention each other's name, incorporating competitions into their own storylines. In this era of fierce competition, the WWE, in addition to its usual programs with storylines and performances characterized by exaggerated expressions and excessive clarity of meaning, started to constantly produce and cooperate with other parties to produce "new ${ }^{160 "}$ form of narratives: narratives that took the scripted nature of wrestling for granted.

With the involvement of the WWE, such new narratives were increasingly exposed through various commercial media outlets. The WWE aided the production of the two famous documentary films on professional wrestling, Hitman Hart: Wrestling with Shadows (1998) and Beyond the Mat (1999), by giving film crews unlimited access to its backstage. As a result, those films documented the production processes of WWE wrestling, in which storywriters, producers and opposing wrestlers worked together to create spectacular shows. ${ }^{161}$ In 1997, the WWE also helped the A\&E Network to produce the television documentary on the history of professional wrestling (The Unreal Story of Professional Wrestling 1998) and a series of television biographies of WWE superstars. Those programs described professional wrestling as scripted

${ }^{159}$ For the extensive description and analysis of the "Mr. McMahon" character, see chapter 3.

${ }^{160}$ As will be stated later, in the 1990 s, this kind of narratives was not new at all for many fans. Here, I use the adjective new with quotation marks, in order only to emphasize that the WWE began to aggressively commercialize those narratives in the late 1990s. That is, they were at least new moves on the WWE's part.

${ }^{161}$ However, interestingly, both of the films ended up receiving no endorsement from the WWE. Hitman Hart revealed Vince McMahon's aforementioned ploy to strip Hart's title. Beyond the Mat, as much as it portrayed humane sides of professional wrestlers, depicted the vast amount of physical and mental abuse that this profession may cause. Both films revealed the dark truth of wrestling more than the WWE wanted them to do. 
entertainment and wrestlers as human beings who perform their characters in the ring. In that era, various forms of news coverage (television, newspapers and magazines) featured the professional wrestling boom emphasizing its business aspects. In cooperating on such coverage, the WWE did not hide its products' scripted nature anymore.

The exposure of such narratives was materialized in a book form, too. The WWE, using its own publishing division, released its own superstar Mick Foley’s autobiography Have a Nice Day!: A Tale of Blood and Sweatsocks, which offered the behind-the-scenes look of the wrestling business and performance in unprecedented details. ${ }^{162}$ As we will see later in this chapter, the success of this book initiated the publishing boom of wrestlers' autobiography, which took professional wrestling's scripted nature for granted.

Different versions of new narratives appeared in WWE's weekly television programs. On May 24th, 1999, following the accidental death of its superstar Owen Hart on the previous day, the WWE aired a special live tribute episode in its weekly Monday Night Raw time slot. In this program, all of the ongoing storylines were suspended and wrestlers performed straightforward wrestling matches with clean finishes. Aired between those matches were interview segments, in which WWE wrestlers and performers, both heroes and villains, removed their in-ring characters and made tributary comments to Hart in serious and sad tones. This started the tradition of "serious" editions of WWE weekly programming in special or extraordinary occasions, in which storylines are suspended and WWE wrestlers and in-ring performers address serious issues as human beings. ${ }^{163}$ In the 2000 s, the WWE kept on producing programs such as a reality television

${ }^{162}$ Mick Foley, Have a Nice Day!: A Tale of Blood and Sweatsocks (New York: Reganbooks, 1999).

${ }^{163}$ In fact, before the tributary program for Owen Hart, the WWE aired serious "ten bell salute" segments to honor deceased wrestlers such as Andre the Giant (1993) and Brian Pillman (1997). However, those segments 
series WWF Tough Enough (2000-2004) ${ }^{164}$ and a talk show WWF confidential (2002-2004), which centered on nonfictional narratives that reveal the inner-working of the professional wrestling business. The WWE also started to include backstage stories in its home video and DVD products.

Such "new" narratives distinguished themselves from "usual” WWE wrestling narratives (which consisted of storylines, matches, and other in-ring and off ring performances in usual presentation of professional wrestling). That is, by showing that usual wrestling narratives were actually manufactured, new narratives identified themselves as meta-narratives of those usual narratives, meta-narratives that revealed the "truth." Through this new form of narratives with truth claims, the WWE officially and explicitly declared that its usual presentation of professional wrestling were made of entirely manufactured narratives. Of course, in every age, wrestling fans have always heard from someone that professional wrestling matches are scripted or manufactured, and have to agree with the view at least to some extent. In particular, the late 1990s, the scripted nature of wrestling matches was already an open secret; at that time, many fans had an access to backstage information via the Internet and other sources, ${ }^{165}$ and wrestling organizations, including the WWE, were increasingly adopting storylines that indicated the scripted nature of professional wrestling. (The Michaels' staged collapse pulled by the WWE in 1996 "duped" many viewers because they assumed that professional wrestling was basically a

were very short and suspended "usual" ongoing wrestling storylines for only a few minutes. Wrestlers did not break their in-ring characters except for observing a moment of silence while the bell tolled ten times.

${ }^{164}$ Seven years after the discontinuation of the series in 2004, Tough Enough was revived in the USA network, taking a similar format to the original reality series. However, this new program is referred to as the "Season 1" and no mention is made about previous seasons.

${ }^{165}$ As I will explain in more detail later in this chapter, small-scale wrestling publications such as Wrestling Observer Newsletter and Pro Wrestling Torch have been reporting the wrestling industry's behind the scenes news of the wrestling industry since long before the late 1990s. Thus, again, for readers of those publications, what I have been refereeing to as "new" narratives were not really new at all. 
staged performance.) In this sense, the emergence of those new narratives in commercialized forms was almost a final confirmation of the open secret. Since the company explicitly revealed its products' manufactured nature, those narratives gained credibility and persuasion that was nowhere to be found. Now, instead of the past ambivalent policy of hinting at and hiding the scripted nature of professional wrestling at the same time, the WWE deliberately promotes two differentiated types of narratives: usual narratives of professional wrestling that present manufactured performances, and new narratives that reveal the truth behind the production of manufactured performances. (As mentioned, in the late 1990s, the WWE began to increasingly incorporate real-life elements into its scripted narratives to further complicate matters. However, at this moment, I would like to concentrate on effects of demarcation of two forms of narratives.)

Bill Nichols' distinction between fiction and documentary helps us to grasp the difference between the two types of narratives more lucidly. In Representing Reality, he states that the distinction between narrative fiction and documentary lies in the assumption regarding their relations to the "historical world," the world we live in. He argues that we assume that fiction constructs an artificial world, which only has a "metaphorical" relationship with the historical world. In contrast, a documentary, we assume, "metonymically" represents the historical world (as a part that represents the whole). That is, while fiction is supposed to invite us to "a world," documentary is supposed to offer an access to "the world.",166

Along this line of thought, narratives presented by the usual WWE wrestling storylines can obviously be called fictional. We now assume that they primarily aim at constructing an entirely fantastic world made by absurd and exaggerated characters, which is basically an

${ }^{166}$ Bill Nichols, Representing Reality: Issues and Concepts in Documentary (Bloomington: Indiana University Press, 1991), 109. 
extremely oversimplified and exaggerated reflection of the historical (real-life) world. In contrast, new narratives claim to have a similar function to Nichols' documentary; they allegedly give a faithful representation of the "real" process of manufacturing of the usual fictional narratives of wrestling in the historical (real-life) world, and depict wrestlers as human beings who perform in-ring characters. From now on, I will refer to these new narratives as nonfictional narratives without using the word documentary, as they do not claim to have serious public purposes that the word usually suggests. ${ }^{167}$

It is important to realize that realism in fictional narratives and that in nonfictional narratives basically have different purposes. Nichols' argument again provides us a helpful perspective. While admitting that documentary shares many characteristics with fiction in creating various reality effects and making viewers engage with it, he argues that there is an essential difference between realism in fiction and that in documentary, "In fiction, realism serves to make a plausible world seem real, while, in documentary, realism serves to make an argument about the historical world persuasive." 168 He states, realism in fiction is "selfeffacing," that is, it mainly aims at making viewers engage with the manufactured world without raising their consciousness of the process of its construction. Realism in documentary also serves to make viewers engage with its narrative. However, according to Nichols, it has more differentiated functions. He asserts that documentary has a dual relationship with the historical world; it is the representation of the world, and at the same time, the representation about the

\footnotetext{
${ }^{167}$ Here, whether nonfictional narratives actually make the accurate representation of the world or not should not be our primary concern. The point is that this is a narrative that claims itself to be the metonymical representation of the world.

${ }^{168}$ Ibid., 165.
} 
world. ${ }^{169}$ On the one hand, documentary serves as the evidence of the matters in the historical world, and convinces viewers that images and sounds in front of them are "indexical" representations of the historical world that we live. On the other hand, documentary also tries to persuade viewers by presenting an argument about the historical world, and is itself a form of social engagement and consciousness raising.

This distinction is highly applicable to our subject. Realism in the fictional narratives primarily has an immersive function; it aims at making viewers engage with (or immerse themselves in) the fantasy world of professional wrestling. In contrast, realism in new nonfictional narratives is more sobering, since it is supposed to give viewers the evidence of "real" events and dramas (on the level of the historical world) behind the production of fictional narratives. At the same time, it presents viewers a powerful argument about the reality of usual fictional narratives of wrestling; it makes viewers realize that all wrestling matches can be viewed as an entertainment performed by human beings. It suggests (or argues) that, when watching wrestling matches, viewers can either immerse themselves in the fictional world as they are normally supposed to do, or raise their consciousness about its manufactured nature and see those same matches as the evidence of human activities in the historical world. Here, we have to revise our argument about the differentiating function of nonfictional narratives of WWE wrestling. Nonfictional narratives do not merely define usual storylines of wrestling as fictional narratives, in which viewers should immerse themselves. Paradoxically, nonfictional narratives also declare that the usual fictional narratives of wrestling can be read both fictionally and nonfictionally. That is, nonfictional narratives tell viewers that usual "fictional" wrestling matches exhibit two different forms of realism: realism in fiction and in nonfiction. Of course, as

\footnotetext{
${ }^{169}$ Ibid., 177.
} 
previous studies on wrestling that we saw in the first section show, quite a few wrestling fans in the 1970 s already viewed wrestling matches fictionally and at the same time nonfictionally. However, this dual interpretation is now officially endorsed and encouraged by the WWE, the author of wrestling texts.

This distinction between a fictional reading and a nonfictional reading is only a theoretical one, and very often to be dissolved on the level of actual experience. As we saw, the stylistic convention of exaggeration in wrestling performance often makes it difficult for viewers to entirely immerse themselves in the fantasy. Also, conversely, most viewers, even after learning a sobering perspective from nonfictional narratives, will allow themselves to be engaged with fictional narratives of WWE wrestling to some extent. Finally, as mentioned, the WWE often intentionally incorporates (seemingly) real-life elements into its fictional storylines, blurring the boundary between reality and fantasy. This complexity of presentation does not allow viewers to figure out when they should adopt a certain mode of reading.

Nevertheless, it is important to recognize that, through the diffusion of nonfictional narratives, the WWE officially brought dualization effects in its wrestling world and promoted them. The WWE clarified that there were two modes of interpreting WWE wrestling (and professional wrestling in general); to immerse oneself in battles in the fictional world by suspending one's disbelief, and to be sober and see what is "really" going on in the performance of the battle, raising one's consciousness about the process of manufacturing the fantasy. As we will see later, this dualization enables the WWE to present the significance of its products in more elaborate ways than before. 


\section{Section 3}

\section{Realism, or Making Sense of WWE Wrestling as Fiction}

\section{Mastering Competence in Viewing Wrestling}

Before we extensively examine the significances and influences of the emergence and circulation of nonfictional narratives by the WWE, the discussion of the mechanism of the realism in fictional narratives of professional wrestling is in order. That is, processes in which viewers immerse themselves, and are emotionally engaged in the fictional world of professional wrestling are to be considered. This issue concerns a simple yet fundamental and long-standing mystery of the genre of professional wrestling; why does such an obvious fakery fascinate so many people? Of course, the elucidation of realism in professional wrestling does not solve the entire mystery of the fascination of it, as realism most likely is only a part of the fascination. However, the investigation of realism of wrestling as fiction will provide one possible explanation for why the fascination of fantasy can be sustained without being entirely destroyed by the intrusion of hard cold reality.

In order to consider the realism of professional wrestling as fiction, I would like to pay close attention to underlying mechanisms, or systems of rules that enable the production and perception of the meaning of wrestling, as opposed to analyzing specific contents of wrestling storylines and characters. In other words, rather than performing the interpretation of specific "texts" of wrestling, I would like to place a stronger focus on the underling "grammar" of wrestling, of which mastery allows producers and viewers to make sense of wrestling texts. It is my hope that the following examination in this section will provide the basis for further analysis of specific wrestling texts, that is, contents and characters of specific wrestling organizations in 
specific periods.

Jonathan Culler's linguistic/structuralist approach to the verisimilitude of literary texts provides a helpful theoretical model to understand the mystery of realism (of an obvious fakery) in professional wrestling. In Structuralist Poetics, he discusses the paradoxical state of literature. On the one hand, literature attracts us because it is different from ordinary ways of communication. However, on the other hand, in order to appreciate literature, we have to somehow "reduce its strangeness," or "naturalize" it. Culler explains this naturalization process by applying the theoretical model of linguistics. Since we consciously and unconsciously understand the rules of complex system of relations and distinctions in our native language (we may not be able to explain the whole grammar, but we could tell what is right or wrong about particular sentences), we are able to produce and understand meaningful words. Likewise, Culler assumes, in literature, there must be underlying systems of conventions and expectations that are shared by writers and readers. Because readers have mastered those implicit conventions and acquired "literary competence," they could naturalize literary texts and perceive verisimilitude in them. ${ }^{170}$

Culler's model is designed to understand the perception of literature, a so-called highbrow and complex art. However, oddly enough, it is very applicable to the study of underlying mechanisms that activate verisimilitude in professional wrestling's fictional and absurd performances and narratives. ${ }^{171}$ In fact, the production and consumption of wrestling are

\footnotetext{
${ }^{170}$ Jonathan Culler, Structuralist Poetics: Structuralism, Linguistics, and the Study of Literature (Ithaca: Cornell University Press, 1975), 113-130.

${ }^{171}$ Here, a couple of methodological clarifications regarding the usage of this linguistic/structuralist model is needed. First, as Culler explains on his application the model to literary studies (Culler, Structuralist Poetics, 120-121), the linguistic/structuralist approach to professional wrestling, which suggests that there are certain common conventions and frameworks in presenting/viewing professional wrestling, does not indicate that there is one correct reading of wrestling, nor does it imply that there should be a perfect correspondence between producers'
} 
mediated by various conventions and expectations shared by performers and viewers. It is obvious that performance and storytelling of wrestling are highly conventionalized and stylized. Producers (promoters, storywriters and wrestlers) master those conventions and are competent enough to offer products that meet the expectations of viewers. Viewers, in order to immerse themselves (to some extent) in the fictional world of wrestling and enjoy it, need to be competent enough to naturalize conventionalized performances and storylines and to interpret them. In other words, viewers need to acquire the "grammar" of professional wrestling and master "wrestling viewing competence."

In fact, watching wrestling embodies the paradox of literary competence that Culler describes in the most extreme way, because, in wrestling, the most unnatural matters are to be naturalized. As we saw, the fundamental convention of wrestling lies in the exaggeration and excessiveness in its expressions. In wrestling, almost all of meaningful movements and gestures are shown with excessive clarity. All offensive and defensive moves have to look spectacular. Otherwise, they do not exist in the semiotics of wrestling, since viewers are trained to only accept clearly visible moves as meaningful signs. A wrestler who is beaten by the opponent is expected to "sell" his offensive moves, that is, to express his pain with his whole body, giving an excessively agonized look. Exaggerated moves and expressions, which will baffle viewers if performed in other legitimate martial arts and fighting sports competitions, are naturalized in the

(promoters', storywriters' and wrestlers') intention and viewers' interpretation. Shared interpretive frameworks certainly limit the range of possible presentation and interpretation, but do not finalize all forms of performance and interpretation; there is always a room for personal viewpoints and judgments to influence. This approach aims at clarifying why wrestling and its verisimilitudes are expressed and experienced in certain ways, not in any random way.

Second, this approach does not suggest that all of common performative/interpretive conventions are static and closed. On the contrary, it leads us to the historical examination of such conventions, which allows us to look at their dynamic, developing and open-to-change nature. As I will show, in professional wrestling, conventions are constantly broken and a convention-breaking becomes a new convention in a moment. 
genre of professional wrestling, where exaggeration is, consciously and unconsciously, accepted as a fundamental principle by performers and viewers. In order to experience professional wrestling "as it should be," and find verisimilitude in it, viewers have to acknowledge that the performance in front of them belongs to the genre of professional wrestling, and (consciously or unconsciously) master various conventions and expectations assumed in this genre. Once unnaturalness involved in wrestlers' exaggerated expressions and moves is naturalized, various types of visible physicality involved in those expressions and moves (such as the extraordinary physical presence of wrestlers and the intensity of bodily contacts involved in the moves) generate strong verisimilitude and help viewers immerse themselves in the fantastic world of wrestling. In this sense, the "naturalization of the unnatural" in wrestling involves a process by which the sense of physical reality is translated into the world of fiction.

Here, it should be noted that, to a large degree, the mastery of "wrestling viewing competence" (the ability to naturalize unnatural expressions in wrestling), can also be described as the mastery of the skill to temporarily forget or ignore the subtlety and complexity of matters that one has learnt in his/her life. Without this skill of temporary oblivion, he/she will grow the sense of disbelief that prevents him/her from smoothly accepting excessively intelligible expressions. It is the ability to block the intrusion of real-life logics into the immersive world of fantasy, the ability to watch wrestling just like children who are reading books or watching cartoons aimed at their ages. In fact, many professional organizations consider children their target audience, as children have not yet developed a sense of disbelief for excessively simple and intelligible expressions. In this sense, wrestling no doubt has "cartoonish" and "childish" aspects, as the common sense wisdom (or prejudice) of the general public suggests. However, it is also true that conventions in professional wrestling are diverse, dynamic, and quite 
complicated, and include interesting rhetorical effects. While many "casual" fans watch wrestling to forget their complex thoughts and enjoy the world of extreme clarity, simplicity, and intelligibility, other fans enthusiastically discuss, analyze, and evaluate the fictional world by raising their awareness of those conventions. In the following, I would like to further explore some of many specific conventions, or "grammatical" and "rhetorical" rules, that activate the experience of verisimilitude in professional wrestling as fiction.

\section{Hitting the Ropes: A Basic Expectation}

Professional wrestling has developed quite an intricate (open and dynamic) system of conventions and expectations, which is penetrated by the principle of exaggeration and excessiveness. One of the most visible of those conventions is a series of movement called "hitting the ropes," which is frequently seen in WWE wrestling as well as in other wrestling organizations around the world. ${ }^{172}$ One of the typical sequences of this convention goes as follows:

(i) Wrestler A applies the headlock to wrestler B.

(ii) The two wrestlers step back together while keeping the headlock position, hit the ring ropes with their backs, and lean against the ropes to bounce back.

(iii) Using the momentum, wrestler B pushes wrestler A's back with his hand towards the far side of the ropes.

(iv) Wrestler A releases the headlock and runs toward the far side of the ring ropes.

(v) Wrestler A turns his bodies, hits the far side of the ropes with his back, lean against the ropes

\footnotetext{
${ }^{172}$ There are exceptions. Some Japanese wrestling organizations exhibit the "(worked) shoot style," in which wrestlers refuse to hit the ropes to express a higher sense of realness than other styles of professional wrestling.
} 
to bounce back, and runs toward the wrestler B, as Wrestler B also starts to run towards wrestler A.

(vi) The two wrestlers, both with momentum, meet at the center of the ring to exhibit a wrestling move, which is called a "spot."

The objective of this series of movements is to create a spectacular "spot" at (vi), in which two wrestlers crash into each other with momentum and exchange moves in an exaggerated way. The hitting the rope sequence looks completely absurd if a viewer assumes that the two wrestlers are seriously competing with each other for victory. However, it is naturalized and accepted as a norm by viewers who consciously or unconsciously understand and expect that, in wrestling, a wrestler who is pushed towards the far-side of the ring ropes is supposed to hit the ropes and bounce back. Such viewers have mastered one of the many "grammatical" rules of professional wrestling to make sense of the performance. (Again, however, children who have not developed a sense of doubt for such an exaggeration will also have no problem in accepting this sequence of moves as a natural flow as well.)

\section{The Betrayal of Expectation}

The mastery of conventions and expectations also makes one able to understand the presentation of the unexpected, that is, when conventional moves are broken for a surprise. For example, Wrestler A, instead of releasing the headlock and running towards the ropes at (iii), may insist on keeping on squeezing Wrestler B's head. Or, instead of bouncing back towards the Wrestler B after hitting the ropes at (iv), he may hold the ropes with his arms and choose not to run towards his opponent, avoiding the encounter at the center of the ring. In such cases, only viewers who have understood the convention of the hitting the ropes are able to recognize that a normal form of expectation was negated by Wrestler A. That is, they are able to appropriately 
decode a surprise effect encoded by him. An act called "no-selling" also presents the unexpected within the semiotic system of fictional narratives in professional wrestling. As stated, in wrestling, a wrestler is most likely expected to "sell" the opponent's offensive moves, that is, to clearly externalize the damage inflicted by those moves. However, at certain times, a wrestler stops to "sell" the opponent's offensive moves and shows off his physical and mental toughness. If this "no selling" is done when most of the viewers (with "wrestling-viewing competence") are expected that he would keep on "selling" the opponent's attacks, it creates a surprise effect and generates excitement in the crowd.

Such presentations of the unexpected, betrayals of orthodox expectations and conventions such as "hitting the ropes" and "selling," are basically done within the system of conventions that constitute fictional narratives of professional wrestling. That is, the delivery of the unexpected too has to follow wrestling's fundamental principle of exaggeration and excessiveness, or it will end up being undecoded and unrecognized by viewers. In this sense, the display of the unexpected enhances the verisimilitude of the fictional narrative of wrestling, rather than damaging the verisimilitude by exposing the conventions. ${ }^{173}$ In fact, many of those presentations of the unexpected have already been established as conventions. The existence of a term "noselling" suggests that this form of the betrayal of expectation is recognized as a norm by those who acquired professional wrestling competence. The effective and creative presentations of the

\footnotetext{
${ }^{173}$ However, it is also true that the possibility for a "real," accidental convention-breaking is always latent in professional wrestling. These accidents occur outside the context of fictional narratives, but good wrestlers would immediately cover up and incorporate them in the fictional storyline. Also, as exemplified by Shawn Michaels staged collapse in 1996, the WWE sometimes stages accidental convention-breakings in an attempt to make viewers believe them to be a "real" accidents that are not supposed to happen. Although such "swerves" may sometimes be effective, it is important for wrestling producers to preserve conventions of the genre and fulfill the expectation of the viewers. Many people attribute the decline of the WCW, the WWE's rival organization, to its overstaging of accidents. The key for the longevity of wrestling products is the balance between showing the unexpected and gratifying viewers' expectations.
} 
unexpected are always welcomed by fans, and those moves will soon become new conventions in the genre of professional wrestling.

\section{Crowd Participation}

Exaggerated conventional performances in wrestling are incorporated with another important convention of the genre: the participation of the live crowd. The mastery of the sets of conventions and expectations in wrestling enables viewers to know when to react to, cheer, or boo certain actions and words presented by wrestlers. When a heel (a villain, or a wrestler who is supposed to be hated by the audience) catches a babyface (a hero, or a wrestler who is supposed to be cheered by the audience) in submission holds, such as bear hug or standing sleeper hold, a babyface expresses his agony for a while, and sometimes even makes his arms limp as if he were about to pass out. However, just when the referee is about to stop the match, a babyface makes a fist, and raises his arm high to explicitly tell the audience that he is not done yet. The audience realizes that it is a prelude for his "big comeback," and start to cheer him. A babyface answers the crowd by shaking the head, and eventually begins to hit his opponent with big follow-through motions. As the audience reaction goes to the maximum voltage, a babyface keeps hitting a heel and finally forces him to release the submission hold. A good wrestling live show needs the crowd with a wrestling viewing competence, who are able to read the match and know when to play their part.

\section{The World of Binary Characters}

The fundamental principle of exaggeration and excessiveness in professional wrestling is all encompassing and penetrates into the whole fictional world of it. The majority of wrestling storylines have a simple binary worldview. As discussed in chapter 1, wrestlers are either 
babyfaces or heels, both of which fight each other for simple objectives (such as justice, friendship, power, women, and money, etc.). Wrestlers of both groups have extremely intelligible characters ("gimmicks"). Until the mid 1990s, babyfaces were "good" guys who basically behaved in righteous manners and fought for the right cause and heels were bad guys who did not hesitate to cheat to win. Babyfaces transgressed moral codes only when they needed to cope with the wrongdoing of heels. Many of wrestlers' characters (including their appearances) were simplified and flattened version of social (racial, ethnic, and gender) stereotypes. In such cases, which are not so rare today as well, the verisimilitude of characters does not come so much from a precise approximation to human beings that viewers communicate with in their everyday lives. Rather, it comes from the correspondence with socially shared and patterned images. ${ }^{174}$ As we will see in detail later, the success of the WWE in the late 1990s lay in the creation of new and original characters that blurred the boundary between the good and the bad (for example, the popularity of babyfaces with an attitude such as "Stone Cold" Steve Austin and The Rock exploded), and the incorporation of real-life business matters and personal relations into fictional storylines. However, even after the complication of characters in the late 1990s, the gimmicks of WWE superstars have maintained their extremity and intelligibility. Also, in almost all of the feuds, the WWE keeps a binary view and makes it clear which wrestlers viewers are supposed to cheer (babyfaces) or boo (heels). Although viewers often express their disagreement and force the WWE to turn babyfaces to heels or vice versa, the binary is almost always maintained. Such fidelity of WWE wrestling to the convention

\footnotetext{
${ }^{174}$ Therefore, the verisimilitude of typical wrestling characters is far from that of 19th century "realist" novels that aimed at the fidelity to everyday lives of ordinary human beings. It seems much closer to the verisimilitude generated from the characters in comic books, which consist of simple line drawings and symbols and are given patterned attributes.
} 
of presenting a binary world helps viewers to engage with it, since they are conditioned to regard such simplistic dichotomy as natural in this genre.

It should be noted here that conventions and expectations discussed above are also the result the extensive stylization of products in professional wrestling. As discussed in chapter 1, stylized or conventionalized performances in the ring condition the audience to react in certain ways, and enable promoters and wrestlers to pre-calculate the reaction from the audience. Therefore, the stylization or conventionalization of wrestling performance had two major functions; to form the structure in which the verisimilitude of professional wrestling is activated, and to make the effects of the products on audience pre-calculable.

Forms of Verisimilitude with Sobering Effects: Parody and Irony

The principle of exaggeration and excessiveness in professional wrestling not only helps viewers to immerse in its fictional world, but also has more "sobering" effects, such as parody and irony, on viewers. As Culler explains those in literature, both parodic and ironical effects are produced via the juxtaposition of two different modes of verisimilitude and the assertion of the superiority of a particular one. ${ }^{175}$

Exaggeration in professional wrestling performance renders the genre a fundamentally parodic nature. Wrestling exaggerates all sorts of matters in the historical (real-life) world and put them into question. Via the "Mr. McMahon" characters' extraordinary greediness and unlimited desire to make people surrender, the WWE laughs at men of power in capitalist societies. Exaggeration in wrestling performance, albeit momentarily, allows us escape from the seriousness and taken-for-grantedness of our everyday life. To borrow Culler's argument about

\footnotetext{
${ }^{175}$ Ibid., 152-159.
} 
parody in literature, "the dominance of the parodist's vraisemblance (verisimilitude) is temporarily asserted." ${ }^{, 176}$ In similar manners, wrestling incessantly parodizes the conventions of other genres. As discussed in the introduction of this dissertation, John Fiske correctly calls WWE wrestling in the 1980s a parody of sport, in which many serious assumptions of legitimate sports (the respect for authority, the principle of fair play, the code of sportsmanship) are ignored and laughed at. ${ }^{177}$ Such a parodic orientation inherent in wrestling provides an alternative mode of verisimilitude to modes of verisimilitude in various socially accepted conventions and assumptions in the real-life world.

Culler's argument on irony in literature is also suggestive to us. He states that irony puts two orders (modes of verisimilitude), the protagonist's and the readers', in contrast with one another. The latter objectifies the former: "dramatic irony in literature involves the contrasts between a protagonist's vision of the world and the contrary order which the reader, armed with foreknowledge, can grasp." ${ }^{178}$ The principle of exaggeration and excessiveness in wrestling creates a similar contrast between the visions of performers and viewers. As mentioned earlier, wrestling performance naturally contains self-referential elements; the exaggeratedness of the performance communicates its own manufactured nature to viewers. In wrestling, performers (wrestlers, referees, announcers and all other in-ring characters) act as if they were involved in serious competitions, while the extraordinary way in which they play their roles leaks the contrived nature of the competitions to viewers. Hence viewers acquire the perspective that regards wrestling as manufactured performance, the perspective that in-ring characters are

\footnotetext{
${ }^{176}$ Ibid., 154.

${ }^{177}$ Fiske, Television Culture, 245-246.

${ }^{178}$ Culler, Structuralist Poetics, 154.
} 
basically deprived of. Here, self-referentiality in professional wrestling texts produces another mode of verisimilitude on the part of viewers, which enables them to objectify the literal meaning of the texts. Self-referentiality in wrestling ironically allows the intrusion of a real-life based perspective on the part of viewers that questions the logic of the fantasy world.

It should be noted that such irony in wrestling performance, when expressed properly, should produce jovial and pleasant effects, not sarcastic and bitter tastes. In the 1980s, when Hulk Hogan, the most popular babyface in the history of professional wrestling, "no-sold" his opponent's strikes by over-exaggeratedly shaking his head and flexing his arms and chest to express his toughness, determination, and anger, or when he yelled at his evil enemies with an extremely energetic tone in interview segments, his performance undoubtedly communicated to grown viewers its own contrived nature. Viewers, consciously or unconsciously, accepted the contrivance in his performance with joy and pleasantly cheered him. "Mr. McMahon," the evil owner, the parody of Vince McMahon's real-life self, is another master of generating this pleasant and jovial irony via his performance. When he enters into the ring with his signature "power walk," the over-exaggerated strut, or slowly yells at his wrestler "You're Fired!" with an excessively hateful tone, many in the audience boo him with joyful smiles on their faces. They acknowledge the over-exaggerated quality in his performance, and love to hate him. ${ }^{179}$

Parody and irony in professional wrestling, while introducing sobering and objectifying elements, are ultimately supposed to increase viewers' willingness to engage with the fictional world. Parody, by offering the alternative verisimilitude to the logics of various forms of institutional power in society, induces viewers to participate in the fictional world. Pleasant and

\footnotetext{
${ }^{179}$ In fact, despite his heel character, when McMahon appears, many in the audience pleasantly wave their arms and bow to him, in order to show respect and obedience to his fictional as well as real-life authority.
} 
jovial irony certainly enables viewers to objectify and question the validity of the logic that penetrates wrestling's fictional world. However, it is not supposed to entirely damage the realism of wrestling as fiction. Rather, jovial and pleasant irony in wrestling, by comically presenting its overdone nature, should stimulate viewers' willingness to participate in the collective and exciting experience of the fictional world. Parodic and ironic effects, both of which result from the fundamental principle of exaggeration in professional wrestling, complement the verisimilitude of the fictional world of wrestling.

\section{Diversity in the Semiotics of Professional Wrestling}

So far, I have explained conventions and expectations in the genre of professional wrestling by mainly using WWE examples. However, it should be stressed that there are cultural, regional, and organizational diversities in professional wrestling conventions and expectations. That is, while WWE wrestling shares many performative conventions and expectations as well as the fundamental principle of exaggeration and excessiveness with many other wrestling federations in the world, not all conventions and expectations in the WWE necessarily coincide with those of professional wrestling in other regions and periods. Hence, those who have mastered the "viewing competence" of one wrestling organization may have difficulties in smoothly making sense of other organizations' wrestling products. For example, Hulk Hogan's offensive moves in the WWE have different semiotic functions than when he worked for the New Japan Pro Wrestling (NJPW) in the 1980s. In the WWE, as well as in other wrestling organizations in the U.S., Hogan's signature finishing move is a running leg drop. It is supposed to have devastating power and finish almost all of his opponents. However, in Japan in the 1980s, his running leg drop was only one of his many small offensive moves with small effects. Hogan's finisher in the NJPW was “Axe Bomber," which was almost identical with Running 
Clothesline (a blow with the swinging forearm). In Japan, his Axe Bomber used to finish almost all of his opponents. Hogan continued to use his running clothesline after he left the NJPW and started to work exclusively for the WWE. However, in the U.S., his clothesline is one of many transitional moves that rarely finish his opponents and have no original name. In fact, not only the meanings of Hogan's offensive moves, but also his wrestling style obviously changed when he moved to the WWE; in Japan, he was quite adept at a mat-wrestling oriented style, which he almost forsook in the WWE. Hence, those who have only mastered the "grammar and vocabulary" of contemporary WWE wrestling will have a strange feeling if they watch Hogan's past matches in Japan, since their expectations will not entirely fit to the system of expectations adopted in Japan at that time. Wrestling organizations all over the world have developed their own semiotic systems or the systems of conventions and expectations. In this sense, the WWE's system can be considered only one of many.

However, it is also true that, as wrestling products of specific organizations came to be nationally and internationally broadcasted, it became easier for fans from multiple regions to be familiar with those organizations' products and semiotic systems adopted there. Hence small organizations often appropriate the signifying systems of larger organizations, as many viewers are already familiar with them via television. In this sense, contemporary wrestling products have a higher degree of "intertextuality" than before. Since the WWE has a wider national and international distribution of their products than any other organizations, most of the former WWE superstars (the wrestlers who left the WWE) will take advantage of their history in the WWE in their new organizations. ${ }^{180}$ In this sense, the system of conventions and expectations of

\footnotetext{
${ }^{180}$ However, he will not be able to use his ringname in the WWE, since the WWE almost always trademarks the in-ring names of its talents.
} 
WWE wrestling's fictional narratives most likely have a more universal reach than any other wrestling organizations in the world.

To summarize, although WWE wrestling has developed many specific characters and conventions of its own, it shares common performative and interpretive conventions, including the most fundamental principle of exaggeration, with many other wrestling organizations. The mastery of (open and dynamic) systems of conventions and expectations is cardinal for viewers to experience verisimilitude, which would help them to immerse themselves in the fictional world of WWE wrestling. Wrestling's fundamental principle of exaggeration also creates "sobering" effects such as parody and irony. Yet those effects also help viewers to be willing to engage with the fictional world. As mentioned, however, realism of WWE wrestling as fiction occupies only a half of the officially endorsed realism of WWE wrestling. The rest of this chapter will explore the process by which the other half of realism, realism of WWE wrestling as a nonfiction, has come to the foreground.

\section{Section 4}

\section{The Significance of the Increase of the Promotion of Nonfictional narratives}

The increased commercial promotion and circulation of nonfictional narratives by the WWE in the late 1990s exemplifies a change in the structure of realism in WWE wrestling, or the way in which many viewers make sense of WWE wrestling. As mentioned earlier, those narratives identify themselves as meta-narratives of usual fictional narratives, and claim that they depict the "truth" behind usual fictional narratives, the "truth" that the WWE did not widely disclose. That is, nonfictional narratives, endorsed by the WWE, presented many viewers new ways of finding verisimilitude in professional wrestling performances and storylines. 
nonfictional narratives attempt to redefine the significance of wrestling storylines and emphasize values that have not been emphasized. In what follows, I will examine various types of influence that those nonfictional narratives had on the interpretation of professional wrestling/WWE wrestling.

\section{The Unreal Story of Professional Wrestling}

The Unreal Story of Professional Wrestling (1998), a documentary television program that covers the historical transformation of professional wrestling from a legitimate contest in late nineteenth and early twentieth centuries to an entirely scripted entertainment, is one of the earliest major nonfictional narratives endorsed by the WWE. In its later half, the program contains a short segment that features a new version of Hulk Hogan vs. Andre the Giant, the main event of the WWE's WrestleMania III on March 29th, 1987, a bout that is considered by many as one of the most important matches in the history of professional wrestling. At the time of the event, this match was presented as the closure of a story between a hero and a villain who turned his back on the hero. In the WWE weekly television programs leading to the event, Andre, the most dominant wrestling figure of the $70 \mathrm{~s}$, became jealous of the popularity of Hulk Hogan, the American Hero and his best friend, and finally challenged him after being seduced by the evil manager Bobby Heenan. While Hogan was at first devastated by Andre's turnaround, he soon decided to accept the challenge and fight him with the help of "Hulkamaniacs," the kid supporters of him. On Match 29th, in front of allegedly more than a 90,000 person crowd at the Pontiac Silver Dome in Pontiac Michigan, Hogan did what was considered impossible; he body slammed Andre and scored an undisputed pin-fall victory. The righteous defeated the wicked in the overwhelming spectacle of the crash of two huge bodies.

A segment in The Unreal Story virtually revises this epic battle of 1987 . While showing 
the spectacular footage of the match, the program, in its voiceover, features the "objective" narration of actor Steve Allen, and testimonials by Vince McMahon (the WWE chairman) and Hulk Hogan. Those three voices function as the meta-narrative of the footage shown, and reveal the new "truth" in the production of the match. After the program situates WrestleMania III as the climax of the second golden era of professional wrestling created by WWE, the three voices explain that Andre had already passed his peak and his physical condition was deteriorating at that time. Then, the narrator plainly states that this match was scripted. However, it was followed by the three voices telling that there was another uncontrollable element in this match:

Narrator: For fifteen years, Andre the Giant had ruled the wrestling world like Stranger Lewis and Lou Thesz before him. No man can beat him so he can win or lose a title as he pleased. Being aware that his career was coming to an end, Andre agreed to lose the title (sic) to the younger, healthier Hulk Hogan that night. But Andre was an extremely proud man who liked being on top, and nobody knew for sure whether he would allow Hogan to beat him.

McMahon: Hogan was very very concerned asking me about Andre doing the honors, as we say. And I knew what was in Andre's heart. Hogan knew what could be in Andre's heart, what could have been in Andre's heart. If Hogan didn't play his card right, if Hogan made him angry, no one, no human being alive could tell Andre what to do.

In the next moment, the narrator states "But, Andre was a man of his words," and the program shows the footage of the actual match, in which Hogan body slammed Andre and pinned him to the victory while announcers were screaming, "Look at this!" "I don't believe it!" Then, it is switched to the interview footage of Hogan looking back on this match:

Hogan: That had to be the single most unbelievable moment in my life... Now that I look back on that, in retrospect, he passed the ball to me that night.... After fifteen years, I finally got enough respect from him. He knew I was a businessman. And he just didn't give that victory to anybody. He passed to me. He handed it down and I will never forget it.

After that, the narrator explains that Andre died five years later at the age of 43, and credited Hogan for bringing the professional wrestling business reinvented by Vince McMahon "closer to 
mainstream American life than at any time since Frank Gotch." In short, the three voices in the program offer a new nonfictional version of the match, which describes the production process of the (now determined to be) fictional battle presented in 1987.

Here, in order to illuminate the difference between the 1987 fictional version of the battle and this new nonfictional version, I would like to make a detour and revisit John Fiske's suggestive reading of WWE wrestling television programs titled Rock ' $n$ ' Wrestling ${ }^{181}$ in the late 1980s. Referring to Barthes' analysis of professional wrestling and Mikhail Bakhtin's theory of carnival, Fiske considers Rock ' $n$ ' Wrestling a "carnival of bodies," in which the spectacle of bodies predominates moral values, or "the physicality of the wrestlers is their meaning." 182 Fiske describes a WWE wrestling match, in which Andre the Giant (before he turned his back to Hogan) was unfairly attacked by two villains:

The (apparently) broken sternum of Andre the Giant became an object of spectacle, divorced from the real social world of moral values and law, its meaning was its appearance as a swelling on the huge chest of Andre that the camera zoomed in on, as it did in the subsequent interview. ${ }^{183}$

Here, what Fiske sees in WWE wrestling in the 1980s is the dominance of excessive physicality over representation, surface appearance over deep meaning, signifier over signified. For him, Andre's huge body does not stand for any social significance or moral values, but only for itself. Thus, in his reading, the significance of wrestling's storylines, in particular, the morality play aspects of them, are almost ignored. Also, Fiske does not read any subjectivity or internal selfhood in Andre. For him, wrestlers are not human beings with modern subjectivity, but more

\footnotetext{
${ }^{181}$ Rock 'n' Wrestling is known among American fans as the title of a wrestling cartoon program features various WWE superstars. However, Fiske's text obviously deals with a program that features actual WWE wrestling performances.

${ }^{182}$ Fiske, Television Culture, 243-244.

${ }^{183}$ Ibid., 244.
} 
of characters, whose meanings are always externalized with extreme clarity.

Like Fiske's reading of WWE wrestling, The Unreal Story does not emphasize the morality play aspect of wrestling's fictional storylines. However, while Fiske almost ignores fictional moralist storylines for the sake of claiming the dominance of physicality, surface appearance, and signifier, The Unreal Story replaces fictional storylines with "nonfictional" ones. In other words, The Unreal Story adds "real" human meaning (signified) to the surface appearance (signifier) of wrestlers that Fiske highlights. The Unreal Story tells viewers that, behind hyperbolic characters, there are human beings that have subtle internal selves. ${ }^{184}$ The story the crash of two larger-than-life characters is re-presented as that of two human beings doing business with mutual respect. Andre as a jealous and arrogant monster is reestablished as the great old champion who selflessly and silently passed the torch to a new generation. Hulk Hogan as a simplistically righteous, fearless and courageous American hero is redefined as a nervous man who worried that Andre would double-cross and hurt him. He also presents himself in the interview segment of this program as a modest man who is forever grateful for the favor given by his senior.

Also, by presenting "arguments" about the human reality of wrestling, The Unreal Story attempts to exert an influence on viewers' mode of reading wrestling. It tells viewers that any wrestling match can be interpreted into two versions; a "fictional" version that makes people engage with an extremely simple world, and a "nonfictional" version that reflects the real-life production process of the wrestling match. Hence The Unreal Story induces viewers to interpret "fictional" drama also "nonfictionally"; it encourages viewers to find verisimilitude not only in

\footnotetext{
${ }^{184}$ The emphasis on inner subjectivity reflects the change in the postmodern aesthetic of WWE wrestling in the late 1990s. See chapter 3 for a detailed discussion.
} 
the absorbing fictional world of characters but also on the actual process of the production of the fictional world in this historical (real-life) world.

Another thing should be noted is that The Unreal Story, while establishing its truth claim by the admission of the scripted nature of professional wrestling, constructs a very televisual and mythic image of the professional wrestling industry as a spectacular entertainment business. It suggests that that Andre had legitimate fighting skills that the old wrestling legends such as Ed "Strangler" Lewis and Lou Thesz were supposed to have. That is, it alludes that contemporary WWE wrestling still inherits the legacy of past professional wrestling as legitimate contest, and even contains the possibility of legitimate fighting breaking out. While defining WWE wrestling as a manufactured entertainment, The Unreal Story once again attempts to incorporate the element of legitimate fighting into it to blur the boundary between the scripted and the nonscripted, seducing viewers to see through and find the real demarcation line. In other words, The Unreal Story at first destroys viewers' wish to find authenticity in wrestling by exposing wrestling's manufactured nature, and then recuperates their wishes by providing another form of authenticity. However, in the next moment, by showing that Andre stayed true to the pre-match agreement, the program makes sure that the wrestling business is big and respected enough to subdue such uncontrollable elements. The celebration of the wrestling industry in this program was reinforced by the abundance of dazzling images of spectacular wrestling events. Here, presenting itself as a nonfictional narrative not only helps The Unreal Story raise viewers' consciousness of events in the historical (real-life) world, but also gives the program power to mesmerize viewers with a new fantastic image of the professional wrestling industry. It tells viewers not only how to read the professional wrestling nonfictionally, but also how to respect and be mesmerized by the wrestling industry that have a real (yet spectacular and mythic) 
presence in the historical world.

\section{Have a Nice Day!: A Tale of Blood and Sweatsocks}

Have a Nice Day!: A Tale of Blood and Sweatsocks, the autobiography of Mick Foley, one of the top active WWE superstars at that time, exemplifies another significant moment of the official self-refashioning of professional wrestling via nonfictional narratives. After stating in the beginning of the book that he is not going to insult the intelligence of readers by portraying wrestling as a "real competitive sport" $" 185$ and that it is more of an entertainment, Foley offers personal and compelling accounts of his career from his experience in independent organizations, Japan, and "big leagues" such as the WCW and the WWE. Overall, this book gives one of the most detailed and comprehensive views of the inner-workings of the professional wrestling industry. It reached the No. 1 spot on the New York Times nonfiction best-seller lists. The success of this book influenced the wrestling industry in various ways. This book, which, according to Foley, was written by himself without the help of a ghostwriter, blew off the stereotypical perception that wrestlers cannot write and that wrestling fans do not read, and triggered off the rush of publishing professional wrestlers' autobiographies.

Like the episode of The Unreal Story described above, this book directs readers' attention to wrestlers as human beings who perform their in-ring characters. It encourages readers/viewers to incorporate wrestlers' (in particular, Foley's) life history into their viewing/reading of fictional wrestling matches and storylines that feature characters. ${ }^{186}$ Also, the publishing of this book was

\footnotetext{
${ }^{185}$ Foley, Have a Nice Day!, 3.
}

${ }^{186}$ Henry Jenkins IV, from a perspective of professional wrestling fan, states how this book influenced his mode of watching professional wrestling: "the vivid, step-by-step, behind-the-scenes account of Foley's career changed the way I saw the wrestling business (nine years into my relationship into it). Most of the in-ring performers took on secondary, offstage personas. When I watched RAW, I'd find myself more captivated by the implied real-life dynamics - rivalries between the actors, egotistical behavior, reputations being made or broken- 
immediately incorporated into fictional storylines between Foley and his rivals, and (supposedly) nonfictional contents of this book were often used to create other "fictional" feuds. ${ }^{187}$

Moreover, Have a Nice Day! attempts hard to redefine the image of wrestling spread among the general public. One of the points that Foley repeatedly stresses in this book is that professional wrestling, even though it is scripted entertainment, includes as much "real" elements as other "legitimate" sports do. Foley's numerous stories tell readers that wrestling contains "serious" and "respectable" values of legitimate sports, such as discipline of the body and mind, dedication, the development of skills, respect for internal codes and opponents' physical well being, and the assurance of each other's safety. Moreover, Foley's tales often indicate that, in its extremity, what he does in professional wrestling clearly surpasses what athletes of legitimate sports would do. In fact, Foley explicitly addresses this point in this book's opening story, which depicts the accident during his match against Vader in Germany in 1994. In this match, his right ear was torn apart after he performed a difficult move called the hangman. In order to perform this move, Foley dived into the ring ropes from the head, so that his heads were caught between second and third ropes, which were entangled with each other. Foley's descriptions of the move hangman and his account of how he dealt with the accident summarize his argument in this book:

This is a move known as the hangman because the end result is the illusion of a man being hanged by his neck while his body kicks and writhes in an attempt to get out. Although it is a planned maneuver, it is no illusion, as the man actually is hanging by his neck and the body really does kick and writhe in an attempt to get out. ${ }^{188}$

than by the televised feuds. I'd try to imagine the backroom deals and grow heated over the hirings and firings."( Henry Jenkins IV, "Afterword, Part II: Growing up and Growing More Risqué," in Steel Chair to the Head, ed. Nicholas Sammond, 331-332.

${ }^{187}$ The most famous one will be Foley vs. Rick Flair in 2006. Flair, in his autobiography published in 2004, countered Foley's criticism against him by calling him a glorified stuntman. In 2006, in WWE fictional storyline, Flair called Foley "glorified stuntman" again and initiated in-ring feud with Foley.

${ }^{188}$ Foley, Have a Nice Day!, 4. 
Also at this point, in any other event, a ripped-off ear would probably be cause for a time out. I mean, if Mark McGwire were beaned out at the plate, he probably wouldn't jog to first base with a missing body part. If Shaquille O'Neal drove the lane and came up an war shot of a pair, he probably wouldn't let go to the foul line with "juice" running down his tank top. But in our sport, the fake sport, we have a single rule- "the show must go on." And I went on as best I could. ${ }^{189}$

In the rest of the book, Foley tells various stories in which he put his body to the limit for the sake of entertainment. In another match with Vader, Foley decided to take his powerbomb, one of the most dangerous moves in professional wrestling, on the concrete floor against his boss's advise not to do it. As a result, his right limbs went numb and he ended up laying the concrete floor waiting for an ambulance. ${ }^{190}$ In the now-famous "Hell in the Cell" match with The Undertaker in 1998, Foley convinced his reluctant opponent, and let The Undertaker throw him from the roof of the 20 -foot-high cage to the announcers' table. ${ }^{191}$

The task that Foley's nonfictional narrative attempts to accomplish in those episodes is the inversion of values of professional wrestling as perceived by the general public. Wrestling is generally stigmatized as a "fake" sport, as the results of the matches are in fact predetermined and storylines scripted. Even scholars who see positive aspects in wrestling do rarely find respectable values of legitimate sports in it. Here, again, a comparison to Fiske's thoughtprovoking reading of Rock ' $n$ ' Wrestling, a WWE wrestling television program in the 1980s, is helpful to clarify the characteristic of Foley's efforts to honor his discipline.

As mentioned earlier, Fiske affirmatively (and rightfully) defines wrestling as a parody of sport, which, while taking the appearance of sports, mocks the serious and respectable values of

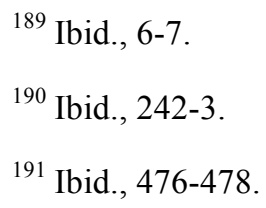


sports. "Rock ' $n$ ' Wrestling refuses 'fairness.' It is unfair. Nobody is given a 'sporting chance' and anyone who attempts to 'play fair' is taken advantage of and suffers as a result." "In sport, the loser is not humiliated or degraded, but in Rock ' $n$ ' Wrestling he is, excessively." ${ }^{, 192}$ In such parodic aspects of WWE wrestling, Fiske sees a liberating popular pleasure that would "evade, resist, or scandalize ideology and social control. ${ }^{, 193}$ That is, he finds alternative (anti-moralist) meaning in wrestling's fictional narratives.

Foley takes an entirely different path to claim the superiority of professional wrestling to sports. Instead of celebrating "mock" aspects of wrestling's fictional narrative, Foley brings wrestling to the same stage as legitimate sports and makes a comparison. That is, he explains what it "really" takes to perform strong professional wrestling matches and storylines. Foley powerfully asserts that, on the nonfictional level, the production of professional wrestling gets as intense and compelling (thus "real,") as legitimate sports, that it contains as much respectable values as legitimate sports, and that it even overcomes legitimate sports in its extremity, in its excessive fortitude to abuse one's own bodies in order to entertain the audience. Just like The Unreal Story, Have a Nice Day! at first takes away fans wish to believe in the authenticity in professional wrestling by admitting the scripted nature of his discipline, then provide another form of authenticity (which explicitly affirms masculine values) for fans to believe in. Both Fiske and Foley claim wrestling's advantage over sports. However, while Fiske primarily sees wrestling's advantage as parodic fiction, Foley argues that professional wrestling transgresses sports in their own game, in the mental and physical dedication in the real-life world. Foley's dedication and willingness to put his body on the line sometimes go too far and extreme, to the

\footnotetext{
${ }^{192}$ Fiske, Television Culture, 146.

${ }^{193}$ Ibid., 240.
} 
degree that the pursuit of "good" and "respectable" values of modern Western society turn into the abnormal and the transcendental. In this sense, Foley's nonfictional narrative, which is generally considered to be a faithful representation of his in-ring performance history, documents the process by which the quest for modern values exceeds the modern. Both Fiske and Foley's descriptions indicate that professional wrestling can be read as postmodern texts that overcome the modernity of sports. Yet they represent very different postmodern moments. Fiske's reading reflects postmodernism prevalent in the 1980 s that celebrates signifier over signified, and the parodic over the serious. In contrast, Foley's tales point to the postmodern as the limits of the pursuit of modernity. Also, while Fiske celebrates the collapse of "modern" belief in the authenticity of metanarratives, Foley's tales indicates the emergence of a more extreme form of substitutive authenticity after the collapse. The next chapter extensively examines the transformation of postmodern features in WWE wrestling beginning the late 1990s. Foley's extremely dangerous performance epitomizes the emergence of "obsession" as a new dominant postmodern aesthetic of contemporary WWE wrestling.

By giving many stories in which his willingness to risk his body exceeds that of normal athletes, Have a Nice Day! demands that readers who have made light of wrestling change their views and respect it. Paradoxically, Foley's nonfictional, that is, "realistic" narrative, brings his discipline, professional wrestling, to a dream place. Have a Nice Day! is a story of a man who has reached to his dream. Foley's memoir in this book begins with his childhood days when he dreamed to be wrestling superstar, and it ended right when he finally captured the WWE world championship. The place he finally reached actually exists, yet at the same time, it is almost impossible to reach without transgressing the limits of what normal human beings can do. Like The Unreal Story does, Have a Nice Day! constructs a mythical image of professional wrestling 
via its nonfictional narrative.

Another thing that should be noted in Have a Nice Day!'s influence on readers'/viewers' interpretation of professional wrestling is that this book offers a lot of accounts and criticisms of the production of the verisimilitude of wrestling matches as fiction. Foley tells the story of his huge mistake in one of his early matches, in which he (exaggeratedly) jumped and went down on the mat when his opponent's attack missed his by more than two feet. Foley and his opponent's misperformance broke the audience's willing suspension of disbelief and caused a burst of laugher from the audience. ${ }^{194} \mathrm{He}$ also regrets that the rapid character change from Cactus Jack to Mankind that he had to go through in the WWE in the 1996 ruined the credibility of his gimmicks and the believability of the ongoing storyline. ${ }^{195}$

Such accounts naturally induce readers to be more aware of the production process of realism (and its failure) in professional wrestling as fiction, and to evaluate the production process on the level of the historical (real-life) world. Foley's book provides very satisfying answers for those who want to see through what "really" happens behinds fictional narratives of wrestling. However, those answers haven't kept people from inquiring the backstage truth of wrestling. On the contrary, the disclosure of behind the scenes stories and the "truth" of the production of fictional narratives of wrestling has only accelerated fans' discussion. Now, there are numerous news sites and discussion boards on the Internet that follow the inside information regarding the "truth" behind the production of wrestling, and enthusiastically discuss what part of wrestling performance is scripted and what part is not. As we saw, fans' wish to "naively" believe in the authenticity of wrestling was entirely destroyed by the diffusion of the fact that

\footnotetext{
${ }^{194}$ Foley, Have a Nice Day! 93-94.

${ }^{195}$ Ibid., 474.
} 
wrestling matches were scripted. Now, they are aspired to find authenticity in their "savvy" mode of reading wrestling.

As discussed in the first section, professional wrestling used to stimulate and frustrate people's desire to peep, know and reveal, by hinting at and hiding its true nature. Now, as Have a Nice Day! does, wrestling discloses its "true" nature and is willing to share in detail what is "really" at stake in the backstage. By doing that, wrestling keeps on stimulating viewers' inexhaustible desire to see through "the real" behind the fictional performances. At the same time, viewers do not give up enjoying wrestling as fiction and attempt to immerse themselves in the fictional world to a certain degree. Hence Foley's account encourages viewers to vacillate between the fictional world (the realm in which unawareness dominates) and the nonfictional world (the realm in which awareness dominates) of wrestling, and thus exemplifies the dualization of realism in wrestling.

\section{"Nonfictional" Fiction}

Of course, there is no guarantee that those commercialized nonfictional narratives in professional wrestling are faithful representations of events in the historical (real-life) world. While Have a Nice Day! was praised by most wrestling writers and critics for its candor, The Unreal Story was criticized for a high degree of distortion and misrepresentation of the historical facts. In particular, writers of small-scale publications on professional wrestling suspect the behind-the-scenes episode of the Hogan-Andre match was a fiction. ${ }^{196}$ Dave Meltzer of Wrestling Observer Newsletter, one of the premier small-scale publications, after noting that several of his insider sources (which include people worked in the WWE at that time) state that

\footnotetext{
${ }^{196}$ Dave Meltzer, Wrestling Observer Newsletter, May 11, 1998, 8; The Phantom Of The Ring, "Unreal Stories," http://www.wrestlingperspective.com/UnrealVideo.html (accessed April 1, 2012).
} 
there was no doubt in Andre's willingness to lose the match, makes an ironical and hilarious comment on the program: "But hey, they admitted it was fake, so therefore, everything else must be accurate. ${ }^{, 197}$ Indeed, the admission of the scripted-nature of wrestling almost automatically makes a strong truth claim, in particular, when it comes out from people involved in the business. However, texts of small publications such as Meltzer's objectify and question the credibility of officially endorsed/produced nonfictional narratives. Those publications such as Wrestling Observer Newsletter frequently cover many issues that the official nonfictional texts of the WWE are not willing to tell—such as the abnormally high mortality rate of contemporary American professional wrestlers and various political motivations behind particular storyline directions - revealing that there are artificial processes of inclusion and exclusion in the construction of "nonfictional" reality by the WWE. Those publications also have created spaces in which enthusiasts scrutinize, evaluate, and criticize various professional wrestling products, questioning if there are any fakery or con. As I will discuss in detail later, the circulation of information taken from such publications via the Internet in the 1990s seem to be one of the major factors that motivated the WWE to aggressively produce and promote nonfictional narratives.

Whether faithful representations of facts or not, nonfictional narratives in professional wrestling have both instructive and constructive effects. By presenting arguments about the events in the historical world that has long been hidden, nonfictional narratives attempt to tell viewers how to interpret professional wrestling, how to find the "real" contexts and motivations behind the surface of fictional performance, how to find human beings behind the characters, and how to respect professional wrestlers. This is also the act of recuperating viewers' wish to find

\footnotetext{
${ }^{197}$ Dave, Meltzer. Wrestling Observer Newsletter, May 11, 1998, 8.
} 
authenticity in wrestling, the wish that was entirely destroyed by the admission of scripted nature of wrestling matched. By doing that, nonfictional narratives such as The Unreal Story and Have a Nice Day! ultimately try to construct the image of the professional wrestling industry and that of the WWE, as a place to be desired. This is a place where all the fantastic spectacles are made, a place where only the chosen ones could reach by repeatedly pushing their bodies to the limit. Nonfictional narratives enabled the WWE to more skillfully construct itself as an object of desire than previous philosophy of "protecting the business," and thus keep attracting viewers' attention and affection.

\section{Section 5}

\section{Nonfictional Narratives as a Channel of Political Discourse}

The apparatus for the promotion of nonfictional narratives is not limited to the media that are external to the usual fictional narratives. When needed, the WWE features nonfictional narratives in the weekly WWE television programs, which is the main domain of the presentation of fictional narratives. As stated, with the special tribute program to Owen Hart in 1999, the WWE initiated the tradition of presenting nonfictional editions of WWE weekly programming in special and extraordinary occasions. In such special editions, ongoing storylines were suspended, and wrestlers and in-ring performers addressed serious issues as human beings, removing their gimmicks.

The WWE eventually adopted this special nonfictional edition format to express overtly patriotic messages. On September 13th, 2001, as a response to a series of suicide attacks two days before, the WWE's SmackDown presented a special tribute version, in which wrestlers expressed sympathy for victims and their families, and stressed the need for the unity of the 
nation. (Some wrestlers even urged revenge on terrorists.) Beginning in 2003, the WWE has established the new yearly tradition of visiting the U.S. troops in Iraq or Afghanistan in Christmas, to say thank you to those who fight for our freedom. ${ }^{198}$ Once a year, in the special editions of Raw or SmackDown, both heroes and villains mingle with soldiers and appreciate them as true American heroes. Professional wrestlers, who used to be celebrated as mythical American heroes, now celebrate others as real American heroes. The WWE's Tribute to the Troops in 2008 broadcasted on NBC emphasized the friendship between Americans and Iraqi people who were grateful for liberation and democratizing of Iraq by the US forces, showing uncritical acceptance of claims by the Bust administration.

The presentation of nonfictional narratives in weekly television programs, which is primarily a terrain of fictional narratives, became an important site for WWE to make (sorts of) public announcements. In 2000s, nonfictional "public service" segments are more frequently inserted in the WWE's weekly programs. In those segments, the WWE superstars engage in various charity activities or receive honorable awards from various institutions. Needless to say, in such footage, wrestlers act in respectable manners, suspending their in-ring characters. The WWE began to use nonfictional narratives as platforms to announce its support for the U.S. policy and its public contribution to the general public as well as its fans.

\section{Division of Labor between Fictional and Nonfictional narratives}

Interestingly, the WWE's usage of nonfictional segments for the enhancement of its public image can be seen as a response to the change in fictional narratives of the WWE. During the 1980s and early 90s, the WWE, which had a "family entertainment" direction and targeted countries.

${ }^{198}$ In the Christmases of 2010 and 2011, the WWE visited domestic U.S. troops instead of those in foreign 
both kids and parents, encoded (or often clearly expressed) its support for the U.S. policy in the fictional storylines. ${ }^{199}$ In those days, one of the most popular presentations in WWE wrestling was the feud between American heroes vs. foreign villains. Hulk Hogan, the WWE's biggest American hero at that time, fought against various foreign menaces to defend America's honor and pride. His opponents included Nikolai Volkoff, a Russian who had a audacity to sing the Russian National anthem before every match, Iron Sheik, an Iranian who somehow became an Iraqi operative when the WWE staged its version of the First Gulf War, Sgt. Slaughter, a former American Marine who later betrayed the U.S. to join the Iraqi force, and Yokozuna, a Japanese sumo champion with a huge and corpulent body. ${ }^{200}$ The storylines almost always assured the final victory of the American heroes who embodied righteous justice and loyalty.

However, in the late 1990s, as the so-called Monday Night Wars with the WCW intensified, the WWE's fictional narratives went through drastic transformations. The "family entertainment" direction was changed to the so-called "Attitude" direction that largely targeted young adults, emphasizing obscenity, physical intensity, and the breaking of pre-existing consensus. The popularity of "Stone Cold" Steve Austin, a tough guy with a bad attitude exploded, as he began his feud against the evil-owner "Mr. McMahon." The good old storylines that offered viewers the opportunity to celebrate patriotism became one of many subsidiary narratives played by "mid-carders." The belief in the triumph of righteous justice and patriotism was replaced with the celebration of individualism that honored self-interest and the pleasure of transgression of preexisting moral codes. The intensified competition demanded fictional

\footnotetext{
${ }^{199}$ Sam Migliore analyzes the contents of WWE wrestling in the early 1990s and argues that the WWE makes political / moral commentaries through its storylines (Migliore, "Moral Commentary”).

${ }^{200}$ In reality, Yokozuna was a Samoan-American who never had a Sumo experience in Japan.
} 
narratives of the WWE be radicalized; they could not center around the old patriotic story that supported the U.S. policy and simply righteous values, anymore. At the same time, in this era of heightened competition, the WWE began to promote and diffuse nonfictional narratives.

Eventually, nonfictional narratives picked up the ball that fictional narratives dropped. They began to feature the WWE's claim for patriotism, its support for government's policy, and righteous public activities. To put it another way, the usage of two different types of narratives provided the WWE a new way of distributing content with contrasting ideological and political connotations; fictional narratives present radical, disloyal, and obscene contents, and nonfictional narratives claim the WWE's obedient and righteous nature, and its public values. ${ }^{201}$

In fact, the distribution of contrasting meanings and ideologies via two different forms of narrative was a very clever move of the WWE to position itself both culturally and politically. Several writers have pointed out that the WWE's products in the late 1990s contained irony that was convenient for the WWE to dodge criticism against it. ${ }^{202}$ That is, the WWE made it obvious that its products were manufactured and it did not even pretend to sell healthy and morally correct products. Hence the WWE could always respond to criticisms of the offensiveness of its products: "Hey, this is just a fake. Don't take it seriously." The presentation of patriotism, support for government's policy, and public contribution in nonfictional narratives has helped to reinforce this defensive logic of the WWE. Now the WWE can claim to the public that, while it may have produced offensive contents in the "fake" (fictional) mode of address, it has shown loyalty to the country and served the public good in the "real" (nonfictional) mode of address.

\footnotetext{
${ }^{201}$ Of course, this binary schema is a generalized one. One can always find the triumph of the righteous WWE wrestling's fictional narratives. However, it is undeniable that since the late 1990s, the WWE started to emphasize controversial and blasphemous contents to an unprecedented degree.

${ }^{202}$ Battema and Sewell, “Trading in Masculinity,” 261; Jenkins IV, “Afterword,” 325.
} 
The new dual structure of expressing messages and ideologies has enabled the WWE to take advantage of the assumed superiority of being "real" (nonfictional) over being "fake" (fictional). In other words, by using two different modes of discourse, the WWE has wisely (if not completely) divided the production of popular cultural commodity and political gesture, which were previously unified. In the 1980s and the early 1990s, politically conservative and morally righteous messages were encoded (or explicitly shown) in the cultural commodity (presentation of wrestling matches and storylines) of the WWE. After the late 1990s, the WWE came to be able to attract viewers with morally problematic and transgressive popular cultural products made of fictional narratives, while assuring its political appropriateness and public values via nonfictional narratives. The division of labor between fictional and nonfictional narratives enabled the WWE to adjust the balance between appearing to be controversial and to be rightminded. When controversial contents went too far in fictional narratives, the WWE could switch to nonfictional narratives to correct it. ${ }^{203}$ The tribute program to Owen Hart after his accidental death during the live broadcast — he died due to an equipment failure in his ring entrance stuntcan be considered a first instance of such adjustment in a large-scale.

\section{Populist Appeal}

The WWE's attempt to express righteous and patriotic values in nonfictional narratives was not only designed to dodge criticisms but also to gain fans' support. In fact, when the WWE features its public contributions or patriotic visits to U.S. troops in nonfictional narratives, it

${ }^{203}$ Of course, the WWE uses fictional narratives for such adjustment, too. In the late 2000s, in particular, after the shocking double murder suicide of WWE superstar Chris Benoit in June 2007, the WWE began to tone down various controversial elements in its fictional narratives. At the same time, the insertions of nonfictional narratives that announce the WWE's public activities are increasing. The WWE use both modes of narratives to enhance its public image now. 
tends to receive favorable reactions from fans. Also, as we saw, various nonfictional narratives told fans how to respect the WWE as the creator of fictional narratives. Hence, Vince McMahon, who has performed an evil and oppressive boss in the fantasy world, has received respect from fans on the real-life level for the very fact that he has created the fantasy. Jenkins IV describes fans of his generation who used to idolize Hulk Hogan in their childhood yet later became fascinated by McMahon who radicalized WWE wrestling: "The late adolescent Hulkamaniacs secretly worshipped McMahon because he gave them smut, but they booed his character for threatening to take it away."204

That is, the promotion and circulation of nonfictional narratives prepared the situation in which the WWE could gain two somewhat contradictory forms of real-life based respect from fans. On the one hand, fans respect the WWE for the fact that it actually produces a world of fantasy full of a "wrong" type of pleasure. Yet on the other hand, they appreciate the WWE when it announces that it actually does a "right" thing for the country and makes public contributions. The two forms of respect for the WWE coexist due to the fact that the former is about the production of "fictional" cultural commodities, and the later belongs to the terrain of making "real" political and social contributions. This dual form of respect suggests that the WWE, via the use of fictional and nonfictional narratives, has succeeded in appealing to a version of American populism, in which belief in patriotism and jingoism coexists with the celebration of a popular, lowbrow form of pleasure. However, the populist appeal that the WWE since the late 1990s has embodied seems to be distant from "progressive" populism that aimed at

\footnotetext{
${ }^{204}$ Jenkins IV, “Afterword,” 325.
} 
the empowerment of working people against those with privilege, power, and capital. ${ }^{205}$ The WWE's text since the late 1990s has embraced Vince McMahon, the real-life billionaire and his aggressive entrepreneurism via both fictional and nonfictional narratives, as much as it has celebrated bad guys such as "Stone Cold" Steve Austin, the rebellious redneck who always "beat the hell out of" McMahon. In this sense, as Battema and Sewell argue, the WWE since the late 1990s has had a strong affinity with what Thomas Frank refers to as "market populism," which celebrates various controversial and transgressive cultural commodities produced by economic elites and entrepreneurs in the belief that the market reflects people's will. ${ }^{206}$

The adoption of the nonfictional narratives offered the WWE opportunities to make public statements that it could not make before. Via the combinational usage of fictional and nonfictional narratives, the WWE is now able to balance the production of controversial contents and the appeal for its "righteous" activities (such as the support for the U.S. policy) more subtly and effectively than before. The dual usage of narratives has enabled the WWE to exert its own populist cultural politics, in which celebration and degradation of capitalism/entrepreneurism, the production of transgressive and controversial contents, righteous activities that serve the public good, and the embrace of patriotism all coexist.

\section{Section 6}

\section{Nonfictional Narratives as Repeatedly Appropriated Texts}

Before concluding the chapter, more detailed discussions of the origin of nonfictional

\footnotetext{
${ }^{205}$ In his thoughtful analysis of WWE wrestling in the early 1990s, Henry Jenkins argues that WWE's storylines appeal to progressive elements of the American populist tradition that dream the empowerment of economically disadvantaged male workers (Jenkins, "Never Trust a Snake," 69-72).

${ }^{206}$ Battema and Sewell, "Trading in Masculinity," 275-286.
} 
narratives of professional wrestling and the process in which these narratives became the official product of the WWE are in order. Such discussions allow to understand the diffusion of nonfictional narratives as a result of the complex interplay between fans and producers and to consider its unique implications.

Nonfictional narratives should not be considered the WWE's original concept. As a matter of fact, even before Vince McMahon admitted the scripted nature of his product in 1988, nonfictional discourses of professional wrestling were circulated among small numbers of "hardcore" fans. There were several "underground" small-scale publications that reported the inner workings of the business, taking the scripted nature of professional wrestling matches for granted. Dave Meltzer's Wrestling Observer Newsletter (started in 1982) and Wade Keller's Pro Wrestling Torch (started in 1987), both of which still continue their business, are the most famous examples of those publications. These publications somehow gained access to inside information (sometimes second and third hand one though), uncovered backstage news, and analyzed the wrestling business and performance, using insider jargons that were not supposed to go public. ${ }^{207}$ They also featured discussions of readers and information on trading rare wrestling tapes. Therefore these publications helped the formation of groups of enthusiasts who shared and exchanged unofficial views and interpretations of wrestling matches and storylines. In the 1980s, although many in the wrestling industry recognized the existence of such publications and some were even influenced by what was written in them, they refused to officially acknowledge the existence of those publications or called them "dirtsheets" or "shit-sheets.",208

\footnotetext{
${ }^{207}$ Many of those jargons, which are now very widely known, take the scripted nature of professional wrestling for granted. For example, "jobber" means a wrestler who loses the match to enhance the image the opponent. "Turn" means to change one's in-ring character from babyface (hero) to heel (villain), or vice versa.

${ }^{208}$ Foley, Have a Nice Day!, 114; Hart, Forward to Tributes II, viii.
} 
However, the situation began to change in the early 1990s, as several wrestlers and promoters began to open up and appear in such publications to tell inner workings of the business. In 1993, Jim Cornette, who was the promoter of Smokey Mountain Wrestling and made a joint deal with the WWE, took an interview with Pro Wrestling Torch. ${ }^{209}$ In this interview, which included a frank explanation of how promoters decided the winner and the loser of matches, he gave his reason for taking such interviews to reveal the previously concealed truth of the business:

It's (Pro Wrestling Torch) not dropped on people's doorstop. It's not broadcast over the airwaves. It goes to a couple thousand people across the country. It's like pornography. They don't deliver it to you unsolicited, you don't hand out free samples. You have to buy it. It goes to people who are going to hear this shit regardless of whether I say it or not, so I'd at least want them to know what the truth is....A lot of people would knock me for doing the interview or whatever, but protecting the business now can be done for the general population - and I believe it should be-but for your readers, they're going to hear this shit anyway. Sometimes, if you don't talk fairly openly about it, they're going to hear incorrect information and form a false opinion, so you might as well straighten the daggum [sic.] shit out. ${ }^{210}$

Here, Cornette acknowledged the fact the there were enthusiasts or readers of small-scale wrestling publications who tried to access behind-the-scenes information that the business did not want to expose, and recognized the need to respond to them by providing his honest insider accounts. This suggest that at that time unauthorized circulation of inside information and oppositional interpretation of wrestling by "dirt sheets" readers was changing his perception of how to protect his business, or how to control the circulation of discourses regarding the "truth" of wrestling. At the same time, however, in Cornette's mind, insiders should have responded to only a limited numbers of fans, and that inside information regarding the production of wrestling

\footnotetext{
${ }^{209}$ Jim Cornette, “Jim Cornette's Opinion on the Torch and Wrestling Press," interview by Wade Keller, Pro Wrestling Torch 243 (1993), 7-8.

${ }^{210}$ Ibid
} 
should have been kept from the majority of fans and non-fans. In an interview for the same publication in 1994, Eric Bischoff, who was in charge of the production of the WCW, in a somewhat contemptuous tone, acknowledged the raison d'etre of those publications, too. He stated that the publications at least "[kept] a very small segment of society which [was] made up of people obsessed with professional wrestling entertained, interested, up to date." ${ }^{211}$ Wrestling promoters came to allow or even promote the circulation of behind-the-scenes information at least among a "very small segment of society.",212

The state of affair progressed further in the late 1990s. As previously discussed, both the WWE and the WCW began to feature storylines that took the scripted nature of wrestling matches for granted in their national television programs. The WWE eventually promoted nonfictional narratives in various media outlets. Now, the former "unofficial" discourses, which circulated only among small amounts of fans through so-called "dirt" or "shit" publications, finally became the official discourse of the industry. ${ }^{213}$

${ }^{211}$ Eric Bischoff, "Eric Bischoff on ECW, Wrestling Media, WCW," interview by Wade Keller, Pro Wrestling Torch 278 (1994), 9.

212 Ibid.

${ }^{213}$ Presumably, the rapid diffusion of the Internet in the mid 1990s influenced the WWE and other organization's decision to produce and promote nonfictional narratives of professional wrestling. During that time, the Internet, the most famously RSPW (rec.sport.pro-wrestling) of Usenet newsgroups, provided platforms in which unofficial information, which was previously shared only among the readers of small-scale publications, was circulated in a much larger scale. Jenkins IV described how his discovery of the Internet and RSPW in the mid 1990s expanded his knowledge and views of professional wrestling (Jenkins IV, "Afterword," 320-321). As of today, the Internet is still a site where "beginner fans" are exposed to inside information and discourses on the inner working of professional wrestling for the first time. Dan Weisberg, who conducted a research of Internet wrestling fans of more recent era, argues that Internet fans have largely two conflicting opinions on their experience of participating in cyber wrestling community; while some fans pleasantly consider the Internet helped to enhance their knowledge of the inner workings of professional wrestling, there are others who lament that knowledge that they gained via the Internet took their pleasure of enjoying professional wrestling away. In both cases, it is assumed that the Internet is the place where fans are able to access information that wrestling organizations do not reveal in public (Dan Weisberg, "Wrestling with the Audience: Fan Culture on the Internet" [PhD diss., Northwestern University, 2005], 120-121). Internet has granted many fans, who are not "hardcore" enough to know small-scale wrestling publications such as Wrestling Observer Newsletter, access to "unofficial" truth about wrestling. It would not be unreasonable to assume that the increase of informed fans, possessors of knowledge that was not supposed to go 
Now, the "officialization" of nonfictional narratives by the WWE has interesting implications in terms of the theory of fan culture and the nature of professional wrestling. The activities and discourses of wrestling enthusiasts surrounding small-scale publications back in the 1980s were to be viewed as a version of what Henry Jenkins calls "textual poaching." $" 14$ This term refers to popular culture fans' activity of seizing mass culture or popular texts and "remaking them in their own image, forcing them to their needs and to gratify their desires,"215 going beyond (and sometimes against) producers' intensions. Likewise, readers and contributors of those wrestling publications, with the corporation of "squealers" inside, gained access to knowledge that the wrestling industry did not want to go public, and performed interpretations of wrestling matches and storylines that the producers attempted to prevent them from doing. From this perspective, the diffusion of nonfictional narratives by the WWE was considered the culture industry's attempt to incorporate fans' "poaching" activities into itself. In doing so, the industry aimed at regaining the control of "poached" texts and information.

However, the case of professional wrestling contained a twist that was not suggest in Jenkins' idea of textual poaching. Jenkins argues that textual poachers, for example, female fans who reinterpret and rewrite Star Trek as a form of feminist Romance, are largely stigmatized by mainstream media as problematic and weird due to their activities. In contrast, one of the main activities of readers of small-scale wrestling publications was quite legitimate by modern society's standard; they tried to gain the concealed truth behind the crooked entertainment of

public, helped the WWE to produce and promote such knowledge so that it could control and commercialize the truth about its own product. The diffusion of nonfictional narratives by the WWE was conditioned by a larger trend in American society, and change in the availability of information for fans.

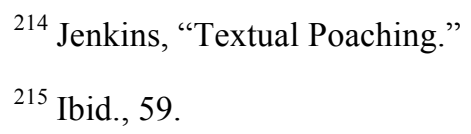


professional wrestling. In other words, while Star Trek fans poach the authentic original text and distort it, wrestling fans poached the dubious original text and attempted to give it (what society assumed to be) an authentic treatment and expose the concealed truth.

Nevertheless, just like Star Trek fans, readers of wrestling's small-scale publications never enjoyed a privileged status in society, because they after all remained to be avid fans of wrestling. Instead of searching for the truth of professional wrestling to denounce it, these fans undertook "authentic" truth-seeking activities in order to further enjoy the underhanded, lowbrow entertainment. In other words, these wrestling fans were poachers in two different senses. They poached the dubious text of professional wrestling and sought the truth against the intention of producers who wanted fans to be "dupes." At the same time, the fans poached the authentic method of truth seeking from the society they belonged to, and appropriated the method to further involve themselves in the devious culture of professional wrestling.

Therefore, the official sanction of nonfictional narratives by the WWE is to be viewed as the re-appropriation of the authentic method that readers of small-scale wrestling publications adopted in the 1980s. By officially producing nonfictional narratives of itself, the WWE is now able to claim that they are undertaking legitimate activities of offering the truth to anyone who seeks it. Through nonfictional narratives, the WWE also authenticates its controversial fictional narratives by emphasizing real discipline, respect, and pain involved in them, and it caters to informed fans' desire to have further access to the behind the scenes truth. Nevertheless, as we have seen, avid fans and small-scale publications have not lost their critical perspectives on the WWE and its nonfictional narratives and continue to point out the deceptive elements in these official nonfictional narratives. The diffusion of nonfictional narratives by the WWE in the late 1990s was the result of a series of textual poaching and appropriation of methods between fans 
and producers. The complex interplay between them still continues.

In this chapter, I have demonstrated that the promotion and production of nonfictional narratives are one of the most important (yet understudied) phenomenon in contemporary WWE wrestling. I have discussed the transformation in the realism of WWE wrestling brought by these nonfictional narratives and their significances. The next chapter deals with the larger trend behind the nonfictional turn in WWE wrestling: the development of postmodern features in WWE wrestling. It will be shown that the diffusion of nonfictional narratives by the WWE epitomized the transformation of postmodern aesthetics in the company during the late 1990s. 


\section{Chapter 3}

\section{The Modern, the Postmodern, and Obsession in Professional Wrestling}

\section{Introduction}

On March 28th, 2010, the final match of WrestleMania featured two of the most popular babyfaces (heroes, or "good guys"): Shawn Michaels and The Undertaker. Widely acknowledged as the best match of the year, ${ }^{216}$ this premier event prominently displayed the most appealing elements of contemporary WWE wrestling. The pre-match storyline focused on the unusual determination of Michaels, who lost an extremely competitive match against The Undertaker at previous years' WrestleMania, to have a rematch with the rival. When he failed to win the Royal Rumble (battle royal) match in January to gain the right to face The Undertaker again at WrestleMania, Michaels was utterly confused. Refusing to accept what had just happened, he knocked out the referees who were telling him to leave. For the following few weeks, the storyline repeatedly emphasized Michaels' "obsession" with the rematch. In February's showcase Elimination Chamber pay-per-view event, Michaels broke into the ring, attacked The Undertaker, and caused the rival to lose the match. The furious Undertaker agreed to the rematch with Michaels, on the condition that Michaels would retire if he lost again. Michaels accepted the deal without hesitation. The crowd wildly cheered, anticipating that the two superstars would perform another great match.

The rematch between the two at the 2010's WrestleMania became a gruesome battle.

Both of them executed their finishing moves against each other several times but still could not

${ }^{216}$ This match was selected as the best pro wrestling match of 2010 in Wrestling Observer Awards (Dave Meltzer, Wrestling Observer Newsletter. Jan. 31, 2011, 7). 
finish the rival. Finally, The Undertaker nailed Michaels' head with the tombstone piledriver, his most lethal finishing move, and attempted to pin Michaels' shoulders to the mat for the threecount. But Michaels "kicked out" (escaped) a moment before the referee counted three, taking the crowd to the peak of excitement. After expressing his disbelief and frustration, The Undertaker eventually regained his sprit, stood up, and went to finish Michaels who was still lying on the canvas. But then The Undertaker stopped and quietly stared at Michaels, who could barely move anymore. As Michaels, groaning in agony, desperately attempted to stand up, The Undertaker yelled at him to stay down without even bothering to lay hands on him. But Michaels refused to listen. Michaels rallied his last bit of strength, mimicked The Undertaker's signature "throat slashing" gesture, and slapped his face. Instantly infuriated, The Undertaker grabbed Michaels' body, lifted him up, and executed another, even more vicious tombstone piledriver. The Undertaker proceeded to cover the stunned Michaels' body and scored a three-count pinfall victory, forcing Michaels to retire. When The Undertaker helped Michaels up and hugged him, the crowd applauded and chanted "HBK! ("Heart Break Kid," Michael's nickname) and "Thank you Shawn!" in appreciation and celebration of his career.

Both the build-up and the finishing sequence of the match demonstrated the obsession that led to the exhaustion and self-destruction of wrestlers. The match also confirmed that such obsession was the most privileged state and a premier commodity in contemporary WWE wrestling. In the entire Michaels-Undertaker storyline, obsession was presented as the ultimate right that would transgress any other codes of conduct and values. Even after inflicting irrational violence to innocent referees and unfairly attacking The Undertaker from the back, Michael's status as a babyface was never threatened; his obsession for the rematch justified all his villainous acts. 
The match itself glorified obsessive men. Both wrestlers repeatedly expressed their abnormal (therefore obsessive) will to compete; they fought back after even suffering significant damage from the opponent's finishing moves. The crowd responded with enthusiastic cheers and roars often showing their appreciation by giving a "This is awesome!" chant. The final sequence of the match described the obsessed Michaels' self-destruction as the realization of ultimate justice and manliness in the ring. When The Undertaker hesitated to inflict further damage on him, Michaels refused his mercy and ultimately had the opponent destroy his body and end his career. The crowd showed the utmost respect and appreciation for the two's performance. In a very similar fashion to the ending of The Wrestler described in the introduction of this dissertation, the match glamorized and celebrated obsession, or an irrational urge to push one's body until it exhausted.

An equally important element that made this match stand out was the fact the narrative of this match revolved around a real-life event of significance: Michaels' retirement. This was not one of the fake "storyline" retirements abundant in professional wrestling. On the following night's episode of Raw, Michaels came into the ring and gave a farewell speech. In a sober, "offcharacter" tone, he ensured that he would never come back as a wrestler, implying that the retirement was his own decision prior to the match. Michaels emphasized that he had a wonderful time as a wrestler and thanked fans and colleagues. He also addressed to his family saying, "Daddy’s coming home."

This "serious" farewell speech told quite a different "real-life" story than the fictional storyline starring the obsessed Michaels. The fictional and real-life narratives certainly shared some historical contexts. For example, Michaels' fictional persona effectively incorporated the real-life fact that he had been performing extremely dangerous and exhausting matches for a long 
time and gone through numerous injuries. However, in the real-life story of the match, instead of entirely destroying himself in the ring, Michaels survived all the hardships and turmoil and came back home well. In this sense, as Bruce Mitchell of Pro Wrestling Torch argues, his final match against The Undertaker masterly fused two different stories into one. The ending of the match was not only the expression of Michaels' self-destructive obsession, but also the symbolic glorification of a real-life fact that Michaels "push[ed] his body through one last great performance, then [went] home on his own terms. ${ }^{, 217}$ From the later, real-life perspective, Michaels' last-ditch slap to The Undertaker was to be viewed as his explicit request to a longtime comrade to end his career and send him off to a normal life. At the level of fiction, Michaels was entirely engulfed by his own obsession to fight and exhausted himself. At the level of nonfiction, Michaels proudly left, exercising his autonomy to the brutality of the business. The match overlapped two contrasting narratives, presenting both as the ultimate objects of celebration and appreciation.

How can one understand the social and cultural implications of the dual, over-the-top aesthetic of the match? In this chapter I develop an approach that has rarely, if any, been used in the existing studies of professional wrestling. That is, I view contemporary WWE wrestling as well as the historical development of American professional wrestling as a "postmodern" phenomenon. I understand postmodern as an adjective that qualifies ideas and expressions that question, distrust, or subvert dominant assumptions, states of subjectivity, and promises upon which modern societies are built. However, the modern and the postmodern do not form a binary opposition. The postmodern is to be found in the extension of the modernization process, in particular, the full-fledged development and dominance of modern capitalism. The postmodern

${ }^{217}$ Bruce Mitchell, “WRESTLEMANIA 26 PPV Roundtable.” Pro Wrestling Torch 1140/1141 (2010), 8. 
also shares many common features with so-called postmodernism, which has often been considered to be "centered on the cultural elite - members of the 'creative' professions, including academics. ${ }^{218}$ However, as opposed to postmodernism as a highbrow movement, what I refer to as the postmodern here includes ideas and sensibilities found in more widespread cultural products that target popular masses or so-called "lowest common denominator" people, products such as professional wrestling. To approach wrestling as a postmodern phenomenon is to consider the ways in which wrestling represents its complex relation with normative values, subjectivities, and masculinities of modernity, while paying close attention to how wrestling addresses and reflects the nature and principle of capitalism to which it is subject.

This chapter demonstrates that a carefully developed modern-postmodern framework allows us to illuminate wrestling's unique and often extreme politics and aesthetics of presentation and performance. In particular, it attempts to consider professional wrestling through the theory of disciplinary power and the construction of modern disciplined subject developed by Michel Foucault. Then the chapter examines how wrestling (often critically) addresses problems that emerge when disciplinary power and the often-ferocious nature of capitalism conflict with each other, or are merged into one.

From this perspective, The Michaels-Undertaker match was to be viewed as a unique form of postmodern expression that addressed contradictions of wrestlers as modern disciplined subjects in two different (fictional and nonfictional) senses. First, the obsession and selfdestruction of Michaels in the fictional storyline pointed to the contradiction of wrestlers as modern disciplined competitors, who were conditioned by disciplinary power to constantly urge

\footnotetext{
218 John Fiske, "Postmodernism and Television," in Mass Media and Society, ed. James Curran and Michael Gurevitch (London, Edward Arnold, 1991), 64.
} 
themselves to keep competing. That is, Michaels' fate suggested that when a modern disciplined subject attempted to be absolutely loyal to his inner urges, he would eventually reach the breaking point. Second, the match also reflected the real-life plight of wrestlers as modern disciplined laborers, who were always urged to make themselves the most profitable commodities. The current enthusiasm for this type of over-the-top match indicated that, in order to produce as much profit as possible, wrestlers needed to (obsessively) perform extremely physically demanding matches and exploit their own bodies. As capitalist enterprises, the WWE had to be obedient to the brutal nature of capitalism and to endanger its wrester's bodies by featuring this type of match.

This match was also the WWE's clever, dual response to above problems. At the level of fiction, the WWE featured the pain of Michaels as an attractive commodity to garner profit; as we saw, Michaels' obsession and self-destruction was presented as the most valuable thing in the masculine world of the WWE, and fans ate the masculine aesthetic up. At the level of nonfiction, the WWE answered to the problem in an entirely different way. Through the glorious retirement ceremony of Michaels, the WWE claimed its autonomy against the ferociousness of contemporary capitalism. By sending him home well, the WWE declared that the company and wrestlers were not being swallowed up by the laws of capitalism. The Michaels-Undertaker match exemplified how the WWE illuminated and dealt with problems and contradictions concerning the brutal nature of capitalism, modern disciplined subject, obsession, and human bodies.

This chapter is comprised of three sections. The first section aims to construct theoretical frameworks to understand professional wrestling. I explore significant features of the modern and the postmodern in order to clarify their complex relations. Foucault's theory of disciplinary 
power and the production of modern disciplined subject occupies the central place in my exploration of features of the modern. After giving an overview of Foucault's theory, I examine how disciplinary power has exerted itself in the emergence and development of modern sport to construct the dominant ideal of modern sportsmen. I also argue how the construction of modern disciplined subject has become the origin of obsession as a major theme in contemporary popular culture. Foucault's theory is relevant to my understanding of the postmodern, too. After exploring major theories of the postmodern by Frederic Jameson and David Harvey, I argue that one of the major causes of the advent of the postmodern is the tension (inherent in modernity) between the disruptive nature of capitalism and disciplinary power. Here, the postmodern is grasped as a dynamic and ever-developing phenomenon, as opposed to a static binary opposite of the modern.

The main arguments of the chapter are developed in the second and third sections, where I use the concepts and perspectives acquired in the first section to explore American professional wrestling. The purpose of the second section is to contextualize the history of the development of American professional wrestling as a dynamic postmodern phenomenon. I argue that the seed of the postmodern was planted into professional wrestling at its birth around the turn of the twentieth century, as it parted ways with serious modern sports. I then pay attention to three key periods in the history of professional wrestling - the 1950s, the 1980s, and the late 1990swhere professional wrestling, or WWE wrestling in the case of the later two periods, successfully innovated its product to gain national popularity. I attempt to put into perspective various values, aesthetics and masculinities that wrestling has demonstrated during these periods. More specifically, my exploration revolves around the following four questions: (1) How has professional wrestling demonstrated multiple alternative forms of masculinity that would 
challenge the normative ideal of modern sportsmen? (2) How has professional wrestling expressed its ambivalent attitudes (criticism and conformity) towards modern ideologies and values? (3) How has professional wrestling increasingly developed and intensified so-called postmodern aesthetics and sensibilities in its presentation and performance? (4) How, since the 1980s, has WWE wrestling developed and illuminated its own serious issues - exhaustion of wrestlers' bodies and minds - as a result of the intensification of its postmodern aesthetics?

The fourth question leads us to the third section, which links directly to the MichaelsUndertaker match discussed in the beginning of this chapter. In the section, I examine obsessive states of mind and obsessive forms of presentation and performance that have been predominant in contemporary WWE wrestling since the late 1990s. I argue that, at multiple levels, expressions of obsession in WWE wrestling describe the critical situation of modern disciplined subjects that are exposed to intensified competition under current capitalism. The extraordinary performance of the "Mr. McMahon" character (played by the WWE owner Vince McMahon himself) will be extensively discussed as an example that closely reflects the predominance of obsession in the WWE. The Mr. McMahon character is to be viewed as the WWE's exposure of its own brutality as capitalist enterprises. Such a self-exposure rather attracts today's cynical consumers who support the reign of capitalism while recognizing its wicked nature.

In the same section, I also examine the significance of intense, painful, over-the-top matches that have become the most valuable commodity in contemporary WWE wrestling. I explore how these matches illuminate problems and contradictions of disciplined subjects, capitalism, and WWE wrestling, while glorifying the obsession and self-destruction of wrestlers. Over-the-top matches feature broken-down bodies and inner obsessive states of minds of wrestlers that were concealed behind glittering surface of hyper-masculinity in the 1980s and 
develop a new form of masculine aesthetic. These matches therefore call for an update of the existing theory of postmodern culture that stresses the predominance of surface appearance. The section ends with the examination of the sequel of the Michaels-Undertaker match at the following year's WrestleMania. In this match, the WWE renewed and intensified aesthetics, narratives, and critical views demonstrated in Michaels-Undertaker match and produced another compelling postmodern entertainment.

\section{Section 1}

\section{Framing the Modern and the Postmodern}

\section{The Dominant Ideologies of Modernity as Metanarratives}

As Jürgen Habermas argues, the ideological origin of Western modernization, or the "project of modernity" as he calls it, lies in the work of eighteenth century Enlightenment thinkers. They championed the idea of progress and brighter future, and pursued the development of intellectual spheres such as science, morality (law), and art. ${ }^{219}$ Enlightenment thinkers believed that the development and accumulation of knowledge in these areas would lead to the emancipation and prosperity of human race. The development of Western society has built upon the promise of and the belief in progress. Jean-François Lyotard argues that such dominant ideologies of modernity functions as "metanarratives." 220 Metanarratives give "legitimation" to any form of human activities and experience regarding knowledge and provide foundational and

${ }^{219}$ Jürgen Habermas, "Modernity: An Incomplete Project," in The Anti-aesthetic: Essays on Postmodern Culture, ed. Hal Foster (Washington: Bay Press, 1983), 9.

${ }^{220}$ Jean-François Lyotard, The Postmodern Condition: A Report on Knowledge, trans. Geoff Bennington and Brian Massumi (Minneapolis: University of Minnesota Press, 1984). Lyotard and Habermas oppose with each other regarding the contemporary significance of the project of modernity. However, there are no significant difference between their grasp of the ideology of modernity and modernization. 
comprehensive contexts, against which the meaning of experience can be validated. A major version of modern metanarratives assumes people as its heroes, whose acquisition of knowledge and enhanced well-being will lead them to progress towards a brighter future. The metanarrative legitimizes modern nation-states as institutional bases for the project of modernity. Nation-states as rationalized systems are supposed to provide substantial support for nations, the heroes, to walk the glorious and emancipatory path. ${ }^{221}$

\section{Construction of Modern Subjects through Discipline}

However, Michel Foucault reveals an entirely different picture of the modern people. In Discipline and Punish, he convincingly describes the process in which these people, the assumed masters of their own destiny, have become loyal and obedient subjects. ${ }^{222}$ Foucault argues that during the eighteenth and nineteenth centuries Western societies saw the development and diffusion of the method he calls "discipline" into all corners of society. Various institutions such as prisons, schools, hospitals, workshops, military institutions, and factories adopted the method and exerted disciplinary power on inmates to turn them into obedient subjects. To date, discipline has been the essential technology for Western states to produce loyal national subjects, although Foucault rather emphasizes the "bottom-up" nature of the disciplinary power that may be produced at the everyday spheres of people. ${ }^{223}$

In the exercise of disciplinary power, the discipline of bodies and that of minds are merged and complemented with each other. The discipline of bodies requires the extensive

${ }^{221}$ Lyotard, The Postmodern Condition, 31-32.

${ }^{222}$ Michel Foucault, Discipline and Punish: The Birth of the Prison, trans. Alan Sheridan (New York: Vintage Books, 1995).

$$
{ }^{223} \text { Ibid., } 138 .
$$


regulation of space and time. Inmates are hierarchically positioned within the closed architecture according to their levels, and given the timetable that regulates their activities to the minute. They are put into the organized training plan, which are designed to transform their bodies so that their movements and gestures are subject to detailed standards or norms. The standards are elaborately designed to make bodies as cogs of the wheels, to use them exhaustively, and to realize maximum productivity.

For the effective exercise of power, the bodily discipline needs to be accompanied by the discipline of minds. Foucault argues that the technology of surveillance played pivotal roles in disciplining inmates' minds, not only in exerting a moral influence in their behavior, but also in transforming their bodies into the most productive ones. The enclosed and minutely divided architecture of disciplinary institutions enables the systematic and consistent observation of inmates. ${ }^{224}$ Constant examinations also function as a form of surveillance; they monitor and numerically record inmates' progress. The most important point of the technology of surveillance is that, by objectifying inmates, it also "subjectifies" them. Surveillance forces inmates to develop the sense that they are always watched by the observer. That is, inmates internalize the gaze of the observer and all the coercions imposed on them, and voluntarily behave themselves. In Foucault's words, an individual "assumes responsibility for the constraints of power; he makes them play spontaneously upon himself; he inscribes in himself the power relation in which he simultaneously plays both roles; he becomes the principle of his own

\footnotetext{
${ }^{224}$ Foucault argues that Jeremy Bentham's Panopticon represents the ideal architectural model that enables the most effective surveillance. Panopticon is composed of an annular building for the prisoners at the periphery and the observatory tower at the center. The key of this architecture is the asymmetry of the gaze. While a watchman at the central tower is able to observe all of the inmates who are confined in cells in an annular building, he is invisible from the inmates.
} 
subjection." ${ }^{, 25}$ Through the internalization of external urges, individuals acquire subjectivity peculiar to the modern age, where an inner self-regulatory agency constantly urges himself or herself to be as moral and productive as possible.

It should be noted that, according to Foucault, discipline constitutes the dark side of the egalitarian juridical system that modern societies are built upon. The modern juridical system seems to protect rights of people and limit the power of economic and political authorities. However, the system was supported by discipline, a fundamentally non-egalitarian mechanism that regulates everyday, private spheres of people. While the law and contracts under the law in principle guarantee liberties, discipline confirms the "non-reversible subordination of one group of people by another." ${ }^{226}$ The coercion of disciplinary power often transgresses the law, ignoring contractual restrictions. In this sense, Foucault argues that discipline should be regarded as a “counter-law."

Foucault also stresses that disciplinary institutions are sites in which knowledge and truth on human beings are produced and used as a form of power. Discipline ranks, grades, evaluates, rewards and punishes inmates according to the results of examinations and observations. These collected records will be used to form and redefine knowledge on normality and abnormality of human beings. The redefined knowledge becomes renewed standards to judge inmates' progress and categorize and reposition them within disciplinary institutions. Inmates are stamped as "good," "bad," "normal," or "deviant" ones, and again hierarchically placed according to renewed standards. All of these ways of objectification give subjects the goals to attain and standards to meet. In order to receive praises, become tagged as normal, and pass the exam to

$$
\begin{aligned}
& { }^{225} \text { Ibid., 202-3. } \\
& { }^{226} \text { Ibid., 222-3. }
\end{aligned}
$$


proceed to the next level, individuals voluntarily and willingly attune their bodies to the standards, and become productive and moral. In this fashion, disciplinary power inscribes into inmates urges to compete against others, as "(r)ank in itself serves as a reward or punishment."227 Here, knowledge functions as a form of power that decides inmates' positions and statuses, and have them discipline themselves.

\section{Modern Sport as a Form of Disciplinary Power}

The emergence and development of sport competition is to be viewed as the example of the spread of modern disciplinary power in the West, although Foucault does not explicitly discuss the matter. During the eighteenth and nineteenth centuries, as the modern Western world took shape, unruly, and often violent physical contests of the Medieval and Renaissance eras (e.g., folk ball games and bare-handed fighting) were transformed into more organized and regulated forms of sport competition (e.g., soccer and boxing). These "modern" sports initially emerged in England and came to occupy the central part of the curriculums of public schools and universities, and then the central place in urban working class culture in England. Each of modern sports eventually spread across the border, developed national and international governing bodies. ${ }^{228}$

Modern sport is to be understood as a site where disciplinary power described by Foucault exercises itself. The rules of sport competition demand the competitors to transform their bodies into docile and the most effective ones. In order to gain the best results, competitors' bodies cannot be unruly and formless as those of participants of disorganized premodern games.

${ }^{227}$ Ibid., 181.

${ }^{228}$ Elias and Dunning, Quest for Excitement; Richard Holt, Sport and the British: A Modern History (Oxford: Clarendon Press, 1989); Neil Tranter, Sport, Economy, and Society in Britain 1750-1914 (Cambridge: Cambridge University Press, 1998). 
They need to master the most efficient bodily motions, while observing the rules all the time. Sports competition and training provide the ideal environment for the discipline of mind. In the enclosed field of which time and space are minutely regulated, the performance of players are always watched, recorded, and become comparable with each other. The comprehensive surveillance enforces the subjectification of competitors, who are compelled to be aware of being watched. Eventually, each competitor develops an inner self-regulatory agency that constantly urges himself/herself to make his/her bodies as efficient as possible.

As a form of disciplinary power, sport provided a crucial site for the construction of normality with regard to national character and masculinity. In the elite education of modern England, sport was considered a primary apparatus to produce brave and loyal Englishmen who had strong bodies, embodied high morals, and demonstrated excellent self-control. Here, sporting pupils were expected not only to make their bodies productive, but also to embody the gentlemanly ethos of fair play, that is, to always play in style and elegance, restraining themselves. ${ }^{229}$ The situation was not different in the U.S. during the mid nineteenth century, where sport was viewed both as an "adjunct to morality" and a "reflection of national character." ${ }^{230}$ Such loyal and disciplined sportsmen epitomized the "normal" form of masculinity. The nineteenth century educational discourses of Britain and the U.S. viewed sport as the most powerful way to direct "innocent vitality" of boys into proper channels. That is, sport was essential in preventing pupils from indulging in "deviant" activities such as homosexuality and masturbation, and promoting healthy and harmonious growth of strong body and pure

${ }^{229}$ Holt, Sport and the British, 98-101.

${ }^{230}$ Melvin L. Adelman, A Sporting Time: New York City and the Rise of Modern Athletics, 1820-70 (Urbana: University of Illinois Press, 1986), 277. 
heart. ${ }^{231}$ The virtue of sport lay in its assumed ability to produce disciplined men, who embodied the masculine ideal by being strong, loyal, moral, straight, and self-restraining.

\section{Discipline as the Origin of Obsession}

I also argue that the construction of modern disciplined subjects is to be considered the origin of obsession as one of the major themes in contemporary popular culture. Here, instead of adopting an academic or medical definition of the word "obsession," I follow a more common usage of the word in contemporary everyday language, such as the way the WWE used the word obsession to describe Shawn Michaels' mental condition when he demanded the rematch with The Undertaker. ${ }^{232}$ That is, I regard obsession as a state in which an individual has abnormally strong interest in someone or something, or holds unusually strong inner urges to perform certain actions or to accomplish certain tasks. It becomes serious and even irrational when the urges are so inflated that they keep the individual from conducting any other meaningful activities, just like in the Michaels' case. Such inner urges are the product of the construction of disciplined individuals discussed earlier. The modern disciplinary power, by transplanting various forms of societal coercion into internal agencies of individuals, have them develop inner urges to constantly behave in certain ways and accomplish certain tasks.

In his unique study of obsession as a culturally and medically constructed phenomenon, Lennard J. Davis demonstrates that the state of mind that we refer to as obsession has become a major issue to discuss, analyze, and cure beginning in the middle of the eighteenth century

${ }^{231}$ Holt Holt, Sport and the British, 91; Adelman, A Sporting Time, 283.

${ }^{232}$ One remark regarding the academic definition of the word is needed here. In psychiatry, distinction is usually made between obsession and compulsion. Obsession is mental state and compulsion is act. However, in this dissertation I do not find it necessary to make such a distinction, since this dissertation follows the everyday usage of the word obsession, or obsessive, which cover both mental state and the behaviors caused by the mental state (i.e. obsessive behaviors). 
France and England. ${ }^{233}$ Therefore he sees obsessive behavior as "a cultural problematic starting with modernity." ${ }^{234}$ Davis also notes Stanley J. Rachman and Ray J. Hodgson's description of an obsessive mind, which realizes that the idea comes from inside and does not want it to appear, yet cannot control it, is homologous to a state of modern self-regulatory subjects described by Foucault. Then he wonders "could we perhaps see obsession as the visible end of a regulatory mechanism gone wrong?"235 Although my usage of obsession is not entirely identical with Rachman and Hodgson's, I consider Davis' assumption is valid for the argument of this chapter. A disciplined individual self-regulates him or her by constantly urging himself or herself to behave in certain ways. The mechanism works well as long as the individual follows inner urges of his or her own, realizing that it is for his or her own good. It has "gone wrong" when the urges have become unusually great, and the individual lost ability to control it to the degree that he or she is not able to perform any other productive actions. In this case, the individual is obsessed. By producing self-regulating subjects who constantly urge themselves, modern disciplinary power prepares conditions that are necessary for individuals to have obsession.

\section{Capitalism and Creative Destruction}

In his reading of the work of Karl Marx, David Harvey illuminates another crucial element of modernity. ${ }^{236} \mathrm{He}$ argues that Marx's analysis vividly reveals the unruly nature of capitalist modernization, which constantly urges people to destroy preexisting habits. The

\footnotetext{
${ }^{233}$ Lennard J. Davis, Obsession: A History (Chicago: University of Chicago Press, 2008).

${ }^{234}$ Ibid., 13.

${ }^{235}$ Ibid., 14.

${ }^{236}$ David Harvey, The Condition of Postmodernity: An Enquiry into the Origins of Cultural Change
} (Cambridge: Blackwell, 1990), 99-112. 
“"coercive laws' of market competition, ${ }^{, 237}$ and the needs to keep the laborer under control force all capitalists to constantly pursue technological and organizational innovations to garner profits. Innovations inevitably lead to the incessant devaluations (or even destruction) of existing means of production, making instability a normal state of modern life for both capitalists and workers. The laws of competition also compel capitalist to open new product lines and advertise them to create new forms of desire in consumers. Furthermore, market competition urges capitalists to expand geographically to seek new markets, new material sources, and a more reasonable labor power. Such expansion inevitably spreads the instability of modern life to wider territories. ${ }^{238}$ Harvey summarizes that capitalism is "a social system internalizing rules that ensure it will remain a permanently revolutionary and disruptive force in its own world history, ${ }^{, 239}$ and a fundamental cause of the insecurity in modern life.

Capitalism has frequently worked in harmony with modern disciplinary power. Foucault states that the accumulation of capital in capitalist economy and the "accumulation of men" administered by disciplinary power are two inseparable processes, which complement with each other. ${ }^{240}$ Disciplinary power needs the innovation and growth of the capitalist production technology. The growth of capitalism relies on the disciplinary technology to produce docile and the most productive bodies. In other words, disciplinary power instills in individual capitalists and workers urges to constantly compete and to garner the maximum profits. Under the

\footnotetext{
${ }^{237}$ Ibid., 105.

${ }^{238}$ Ibid., 105-107.

${ }^{239}$ Ibid., 107.

${ }^{240}$ Foucault, Discipline and Punish, 220-221.
} 
intensified competition, the fusion between disciplinary power and capitalism can be a major motor for obsession.

However, due to its "permanently revolutionary and disruptive" nature, capitalism frequently upsets existing forms of disciplinary power, or systems and values that the disciplinary power has established. Capitalism constantly demands the creative destruction within and of existing disciplinary institutions. It urges for the change, expansion, and recreation of temporal and spatial orders that exiting disciplinary power has established and regulated. The instability of and tensions within disciplinary power brought by capitalism give individuals conflicts and insecurity. Disciplinary power primarily aims at constructing stable subjects that observe given moral values and attune their bodies to established standards. In contrast, capitalism urges subjects to cancel existing morals and bodily standards and recreate new ones to garner greater profits. Disciplinary power regulates the individual's desire by leading it to be expressed in a very stoic fashion. Capitalism, however, constantly attempts to create, diversify and multiply individual's desire to facilitate consumption. Modernity innately contains insecurity and tensions between capitalism and disciplinary power.

\section{The Ideas, Aesthetics, and Features of The Postmodern}

The relationship between the modern and the postmodern should not be viewed as a simple binary. The latter, while expressing a profound distrust of the foundational ideas and assumptions of the former, originates from the former. In what follows, I will clarify the complex relationship between the two, by describing the features of the postmodern as ideas, sensibilities, experiences, and expressions, and then by examining social and economic bases of their emergence. In doing so, I intend to turn the concepts of the postmodern into powerful tools to illuminate features of professional wrestling. 
In his book originally published in French in 1979 (translated into English in 1984), Lyotard gives a foundational idea of the postmodern. ${ }^{241}$ He defines "postmodern" as as the "incredulity" towards modern metanarratives discussed earlier. ${ }^{242}$ He observes that as knowledge has increasingly commodified as information, heroic metanarratives that used to give legitimation to activities regarding knowledge have eventually lost their credibility. Now, various forms of scientific knowledge can only be legitimized by how effectively it serves for the convenience of the system such as states and corporations. Although Lyotard's account primarily focused on knowledge, his schema of the decline of metanarratives was highly stretched after the publication of the book, and the adjective postmodern had come to indicate a more general sense of doubt and mistrust of various modern assumptions, which are heroic, emancipatory, and progressive. $^{243}$

Fredric Jameson provides more extensive descriptions of the postmodern, by exploring features of what he calls postmodernism. ${ }^{244}$ He defines postmodernism as a "dominant cultural logic" of late capitalist society. Adopting Ernest Mandel's theory, Jameson asserts that starting in the 1950 s, the advanced nations have gradually entered into a new stage of capitalism's development. $^{245}$ Finally, after the energy crisis of 1973 , the sphere of commodity production

${ }^{241}$ Lyotard, The Postmodern Condition.

${ }^{242}$ Ibid., xxiv.

${ }^{243}$ In fact, at that time, his schema was quite applicable to more general contexts. After witnessing the destruction through various wars, the outbreak of economic and ecological crises, and the rise of despotism, it had become hard for one to believe in the promise made by the emancipation by science, national progress or communism as alternative teleological narrative. Press, 1991).

${ }^{244}$ Fredric Jameson, Postmodernism, or, the Cultural Logic of Late Capitalism (Durham: Duke University

${ }^{245}$ The new stage is characterized by computerization and globalization, the emergence of new forms of multi/trans-national business organization, international division of labor, and financial systems, and the development of media that transgress the national borders. 
incorporated almost all forms of aesthetic practice into its logic, and postmodernism as a "cultural dominant" appeared. Therefore, although Jameson tends to take examples from socalled highbrow cultural products, his postmodernism encompasses all forms of commercialized culture, including popular culture. In fact, he argues that postmodernism is fundamentally populist and claims the dissolution of the older (modernist) distinction between high culture and mass culture. Postmodern expressions tend to contain offensive features, such as obscenity, sexual explicitness, cheapness, and social and political defiance.

Jameson further elaborates several major features of postmodern culture, all of which are useful to understand professional wrestling. First, postmodern culture embodies new types of depthlessness, or superficiality. For example, Andy Warhol's pop art works present flat surfaces of dead commodities, without allowing one to see any "deep truth" behind it. Jameson also suggests that depthlessness is associated with the decreased emphasis on modern subjectivity, which is assumed to be latent in a closed internal realm. ${ }^{246}$ Second, postmodernism signals the weakening of the sense of historicity. Postmodern cultural products demonstrate the abundance of arbitrary quotes of past images. Jameson distinguishes this postmodern pastiche of random past images from modernist parodic practice, which reflects more serious and critical intensions. Fragmented images of postmodern pastiche are considered as simulacra, copies that are disconnected from their original roots. Here the postmodern cultural commodities become pseudo-events or spectacles, which promote "addiction" to photographic images and sell nostalgia. The postmodern nostalgia is disparate from "historicity," or an organic genealogy imagined in the modern age. ${ }^{247}$ Third, the postmodern sense of historical disjunction and the loss

\footnotetext{
${ }^{246}$ Ibid., 6-9.

${ }^{247}$ Ibid., 16-25.
} 
of reality are compensated by more immediate experience of emotional intensities, "hallucinatory exhilaration," and a euphoric tone in postmodern cultural products and texts. As the centered subject of the modern age dissolves, the feelings expressed in postmodern culture have become more free-floating, vivid, intoxicating, celebrating spectacularity. ${ }^{248}$ Fourth, Jameson suggests that such intense experience of is also to be grasped as the "sublime," an experience of the unrepresentable or something that is "difficult for our minds and imaginations to grasp. ${ }^{, 249}$ In particular, the most powerful postmodern texts — such as cyber punk novelsallow us to gain a glimpse of the unimaginable second nature of the postmodern age: the decentered global network of late capitalism. Jameson calls such experience as the postmodern sublime. $^{250}$

Jameson's analysis summarized above provides very extensive and useful frameworks to view contemporary cultural products and their relationship with modern values, sensibilities, and subjectivities. I must add two points here. First, if one includes products that appeal to the socalled "lowest common denominator" people (such as wrestling fans) in postmodern culture, then Jameson's emphasis on postmodern pastiche over parody should be complemented by an alternative perspective. These "lowbrow" cultural products often contain vulgar and obscene elements that will challenge and offend those who expect highbrow qualities and serious values from cultural expressions. As popular culture scholars have indicated, these products often aggressively represent oppositional values to those of the dominant. ${ }^{251}$ When vulgar products

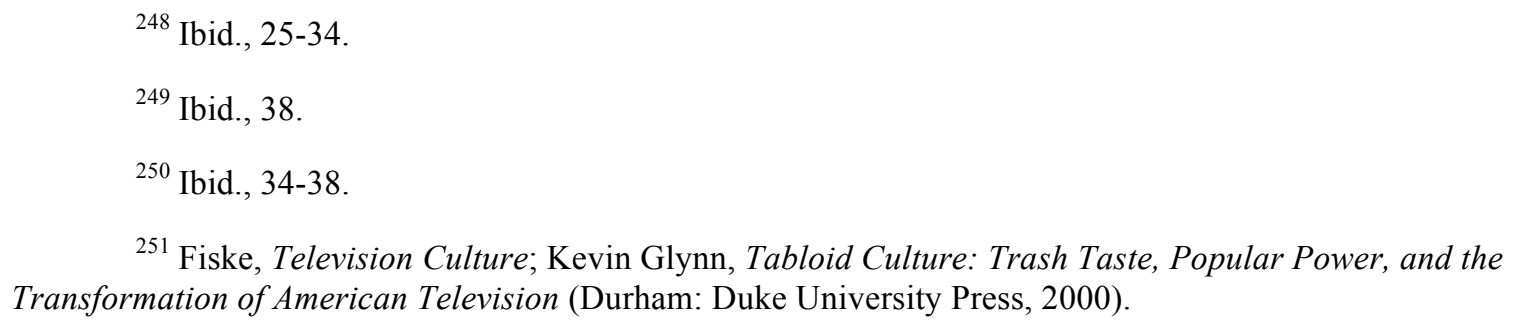
Transformation of American Television (Durham: Duke University Press, 2000). 
mimic and appropriate elements from authentic or highbrow culture, one should find in them parodic or critical views towards the authoritative. Along with random pastiche, parody is one of the important features of the postmodern.

Second, as a popular medium that ties closely to the capitalist market economy, television evinces many postmodern features listed by Jameson. As John Fiske points out, commercial television does not hesitate to contain offensive, vulgar, and exhilarate elements to attract the popular mass. ${ }^{252}$ The technological format of television images — a flat screen — has strong affinity with the postmodern predominance of spectacular surface appearances. Also, as a reproductive device of visual materials, television easily makes the collage of that past historical fragments and delivers to the household. Television's role in the formation of postmodern aesthetics should not be overlooked.

\section{The Social and Economic Origin of the Postmodern}

David Harvey provides an extensive discussion of an important issue that is suggested but not fully elaborated by Jameson: the relationship between the development of capitalist economy and the rise of the postmodern culture. ${ }^{253}$ His view will lead us to develop essential insights in understanding the advent and multi-staged development of postmodern aesthetic in professional wrestling. Harvey pays attention to the large-scale transition of the economic system in the 1970s. During that time, in many Western advanced countries and Japan, Fordist system of production, which had been dominant since 1945 was replaced by a more flexible, so-called post

\footnotetext{
${ }^{252}$ Fiske, Television Culture.

${ }^{253}$ Harvey, The Condition of Postmodernity, 121-259.
} 
Fordist system. According to Harvey, this transformation was a major cause of the emergence of many postmodern sensibilities and aesthetics.

Harvey argues that postwar Fordism was to be considered "less as a mere system of mass production and more as a total way of life. ${ }^{, 254}$ Fordism, while having workers engaged in the assembly-line mass production of standardized products, also encouraged the mass consumption; it paid workers enough wages to purchase the standardized products they produce, and give them enough time off to consume the products. In this sense, Fordism was a form of disciplinary power that successfully responded to capitalist demands. It not only standardized workers' bodies into cogs of the wheel to attain maximum productivity, but also produced them as mass standardized consumers who would homogeneously enjoy the products and come back to work satisfied.

Harvey stresses that Fordism was also an ideological construct. As a system that was depended on the heavy investment from governments, it embraced the power of strong states. It also closely tied to the aesthetic of postwar modernism. This version of modernism was distinct from previous ones in the sense that it was in good terms with corporate and state power that embraced "a corporate capitalist version of the Enlightenment project of development for progress and human emancipation. ${ }^{, 255}$ Fordism-modernism connection during the postwar period reinforced the resurgence of progressive Enlightenment thoughts, while celebrating the hegemony of powerful states.

However, since the late 1960s, advanced countries started to face problems in maintaining steady economic growth under the Fordist system. Harvey argues that in the crisis,

\footnotetext{
${ }^{254}$ Ibid., 135.

${ }^{255}$ Ibid., 35.
} 
modern capitalism's growth oriented, permanently revolutionary, and disruptive nature discussed earlier demanded a large-scale transition in the economic system. In order to compete against other newly emerged countries, advanced countries began to revolutionize its production system and expand. Governments gradually shifted to less interventionist policy and encouraged less regulated competition. More flexible employment led to the increase of part-time labor and short-term contracts. The transnational division of labor was also expanded. The rapid technological and organizational innovation allowed for the acceleration of turnover time, which enabled quick responses to the whims of the market and the production of variety of goods in small batches with less expense.

According to Harvey, this new flexible condition of production was closely related to the emergence of postmodern sensibilities and aesthetics. The new flexible employment led to the celebration of diverse ways of life. The needs to keep creating various types of desire for consumption enhanced the importance of commercial advertisements and the construction of images through media. The accelerated consumption cycle caused constant productions of events, which were consumed instantaneously. In Harvey's word; “The relatively stable aesthetic of Fordist modernism has given way to all the ferment, instability, and fleeting qualities of a postmodernist aesthetic that celebrate difference, ephemerality, spectacle, fashion, and the commodification of cultural forms." ${ }^{, 256}$ Remember that "Fordist modernism" embraced the resurgence of dominant ideologies of modernity. Postmodern sensibilities and aesthetics of the flexible regime represented a challenge against modern promises, values, and assumptions.

From Harvey's account, I derive several points that are essential in developing theoretical frameworks for our investigation of professional wrestling. First, Harvey's analysis suggests that

\footnotetext{
${ }^{256}$ Ibid., 156.
} 
the emergence of postmodern aesthetics or the entry into the so-called postmodern age in the 1970s was the result from tensions inherent in modernity discussed earlier: tensions between capitalism and disciplinary power. The formation of the flexible regime described by Harvey can be grasped as the process in which capitalism demanded the disruption of the Fordist system as a form of disciplinary power. As a result, in place of postwar modernism embraced by the Fordist regime, postmodern aesthetics emerged. Therefore, it is assumed that when capitalist competition has disruptive effects on disciplinary power, it also develops potential for the emergence of postmodern aesthetics and sensibilities.

This leads us to a second supposition. That is, if one of the major causes of the advent of the postmodern is in inherent tensions of modernity, then the postmodern is not necessarily to be viewed as a phenomenon emerged in the 1970s for the first time. Rather, the postmodern may be grasped as a dynamic and constantly developing phenomenon within modernity. Harvey in fact argues that "there is much more continuity than difference between the broad history of modernism and the movement called postmodernism."257 He also carefully covers how various modernist writers and artists had repeatedly expressed their skepticism towards the assumptions of Enlightenment. ${ }^{258}$ Lyotard's fundamental concept of the postmodern - the incredulity towards modern metanarratives — was a long time tradition within modernity.

\footnotetext{
${ }^{257}$ Ibid., 116.
}

${ }^{258}$ Harvey argues that after the international eruption of revolutions and the publication of The Communist Manifesto in 1848, faith in the promise of enlightenment has gradually decreased. Socialist movements and the tough going of class struggle questioned the belief in the benevolence of capitalism, and the ineluctability of progress shared by thinkers in the enlightenment tradition. Then, the violence and destruction during the two world wars suggested the failure of the Enlightenment project. Adorno and Horkheimer's Dialectic of Enlightenment discussed in chapter 1 was a fierce articulation of the incredulity towards the metanarratives of Enlightenment (Harvey, The Condition of Postmodernity, 13, 27-35). 
Therefore, the concept of postmodernity as a means of periodization, which indicates a social and cultural state since the late 1970s, should only be accepted with reservations. It is true that ideas and expressions that challenge modern ideologies and values have become widespread since the 1970s, and have come to be known as the postmodern, or postmodernism. However, this does not negate that what would later be called postmodern ideas and expressions existed before the 1970s and had more humble influence. The postmodern expressions that challenge against dominant ideologies and constructions of modernity are to be found in multiple phases and spaces even before the 1970s, taking varied forms.

Third, the continuity between modernism and postmodernism (suggested by Harvey) indicates that the latter inherits the former's self-reflexive and critical tradition. As Harvey points out, except the postwar version, various forms of modernism had constantly provided critical views against modernity from within. Then, postmodern sensibilities and aesthetics in the contemporary age should also contain critical views towards its own foundational principles, such as those of capitalism. This brings us to a contradiction within contemporary postmodern sensibilities; they include a growing awareness of negative features of culture under capitalism, while also embracing the commodification of culture.

The last formulation raises an obvious question: how does capitalism still maintain its dominance in the age when its own disturbing nature is exposed? In his study of reality television, Mark Andrejevic offers a convincing explanation. He argues that a version of what Slavoj Žižek called cynicism, which we discussed in chapter 1, functions as a strong ideological support of the capitalist rule. According to Andrejevic, cynical people well recognize the contrivance and injustice of the capitalist market economy, "Yes, it's true that powerful elites run the market according to their interests." Nevertheless, they give up seeking an alternative system, 
"but there's nothing to be done ... the hope that things could change is merely naïve idealism."259 People's skepticism towards capitalism only contributes to its continuing dominance.

Andrejevic further explains the relation between this savvy, but ultimately conformist attitude of consumers and the prosperity of popular culture products such as reality television. Like Jameson, Andrejevic suggests that in the postmodern age, as the sense of reality provided by the modern order has faded, the desire for surrogate, intense, and seemingly real experience has increased. Popular reality game-show programs successfully cater to the desire of savvy and cynical viewers. These programs feature unscripted and thus "real" interactions, conflicts and emotions among people in an obviously manufactured environment. Savvy viewers recognize the contrivance involved in these programs. Nevertheless, they continually watch programs to fulfill their desire for the surrogate experience of the real, and therefore support the current prevalence of capitalism and cultural production under it. Andrejevic observes that some reality programs even deliberately emphasize their own artifice and constructed-ness in order to satisfy the viewers' desire to see through the manufactured nature of the programs. ${ }^{260}$ The postmodern awareness of the deceptive and contrived nature of capitalism does not threaten the prosperity of capitalist culture.

He also notes that among current reality television programs there is a trend toward the display of more intense brutality and physical punishment. This tendency provides further support that contemporary viewers want "a bit of authenticity—of 'real' emotion,", 261 even if

\footnotetext{
${ }^{259}$ Andrejevic, Reality TV, 206.

${ }^{260}$ Ibid., 16, 133.

${ }^{261}$ Ibid., 207.
} 
such emotion has already been debunked as a manufactured product. Andrejevic's understanding of the increase of self-exposing, real, intense, and brutal content in popular culture is highly suggestive for our analysis of wrestling.

\section{Section 2}

\section{Professional Wrestling as a Postmodern Phenomenon}

\section{The Birth of Professional Wrestling: the Seed of the Postmodern Planted}

Although it is impossible to identify professional wrestling's exact date and place of birth, it seems appropriate to assume that professional wrestling as we know it took its shape as it gradually parted ways with legitimate sport contests during the late nineteenth to early twentieth centuries. Around the turn of the twentieth century, the boundary between professional wrestling and other fighting contests was not as clear as today. The practice of secretly pre-arranging match outcomes was prevalent not only in wrestling shows, but also in boxing shows. ${ }^{262}$ However, in boxing, as well as in amateur forms of wrestling, efforts were made to prohibit such dishonest practices under the supervision of centralized (national and international) governing bodies. Eventually, boxing and amateur wrestling established themselves as legitimate sports. In contrast, professional wrestling did not see the development of serious governing bodies. By the beginning of the 1920s, pre-arrangement of match outcomes became the standard practice of the business, the trait that defines professional wrestling as we know it.

The division into legitimate sport contests (boxing and Olympic wrestling) and a choreographed entertainment of professional wrestling can be grasped as the reflective of tensions inherent in modernity discussed earlier, tensions between disciplinary power and

\footnotetext{
${ }^{262}$ Beekman, Ringside, 25-27.
} 
capitalism. We have discussed that modern sport has been the embodiment of the method of discipline, or the site in which disciplinary power exercises itself to turn participants into selfregulating subjects with productive bodies. By establishing themselves as legitimate sports, boxing and an amateur form of wrestling assimilated into this form of disciplinary power. However, in the case of professional wrestling, laws of capitalist market competition prevented it from joining the disciplinary power in sport. Scott M. Beekman's summary of the process in which last attempts to have title matches in the form of legitimate contests finally died around the late 1910's attests to this point. He explains that these legitimate title matches, which often took several hours to end, "helped demonstrate that the public quickly tired of long, slow matches." 263 Therefore, to "survive as a economically viable operation, the sport fundamentally altered. No longer a legitimate sporting contest, wrestling became pure entertainment under the guise of an athletic endeavor., ${ }^{, 264}$ In short, in order to make the show more attractive, entertaining, and profitable than other legitimate sports, professional wrestling ignored the fundamental assumption of sport as a method of modern discipline: to hold honest, unscripted competitions. This also meant that professional wrestling abandoned a significant function of sport as discipline: to record legitimate results of athletes to contribute to the knowledge of human beings, knowledge that Enlightenment thinkers assumed to be the base of human progress.

This suggests that, a particular seed of the postmodern was planted into professional wrestling during its formation process. As discussed earlier, the disruption of disciplinary power by the force of capital is one of the major causes for the advent of postmodern aesthetics and

\footnotetext{
${ }^{263}$ Ibid., 52.

${ }^{264}$ Ibid.
} 
sensibilities. In the case of professional wrestling, the competitive nature of capitalism disrupted professional wrestling's formation into a modern sport, defining its alternative status. Of course, it did not mean that professional wrestling became immune to the formation of any type of disciplinary power. Capitalism would demand not only the disruption of, but also the recreation of disciplinary power. Responding to the laws of market, professional wrestling came to adopt a unique, alternative method of discipline, where wrestlers were required to make their bodies the most profitable commodities. In other words, by distinguishing itself from authentic sport as one of the dominant sites of disciplinary power, professional wrestling was born as an alternative site of discipline. Unlike sport, this alternative site of discipline would only give dubious results regarding the athletic performance of disciplined subjects.

Therefore, professional wrestling was destined at birth to develop and represent values, subjectivities, and masculinities that would challenge and de-naturalize those embodied by modern sport. At the same time, as an entertainment form that obeyed the competitive principle of modern capitalism and pretended to be a legitimate modern sport, professional wrestling would also include representations that would conform to dominant modern values. The ambivalence towards the modern would add unique elements to postmodern features of professional wrestling. In what follows, I examine how professional wrestling has enhanced and deepened its postmodern aesthetics at key periods in the history of its development. I also explore and compere how differently wrestling has expressed its ambivalence towards dominant values, subjectivities, and masculinities of the modern in each period. Doing so allows us to construct a new dynamic perspective towards the history of American professional wrestling while illuminating social and cultural implications of its performance and presentation.

Television and the Premature Emergence of the Postmodern in the 1950s 
During the 1920s and 1930s, the wrestling industry gradually developed various dramatics that could not be seen in serious sports contests. The unruly brawls, unnaturally spectacular moves, ballyhoos regarding wrestlers' identities, and the promotion of wrestlers with “freakish" features such as facial deformity and excessive obesity became prominent in wrestling. ${ }^{265}$ As a result, professional wrestling began to demonstrate values that would challenge those of legitimate sport, values such as violence, chaos, dubiousness, and disreputability. Despite promoters' efforts to arouse people's curiosity, however, the popularity of wrestling came to decrease in the mid 1930s. In the early 1940s, the industry suffered a wartime lack of wrestlers. It seemed that wrestling's best days were over. ${ }^{266}$

However, after the end of the World War II, wrestling had a fortunate, life-saving encounter with a burgeoning electronic medium: television. From the late 1940s to the mid 1950’s, professional wrestling enjoyed its success as a staple of prime-time network programing. When technologies were not ready for sports played at larger fields, wrestling, which needed only one fixed camera, provided networks with an excellent material for live broadcasting. Television not only was the driving force of the resurrection of wrestling, but also accelerated its transformation. In Beekman's words “A focus on the need to attract viewers and keep them interested led wrestling promoters to push their product into new, gaudier forms with

\footnotetext{
${ }^{265}$ One of the earliest account of the inside secret of professional wrestling suggests that the so-called Gold Dust Trio, one of the most powerful groups in the business during the early 1920s consisted of promoter Billy Sandow, and Wrestlers Ed "Strangler" Lewes and "Toots" Mondt, innovated wrestling from slow boring exhibition to popular, exciting spectacle. In Mondt's words, they combined the elements of boxing, wrestling and "the old time lumber camp style of fighting" and named it 'Slam Bang Western Style Wrestling.' That is, in order to attract audience, the trio reintroduced wrestling the unruliness and violence that modern sport had eliminated, while also incorporating the physical intensity of boxing. In doing so, professional wrestling gained spectacular elements that would be rarely seen legitimate wrestling contests (Griffin, Fall Guys).

${ }^{266}$ Beekman, Ringside, 79.
} 
increasingly stylized and uncontrollable mock violence. ${ }^{.267}$ Through the transformation, television wrestling came to evince what would later be called postmodern aesthetics.

Wrestler George Wagner, known in the ring as "Gorgeous George," epitomized the premature emergence of postmodern aesthetics in professional wrestling in those days. In fact, he was a pioneer who successfully linked the postmodern potential of professional wrestling and that of television, and became the largest draw in wrestling and a household name even among non-wrestling fans. George made wrestling a spectacle in which glittering surface appearances predominated, fitting to the flat television screen. Calling himself a "human orchid," George wore marcelled blond hair and donned a glitzy robe. He would walk towards the ring to the sounds of Pomp and Circumstance, following his valet who sprayed perfumes to disinfect his path, while responding to jeers from the outraged crowd. As he entered into the ring, George would refuse a mandatory pre-match body-checking by the referee, and have his valet remove his robe and hairnet.

His effeminate and excessively self-absorbed behavior was also an outright mockery of the ideal of a modern, disciplined sportsman. Instead of showing the virtue of internalized selfregulation expected by "real" men, George rather unleashed his narcissistic ego, externalizing it on glimmering, decorated surfaces. As Beekman points out, his appearance and behaviors were "calculated to enrage blue-collar fans by playing on the homophobic tendencies." ${ }^{\text {268 }}$ Also, in the actual wrestling performance, he showed neither the gentlemanly sprit of fair play nor values such as hard work and competitiveness that were embraced in the working class sporting culture. George attempted to cheat whenever he could. He would never accept the defeat, blaming others

$$
\begin{aligned}
& { }^{267} \text { Ibid., } 82 . \\
& { }^{268} \text { Ibid., } 87 .
\end{aligned}
$$


such as the referee or his valet.

It should be noted that George's transgressive behavior, which outraged a male audience who supported the ideal of a disciplined sportsman, also fascinated a new, unconventional wrestling audience. In his study of female wrestling fans in the postwar period, Chad Dell shows that during the early 1950s the number of females among wrestling fans increased both as the spectators of live shows and as television viewers. George was one of the major attractions for growing female fans. Dell points out that television play-by-play announcers at that time gave quite detailed descriptions of George's fashion using technical terms, such as he wore "simulated pockets with the preplum design" or his costume were "a permission red." ${ }^{, 69}$ Such instances, according to Dell, suggest that the producers assumed that the a high number of audiences was women who had a "sophisticated appreciation of color and design." ${ }^{270}$ Complemented by these descriptions, feminized and flamboyant attire of George became a spectacle on the black and white flat screen that targeted women in households.

Dell further argues that female wrestling fans during the late 1940s and the 1950s posed a challenge to the dominant and normative construction of gender roles in modern civilized society. He shows that various mainstream newspaper articles at that time alarmingly reported "strange" behaviors of females who did "flock" to wrestling matches to see wrestlers such as George. ${ }^{271}$ For mainstream media, which played significant roles in forming society’s dominant views, these women possessed the "active, physical, disruptive female body" 272 that would

\footnotetext{
${ }^{269}$ Chad Dell, "Researching Historical Broadcast Audiences: Female Fandom of Professional Wrestling, 1945-1960," (PhD diss., University of Wisconsin-Madison. 1997), 118-120.

${ }^{270}$ Ibid., 119.

${ }^{271}$ Ibid., 153-4.

${ }^{272}$ Ibid., 429.
} 
threaten the dominant concept of femininity in modern society. George was a major catalyst for women's transgressive, order-threatening behavior.

Here, the production and consumption of Gorgeous George through television and live shows exemplified one of our formulations made earlier: the disruptive nature of capitalism would cause the emergence of "postmodern" aesthetics and sensibilities that challenged existing values and orders. The laws of market competition called for the emergence of a transgressive figure such as George, who would not only enrage traditional male wrestling fans, but also attract females via television screens in households. These new female wrestling fans emerged as a disruptive force to the existing, dominant gender order of modernity. George was to be viewed as a historical precedent for introducing postmodern aesthetics in professional wrestling, making full use of the television's radical potential as an ever-popular media outlet.

However, the success of gimmick wrestlers such as George did not mean that professional wrestling at that time entirely ceased to support serious values of modern sport. In fact, the wrestling industry presented the matches as legitimate contests, and embraced the values and discipline of modern sport as its core. Lou Thesz, the most dominant champion in the business during the late 1940s and the 1950s, most compellingly demonstrated the claimed authenticity of professional wrestling. Thesz's was considered to be unparalleled among his contemporaries in terms of his actual competitive wrestling ability. Although he understood that professional wrestling was a form of staged performance, for him, to build the credibility and authenticity of professional wrestling was cardinal in keep attracting fans. ${ }^{273}$ Thesz believed that

\footnotetext{
273 Thesz acknowledges that matches between him and Verne Gagne, a former Olympic wrestler, were the prime example of best wrestling matches. In their matches, "there was a personal competitiveness and pride there , too, unrelated to money or personality, and the fans could see it in our matches" (Lou Thesz and Kit Bauman, Hooker: An Authentic Wrestler's Adventures Inside the Bizarre World of Professional Wrestling, ed. by Mike Chapman [Seattle: Wrestling Channel Press, 2000], 125).
} 
the essence of his profession lay in authentic wrestling skills. ${ }^{274} \mathrm{He}$ would appear in the ring with a simple costume: a black robe, black trunks, black wrestling shoes and a white towel. Then he would perform his "scientific" or "straight" clean-cut style of wrestling. He was in fact well received by the fans. His popularity, due to the authenticity he transmitted, helped the promoters' decision to keep him as their world champion for a long period. ${ }^{275}$ Thesz was often depicted as a disciplined sportsman who would eliminate farcical gimmick wrestlers. And he indeed dominated them in the matches. ${ }^{276}$

Professional wrestling at that time prominently featured two contrasting types of character. It embraced gimmick wrestlers like George who would mock and challenge values and masculinity that authentic sport represented. At the same time, the industry held champions like Thesz, who represented authenticity, discipline, and the dominant form of masculinity in modern sport. The industry even thematized the tension between the two types of character by staging the Thesz's "one man crusade to reform wrestling." 277 By symbolically reenacting the tension between the construction of modern disciplinary power (authentic sportsman) and capitalism's disruptive nature (gimmicked wrestlers that mocked modern dominant values) in its fictional narrative, professional wrestling at that time demonstrated its ambivalence towards modern

\footnotetext{
${ }^{274}$ According to him, the key to perform successful wrestling matches is to "learn all the amateur wrestling you could get anyone to teach you, and then execute the moves with imagination and enthusiasm" (Thesz and Bauman, Hooker, 10).

${ }^{275}$ Another important reason for the promoters' decision lay in his legitimate wrestling skills itself. The promoters thought that Thesz could prevent the possible "double-cross" in the ring. That is, against Thesz, no challenger would try to legitimately beat him during the match to steal the title.

276 For example, a 1952 Los Angels times article, which was published on a day before a big title match between Thesz and Baron Leone, features him as an authentic and disciplined wrestler who is on "his one man crusade to reform wrestling" to end the "age of gimmicks" (Hoffman, Jeane. "Thesz Sez Age of Gimmicks in Wrestling will Soon be Over." Los Angels Times [1923-Current File], May 20, 1952, C3, http://search.proquest.com/docview/166298048? accountid=10141.)

$$
{ }^{277} \text { Hoffman, “Thesz Sez." }
$$
}


values.

Wrestling's highly successful ride with network television proved short-lived. Due to several reasons, such as overexposure and the emergence of competing programs, professional wrestling was dropped from networks' prime-time lineups. Receiving no favored treatments from mainstream newspapers and magazines, wrestling once again went back to "the fringes of popular culture. ${ }^{278}$ Nevertheless, this entertainment form found its way to survive as a localized phenomenon. Local network affiliates found wrestling as one of inexpensive and useful contents to fill airtimes. Regional promoters would use such local wrestling television programs as advertisements for their upcoming live shows in the region. Until the 1980s wrestling survived in various "territories" of promoters across the country.

The 1980s: Full-Fledged Efflorescence of the Postmodern Aesthetic in the WWE

In the 1980s, with the rise of the WWE due to the business acumen of the owner Vince McMahon, professional wrestling once again became a national phenomenon. In 1983, McMahon brought the company, which had enjoyed its success in the Northwest area, from his father. Then he proceeded to change not only the infrastructure of, but also the images and ideas of American professional wrestling. WWE wrestling became a full-fledged postmodern spectacle during that period.

In fact, like the revival of wrestling in the 1950s, the process in which the WWE established its dominance in the industry epitomized the disruptive nature of capitalism. The WWE undermined existing conventions and assumptions of professional wrestling on multiple levels to accumulate its capital. McMahon overtly broke the tacit non-aggression pact that had

\footnotetext{
${ }^{278}$ Beekman, Ringside, 95.
} 
been formed among regional wrestling promoters across the country. In invading other promoters' territories and reaching a wider audience, he devised new ways to present wrestling. The most important key was the use of television, like in the 1950s. Taking advantage of an affluent fund, McMahon had many local stations switch from regional wrestling programs to videotaped products of the WWE. He also aggressively utilized emerging television outlets such as cable and pay-per-view to gain the national viewership. Also, reflecting the transformation into the flexible mode of production since the 1970s discussed earlier, the WWE began to produce multiple forms of wrestling products, using various media platform. The company featured its wrestlers in television shows of other genres, movies, music videos, and video games, and proceeded to create its own versions of them. It also expanded merchandizes such as toys, pajamas, ice-cream bars, and training goods, using its wrestlers' images. The WWE eventually drove many local promotions into out of business, and permanently destroyed the socalled territorial system of North American wrestling that had last for decades.

The change in the mode of production was accompanied with the revolution of aesthetic features of the products. The WWE greatly reduced the dark image of professional wrestling as a violent entertainment form on the fringes of society and turned it into glittering, euphoric, popular spectacle geared for a more general and family audience. WWE television shows recreated what Gorgeous George did in a small, black-and-white television screen with a much more enhanced audio and full color visual effects. The WWE tied up with MTV, the thenemerging music channel and created the "rock'n wrestling connection." Popular singer Cindy Lauper became involved in a WWE wrestling storyline, which culminated in the special live wrestling program featured on MTV. Eventually, all of the star WWE wrestlers would enter into the ring, wearing flashy costumes accompanied by pyrotechnics and original entrance music to 
make WWE shows "as much as Rock concert as wrestling show."279 The WWE also had many other popular celebrities involved in its obviously scripted storylines to garner mainstream media attention and expand its viewership. Beekman also points out that the WWE "broke completely with wrestling tradition and turned on the house lights during shows" in order to excite the live crowd, who were holding placards and wearing WWE merchandise, and to make them part of the spectacle. In this way, the WWE "broke out of the wrestling ghetto and into mainstream popular culture." 280

The creation of WrestleMania, the company's annual mega event started in 1985, epitomized the total spectacualization and the efflorescence of postmodern aesthetics and sensibilities in the WWE. The first WrestleMania attracted nineteen thousands fans in Madison Squared Garden. It was also viewed live by more than one million people in theaters and other venues across the country to become the largest closed-circuit television event in the U.S. at the time. The event was a self-celebration of the commercialized form of American popular culture, featuring various past and present figures of the entertainment business. The final match presented a popular television actor Mr. T teaming up with Hulk Hogan, the company's top babyface, taking on the heel duo of Roddy Piper and Paul Orndorf. The match also featured the former world heavyweight champion boxer Muhammad Ali as a special referee, who knocked Piper out with the fist to ensure the babyface teams victory.

During the broadcast of the event, announcer (future Minnesota Governor) Jesse Ventura said, "WrestleMania is making history!"281 This phrase, despite (in fact because of) its usage of

\footnotetext{
${ }^{279}$ Feigenbaum, "Liminal Experience," 73.

${ }^{280}$ Beekman, Ringside, 125.

${ }^{281}$ Shaun Assael and Mike Mooneyham, Sex, Lies, and Headlocks: The Real Story of Vince McMahon and the World Wrestling Federation (New York: Crown Publishers, 2002), 54.
} 
the word "history," exemplified the waning of the sense of historicity in professional wrestling. Before the rise of the WWE, a championship belt carried the sense of historicity and authenticity by claiming its lineage from the past. ${ }^{282}$ However, in the new postmodern worldview of WWE WrestleMania, history was disconnected from the past. It was to be recreated by artificial entertainment extravaganzas of present and future. ${ }^{283}$

Hulk Hogan, the most popular superstar and the dominant champion of the WWE in the 1980s, exemplified the transformation of values demonstrated in wrestling. In a sense, Hogan inherited traditions from both Lou Thesz and Gorgeous George and intensified them. ${ }^{284}$ He was a dominant and babyface champion like Thesz. However, unlike Thesz, who was the embodiment of the ideal masculinity of modern sportsmen, Hogan was excessively masculine. His hypermasculinity contrasted strongly with the effeminate character of George. However, Hogan was also an heir of George in the sense that he refused to demonstrate "inner" disciplined state of subjectivity, and externalized his excessive character in glittering surface appearances. Being 6'8', 275lbs, and equipped with bulging muscles and a tanned skin, Hogan looked more like a body-builder than an athlete. He was always super elated, run his catch phrases in a hyperactive tone, and frequently flexed his muscles while roaring. In the ring, his main offensive weapons are big punches and kicks as opposed to scientific wrestling techniques exhibited by past

\footnotetext{
${ }^{282}$ For example, during the 1950s, the authenticity of Thesz's NWA championship emerged from the fact that its lineage could be traced from the beginning of the 20th century, where some of championship matches were allegedly legitimate contests.

${ }^{283}$ In fact, recent years, the WWE advertise every WrestleMania as the place where history will be recreated and become memory for the future.

${ }^{284}$ It should also be noted that before the emergence of Hogan, the WWE had champions such as Bruno Sammartino and "Superstar" Billy Graham. Both of them are considered precedents of Hogan in the sense that they had big, impressive physiques and relied on their strength to defeat the opponent. Sammartino's character was as righteous and honest as Thesz's. Graham, a heel champion, was as flamboyant as George. Hogan's character can be considered the fusion of these two former WWE champions, both of whom inherited significant features from the superstars of the 1950s, Thesz and George.
} 
champions such as Thesz. During the matches, Hogan would shake his head and flex his muscles to fight off any attacks from the opponent. After the matches, which he almost always won, he would once again showed his muscles off for several minutes, ecstatically speaking to the crowd. Hogan demonstrated his hyper-masculinity in every aspect of his excessive presence.

I view Hogan's hyper-masculine character as the sign of wrestling's first major response to the transformation of capitalist culture since the 1970s. When a more flexible mode of cultural production enhanced the desire for more glittering spectacle than the past, the WWE created a more spectacular hero who would utterly out-muscle the modern masculine ideal, embodying the intensified state of competition. In this sense, Hogan exemplified capitalism's ability to destabilize and disrupt norms established by modern disciplinary power. Now, hyper-masculinity replaced a more orthodox, disciplined form of masculinity to become the dominant norm in the world of wrestling.

Hogan also exemplified new ways in which wrestling expressed its ambivalence towards dominant modern values, subjectivities, and masculinities. As a dominant hero of American family entertainment, Hogan surely embraced the virtues of dominant modern values. His character was the biggest advocate of the development of healthy and strong bodies, one of the fundamental claims of sport as a form of modern discipline; he repeatedly encouraged his young fans, who he called "little Hulkamaniacs" to exercise well, eat right, and take vitamins, selling them merchandizes of his brand such as training kits and nutrition foods. Also, Hogan was downrightly patriotic; he would enter into the ring to the strains of Real American, of which lyric claimed that he was a real American who would "fight for the rights of every man." Hogan's triumph undoubtedly captured emotions of Americans at that time. As Aaron Feigenbaum points 
out, at a time when America was recovering from the slump of the early 1980s, Hogan's victory

over foreign villains "provided a measure retribution that had been missing in the real world.",285

At the same time, Hogan's excessiveness, or the exaggerated nature of his performance, made him deviate from the ideal of modern disciplined masculinity, adding ambivalence to values he embodied. As explained in our discussion of Roland Barthes' work in the introduction of this dissertation, excessiveness and exaggeration render wrestling a self-referential nature, suggesting to viewers that what they are watching is unnatural and thus constructed. In the case of Hogan, his hyper-masculinity inevitably de-naturalized modern and masculine virtues he represented. Therefore, it is also possible to read Hogan as the mockery of the modern dominant values and masculinity. This argument can be applied to the entire tone WWE wrestling during the 1980s, and therefore supports John Fiske's analysis of WWE wrestling in the late 1980s discussed in introduction and chapter 2. As Fiske argues, WWE wrestling at that time was a fascinating parody of sport, which mocked various sporting values while taking the form of sport.

WWE wrestling in the 1980s expressed the ambivalence towards dominant modern values in a different way than in the 1950s, where wrestling prominently featured two contrasting types of character. Now the ambivalence was expressed in the gap between the content and form of presentation. ${ }^{286}$ At the level of content, or ideological signification, the WWE championed the virtues of modern values, while at the level of form, the WWE de-

${ }^{285}$ Feigenbaum, “Liminal Experience," 74.

${ }^{286}$ Here, like in chapter 1, I am influenced by Henry Krips' (2007) discussion of Adorno's theory of ideology (Krips, “A Mass Media Cure for Auschwitz”). 
naturalized modern values and ideals. We will see later that during the late 1990's the WWE came up with yet another way to express the ambivalence.

Another thing to be noted regarding WWE wrestling during the 1980s is that at that time the company was developing its own serious contradiction, which was homologous to the contradiction of postmodern cityscapes that Jameson pointed out. He argued that while shimmering surface appearances of urban postmodern architecture gave an exhilarating impression, "their essential content — the city itself [had] deteriorated or disintegrated." ${ }^{\text {"287 }}$ The WWE at that time suffered a similar issue, where the dark and hideous reality was in progress behind the surface of a fantastic and euphoric postmodern spectacle. That is, the efflorescence of postmodern aesthetics and hyper-masculinization led wrestlers to choose to inflict significant damage on their bodies and minds. During that period, many wrestlers abused illegal substances and recreational drugs to sustain their bodies as valuable commodities. In doing so, they wore their bodies and minds out while being superstars.

The issue can be understood as a problem of professional wrestling as a unique form of profit-seeking disciplinary institution under capitalism. Wrestling organizations needed to produce wrestlers as disciplined laborers who would constantly urge themselves to make their own bodies as profitable commodities as possible. To be profitable products under the intensified competition of the $1980 \mathrm{~s}$, wrestlers were compelled to urge themselves to create and maintain abnormally masculine physiques, to keep performing damaging matches, and to meet severe schedules on the road. However, in order to follow these inner urges as disciplined laborers, wrestlers needed to abuse and exploit their own bodies and minds, often by resorting to illegal substances. In this sense, the wearing down of wrestlers attested to the nature of discipline as a

\footnotetext{
${ }^{287}$ Jameson, Postmodernism, 33.
} 
"counter-law" discussed by Foucault. The coercion of disciplinary power transgressed the law that was supposed to protect the well-being of humans.

However, such dark reality was concealed from the public during the 1980s, as the WWE only offered a fictional mode of presentation, which prominently featured the fantasy world decorated with shining surfaces. It was not until the late 1990s when the wrestling industry began to commodify the behind the scene truth in order to fulfill fans' desire to access to and experience more "real" contents. The disturbing reality of the 1980s would have significant influences on the WWE's new postmodern aesthetic of in the late 1990s.

Before the WWE began to feature behind the scene truth in their own terms, an outside hand exposed the dark reality of the WWE. In 1990, FBI investigators seized documents and files from the office of Dr. George Zahorian, who served as WWE's house doctor, and found receipts that showed constant drug sales to WWE wrestlers including Hogan as well as McMahon. The incident eventually forced Hogan and McMahon to publicly admit their past "experiment" with steroids, and suggested to the world that the euphoric hyper-masculine fantasy of the WWE was in fact sustained by illegal drug abuse and the exploitation of human bodies. Although McMahon managed to defend himself against the charges for conniving with Zahorian for spreading steroids among WWE wrestlers, the steroid scandal significantly damaged the popularity of the WWE during the early 90s.

\section{The Intensification of the Postmodern in the Late 1990s Wrestling Boom}

In the late 1990s, the WWE once again renovated its products to stage another nationwide wrestling boom. Being driven by ever-fiercer competition and need to cater to a new type of desire in viewers, WWE wrestling's postmodern aesthetics underwent further 
intensification and significant transformation. The intensification and transformation exemplified the dynamic and developing aspect of postmodern culture suggested earlier.

The late 1990s rise of renewed postmodern aesthetics in the WWE was again triggered by the coercive laws of market competition. As discussed in the previous chapter, in September 1995, the rival organization WCW (World Championship Wrestling), launched its weekly television program Monday Nitro in the same time slot as the WWE's Raw (also called Monday Night Raw) and started the so-called Monday Night Wars. As competition forced both programs to present innovative and creative products one after another, the popularity of wrestling skyrocketed. Although the WCW dominated the competition from mid 1996 to the early 1998, the WWE eventually turned the table, and finally bought the rival company up in the early 2001.

The most obvious and widely acknowledged change in WWE wrestling during that period was the inversion of moral order in the storyline. That is, instead of righteous and patriotic characters such as Hogan, offensive and vulgar characters came to be enthusiastically supported by fans. The success of "Stone Cold" Steve Austin epitomized the moral inversion in the WWE. He was a bald-headed, beer-drinking "tough guy" and an extremely rugged individualist who would only believe in his own might and constantly repeat his motto, "Don't trust anybody." Austin would knock innocent wrestlers and referees out with his finishing move out of nowhere for no reason, which would enormously please the crowd. The phrase on his simple black vest "Austin 3:16" —a parody of the John 3:16 bible verse ${ }^{288}$ — symbolized the radical transgressiveness of his character. It was emerged when he defeated Jake Roberts, who was playing a born-again-Christian character, and yelled at him: "You sit there and you thump your

\footnotetext{
288 "For God so loved the world, that he gave his only begotten Son, that whosoever believeth in him should not perish, but have everlasting life."
} 
Bible, and you say your prayers, and it didn't get you anywhere! Talk about your psalms, talk about John 3:16. Austin 3:16 says I just whipped your ass!"

It should be noted that Austin became a fan favorite through his feud with another deeply transgressive rival: the "Mr. McMahon" character performed by Vince McMahon. In the spring of 1998, McMahon began to perform an character based on his real-life self by transgressing the borders between employer and the employee, capitalist and proletariat, promoter and wrestler, reality and fantasy. Mr. McMahon, a mean-spirited boss who loved to control and exploit his wrestlers, would use any kind of scheme necessary to subjugate Austin, who would of course never bent to McMahon's power. Centering around the groundbreaking feud between two transgressive characters, the WWE during that time also created many other colorful and unconventional superstars such as the Rock and Mick Foley, and a rebellious yet extremely popular group D-Ggeneration $\mathrm{X}$ to regain its popularity.

During that period, as opposed to family-oriented contents of the 1980s, storylines and performance inside and outside the ring became more radical and offensive to further advance postmodern features of the WWE. Obscenity and violence drastically increased, and large-scale spectacular stunts became norms. Also, physical intensity and danger involved in wrestling actions visibly proliferated, although the severity of the schedule on the road was significantly reduced. Long, gruesome, over-the-top matches in which wrestlers would fight to their physical and mental limits or engage in extremely dangerous moves became the premier commodity of the company.

The presentation form of Raw epitomized further intensification of postmodern aesthetics, fully utilizing television's ability to constantly create collage, spectacle, and the desire for consumption. As discussed in detail in chapter 1, the program came to consist of numerous 
fragmented segments, all of which were advertisement for the next development or related products of the WWE. Therefore, the program would incessantly celebrate the consumption of cultural products. Every episode of Raw became filled with shimmering visual effects, flashy computer-generated images, and intense heavy metal music. The pace of the development of storyline became frantic. The program featured spectacular stunts, sensational accidents, obscenity and violence week after week, and it became extremely difficult for viewers to remember anything but the immediate past. In other words, the flooding of spectacle washed away the sense of historicity in the WWE story-world. The frequency of title change proliferated since 1997, further decreasing the significance of championship belts and the sense of historical linage and tradition attached to them. ${ }^{289}$

In many ways, the intensification of postmodern features discussed above reflected a significant transformation in the inclination of wrestling fans. That is, they increasingly came to desire more intimate knowledge and intense experience of realness. During the early and mid 1990s, increasing numbers of fans began to have an access to the behind the scene information of professional wrestling, and to show their interest to know more. ${ }^{290}$ As Andrejevic argues regarding reality television, viewers' desire for the knowledge of the real was accompanied with the yearning for the intense experience of it. The emergence of self-referential characters such as Mr. McMahon, the incorporation of real-life business reality into the storyline, and the intensification of physical violence in the ring were the WWE's attempts to cater to viewers' increasing desire for the knowledge and experience of the real.

\footnotetext{
${ }^{289}$ The WWE Championship changed hands only one time in 1995, and two times in 1996. In 1997, it changed hands six times. Then, four times in 1998 and twelve times in 1999.

${ }^{290}$ See chapter 2 of this dissertation for a more detail.
} 
The WWE's active promotion of what I call nonfictional narratives since the same period occurred in the same context. This new form of narrative, which would reveal the truth behind the fictional world of WWE wrestling, fulfilled viewers desire for the backstage reality. Many of these nonfictional narratives showed viewers that wrestlers were in fact extremely disciplined and honorable performers, and the WWE was a patriotic group that represented and supported the interest of American people. ${ }^{291}$ The addition of nonfictional narratives to the usual fictional narratives (fantastic storyline) enabled the WWE to express its ambivalence towards modern values and subjectivities in a new way. We have seen that WWE wrestling of the 1980s embraced dominant values of modern society and sport at the level of content, while denaturalizing them at the level of the form. In contrast, in the late 1990s, with its increasingly radical and transgressive characters and storylines, the WWE began to challenge many modern public values at the level of content, too. Now, the newly introduced nonfictional narratives filled the gap and embraced dominant values of modern society and sport (discipline, honor, patriotism, the public interest, etc.), while the usual fictional narratives challenged them at the levels of both form and content.

It should be noted that some of nonfictional narratives produced at that time sensationally revealed the dark, concealed reality of professional wrestling boom in the 1980s and its devastating consequences. One of the main episodes of 1999 documentary film Beyond the Mat featured the ruin of Jake The Snake Roberts, a WWE superstar of the 1980s and the early 1990s. The film showed shocking, and in a sense disturbing, sights where his bodies and sprits were entirely worn out due to his cocaine addiction, and his relationship with his family were broken to an incurable degree. Also in 1999, Tom Billington, a former WWE superstar known as

\footnotetext{
${ }^{291}$ See chapter 2 of this dissertation for a more detail.
} 
Dynamite Kid who ended up being on wheelchair for the rest of his life, published his autobiography. The memoir frankly showed how he and his colleagues voluntarily abused steroids and other drugs to gain and maintain the top star status in the WWE during the 1980s, exhausting their bodies and minds. ${ }^{292}$ These nonfictional narratives uncovered that the euphoric hyper-masculinization of wrestlers in the 1980s resulted in ruining their bodies and minds. Many wrestlers, even if avoided fatality, had to suffer hardship for the rest of their life. Ironically, the revelation of the battered and reduced state of former superstars has contributed to the current dominance of a new masculine aesthetic of obsessive and self-destructive wrestlers in the WWE.

So far, I have attempted to contextualize the history of American professional wrestling by considering it as a process in which various postmodern features have emerged, developed, and intensified. As a unique form of discipline that parted ways to modern sport at birth, professional wrestling has demonstrated its ambivalence towards modern ideologies and values in multiple ways, using different levels (the formal level and the content levels) and deferent modes (the fictional mode and the nonfictional mode) of presentation. Professional wrestling has also prominently featured characters that are alternative to the masculine ideal of modern disciplined sportsmen, such as an ostentatious, narcissistic, and effeminate one exemplified by Gorgeous George, and a super-elated and hyper-masculine one such as Hulk Hogan. We have also seen that since the 1980s, WWE wrestling has developed the dark reality-the wearing down of bodies and minds of wrestlers as disciplined laborers — behind glitzy surface appearances of postmodern aesthetics. The following section reveals that WWE wrestling has developed another new form of masculine aesthetic, which incorporates into it the concealed dark reality of worn out wrestlers in the 1980s.

\footnotetext{
${ }^{292}$ Billington, Pure Dynamite.
} 


\section{Section 3}

\section{The Aesthetic of Obsession and Over-the-Top Matches in Contemporary WWE Wrestling}

Since the late 1990s, as the intensified competition with another organization triggered the intensification of postmodern aesthetics in WWE wrestling, "obsession" has become the standard tone of the company's product. In the story world that develops at an accelerated pace, where something sensational, spectacular, and violent occurs week after week, wrestlers have become obsessed with "screwing" fellow wrestlers or being "screwed," with humiliating rivals or being humiliated, with giving rivals "payback" or being the receiving end of it, and with winning championship titles or losing them. ${ }^{293}$

This means that WWE wrestling has come to embody issues regarding modern disciplined subjects that are exposed to intensified competition. As discussed earlier, the construction of modern disciplined subjects is to be considered an origin of obsession.

Disciplinary power implants in individuals urges to attain certain tasks. Obsession emerges when individuals' inner urges have become extremely strong and uncontrollable. Therefore, the prevalence of obsession in the WWE points to problems of modern disciplined subject, problems that emerge as the consequence of the intensification of inner urges implanted by disciplinary power. In this sense, representations of obsession in contemporary WWE wrestling are to be viewed as a new type of postmodern, and also hypermodern, text.

${ }^{293}$ The "24/7" rules that was implemented for the WWE Hardcore championship during 1999 to 2002 comically represented the obsessive nature of WWE wrestlers, especially in terms of championship titles. The rules declared that the title change might occur anytime and anywhere as long as the referee was present, and drove wrestlers obsessive in defending and taking the title. Wrestlers attempted to take the title by brining the referee with him and attacking the champion at any moment, such as while he was sleeping in bed, or eating at a restaurant. Under the rules, it was not unusual that the title would change hands multiple times in one night. 
Now, the overall obsessive tone of WWE wrestling reflects problems of three different (but closely related) types of disciplined subjects. The fictional storyline describes the obsession of wrestlers as disciplined competitors, who constantly urge themselves to compete and defeat rivals. At the level of the backstage reality of the fiction, wrestlers who perform spectacular actions week after week emerge as obsessive, disciplined laborers, who urge themselves to become the most valuable commodities all the time. Also, in terms of real-life business operations, the incessant production of frantic storylines points to the obsession of the owners and directors of the WWE as disciplined capitalists, who are always compelled to produce valuable products to defeat rivals in the market. ${ }^{294}$ The most compelling expressions, the most appealing aesthetics, and the most highly rated matches of the contemporary WWE revolve around obsession. At the same time, obsessive wrestlers and performers in the WWE illuminate problems and contradictions of disciplined subjects and current capitalism. They even expose the WWE's own wicked nature and a dilemma it is facing. For the rest of the chapter, I explore the unique significance of representations and aesthetics of obsession in WWE wrestling as new postmodern phenomena.

Vince McMahon or "Mr. McMahon," as an Extraordinary Text of Obsession

The "Mr. McMahon" character performed by the WWE owner Vince McMahon most vividly illustrates the predominance of obsession in WWE wrestling, while providing a complex representation of problems in contemporary capitalism. ${ }^{295}$ Vince McMahon, his real-life self, has

\footnotetext{
${ }^{294}$ As the WWE is itself a unique form of disciplinary institution, its owners and directors are disciplinary agents and disciplined capitalists all at the same time.

${ }^{295}$ With the end of his feud between Bret Hart at WrestleMania XXVI held in April 2010, Vince McMahon or Mr. McMahon ceased to play major roles in the WWE storyline; since then, he has only made sporadic and shorttime appearance in WWE wrestling shows. However, in this dissertation, I use present tense to describe and explore McMahon's performance, as he epitomizes the obsessive tone that characterizes contemporary WWE wrestling.
} 
always been the epitome of capitalism's disruptive nature. He has been a prominent disciplined capitalist who has been constantly urged to destroy existing norms to defeat his competitions and expand his business. Mr. McMahon is an exaggerated self-referential description of Vince McMahon as a real-life disciplined capitalist. Mr. McMahon is always driven by his abnormally strong urges to subjugate all of the people around him. To put it simply, he is absolutely obsessed with power.

One of the elements that makes Mr. McMahon stand out was the utter excessiveness when he expresses his obsession for physical, mental, and economic power. ${ }^{296} \mathrm{He}$ is a man of huge presence. He is taller than many of his wrestlers and has an extraordinary amount of muscle mass, especially for a man in his sixties. ${ }^{297}$ Mr. McMahon enters into the ring wearing a welltailored suit, performing his signature "power walk," an extremely overplayed strut. In order to show his authority, pleasure, and sometimes frustration, he addresses to and yells at people with great intensity. ${ }^{298}$ Such excessiveness in his performance has jovial and pleasant effects on viewers; as discussed in chapter 2, a proper form of over-exaggeration in professional wrestling makes viewers smile by rather candidly exposing its own manufactured nature.

Through his excessive yet comical performance, Mr. McMahon, a fictional character, illuminates the vice of an obsessed capitalist. He attempts to bring everybody to his knees, enslave female wrestlers, humiliate his own family members (son, daughter, and wife, all of

${ }^{296}$ As discussed in chapter 2, excessiveness is among the fundamental performative conventions in professional wrestling. However, in the competitive world of contemporary professional wrestling, to express excessiveness in a compelling and attractive fashion is not an easy task. Only distinguished performers, which include Vince McMahon, are able to accomplish it.

${ }^{297}$ Vince McMahon is 6'2', 250lbs, and a long-time bodybuilding enthusiast.

${ }^{298}$ One of Mr. McMahon's signature acts is his declaration of the termination of contract with his wrestlers or employees whom he loathes. Mr. McMahon utters the phrase "You're Fired!" to them in an exaggeratedly intense and vicious tone, making a hate-filled face. 
which are performed by Vince McMahon's real family members), and even challenge The God. ${ }^{299} \mathrm{He}$ not only resorts to trickery to attain his purpose, but also is willing to compete against wrestlers in the ring, even inside the steel cage. He most likely ends up being defeated by babyface wrestlers in a spectacular fashion, i.e. by being thrown off from the top of the cage to land on the announcers' table and crush it. In this sense, Mr. McMahon's obsession as a disciplined capitalist also makes him an obsessed and disciplined competitor. While linking two kinds of obsession, his absurd and intense conduct exaggeratedly illustrates the formidable nature of contemporary capitalism, which drives people obsessed with competing against and destroying others at all costs.

At the same time, as a self-referential character, Mr. McMahon always illuminates his real-life self, Vince McMahon, a businessman who stages and sells absurdities and wrongdoings of Mr. McMahon. Vince McMahon has created and performed the extraordinary Mr. McMahon character, in responding to the demands of competition in the market. Here, all the transgressive acts of Mr. McMahon — crossing the border between wrestlers and promoters, wearing muscles that are utterly disproportionate to his age, suffering spectacular beatings from wrestlers while being in his $60 \mathrm{~s}$, challenging outright against family and religious values and morals, etc. demonstrate once again that businessman Vince McMahon is the personification of the disruptive, convention destroying nature of capitalism. Through all the drama of Mr. McMahon, Vince McMahon emerges as an obsessive, disciplined laborer, too. Despite being a real-life billionaire and renowned businessman, he constantly urges himself to become the most profitable commodity even by exposing his aged bodies to intense violence and by performing

\footnotetext{
${ }^{299}$ In 2006, he after visiting a church and being not impressed, Mr. McMahon announced new religion called McMahonism, which of course promoted the worship of him.
} 
utterly immoral and profane acts. In multi-layered ways, and through its excessive, absurd, and comical presence, the dual identity of Vince McMahon and Mr. McMahon offers critical views on the disruptive, brutal, and obsession-inducing nature of contemporary capitalism. It is also a self-reflexive display of the WWE's own problematic features.

In an episode of Raw on February 13th, 2006, Mr. McMahon demonstrated another absurd and comical behavior against Shawn Michaels, a real-life born again Christian. This scene, while most explicitly demonstrating the obsession of the capitalist under intensified competition, opened new front in expressing problems caused by the obsessive capitalist. Without any obvious reason or indication, Mr. McMahon, in an extremely high-handed manner, ordered Michaels to retire. Michaels refused the command, having hard time understanding Mr. McMahon's motivation behind it. Mr. McMahon was momentarily enraged, but then forcefully restrained himself and rather quietly began to explain his rationale of the order. Mr. McMahon said he was commanding Michaels' retirement because Michaels had "that inner peace" that Mr. McMahon wanted but could never have or purchase with his money. After quickly pointed out that Michaels knew who he was and what he wanted, Mr. McMahon raised his voice and yelled at Michaels, “I don't have that! And I want it! Time after time I don't know who the hell I am. I don't know what I want except I've got an insatiable appetite for life! And I want more! More! More!" Then Mr. McMahon changed his voice to an appealing tone, and he complained that his life was a nightmare as he was buried under the day-to-day operation of the WWE empire. He showed a hysterical smile and said that the situation would be better as Michaels would sign the retirement paper because he had to. Then, again rather quietly, Mr. McMahon declared that he hated people like Michaels, who had what Mr. McMahon wanted but could not have, and 
repeated the order. Of course, Mr. McMahon's explanation did not convince Michaels to obey the preposterous order, and the feud between the two started.

Here, as always, Mr. McMahon was presented as a "power freak" villain, who would abuse his power and subjugate people around him in an outrageously unjustifiable manner. Nevertheless, this segment was to be distinguished from other episodes of Mr. McMahon as a representation of problems in contemporary capitalism. That is, it described Mr. McMahon as a suffering victim of intensified competition, while making explicit that his suffering was caused by his obsession as a capitalist.

Mr. McMahon's extremely straightforward description of his "insatiable appetite” — “I want more! More! More!"- indicated that his inner urge as a disciplined subject had enlarged to an uncontrollable degree, and therefore he was seriously obsessed. Then, his explanation that his nightmarish life was filled with daily operations of the WWE empire, a capitalist media conglomerate, demonstrated that his obsession was that of a capitalist under intensified competition. This serious obsession as a disciplined capitalist made Mr. McMahon lose the sense of security and identity (“I don't know who the hell I am. I don't know what I want"). Therefore he suffered.

Now, the speech revealed that Mr. McMahon's suffering - the product of his obsession as a disciplined capitalist — caused him to entirely transgress his code of conduct as an obsessed capitalist. What drove McMahon's act was not his capitalist urges, but (unjustified) resentment against people, like Michaels, who possessed "that inner peace," people who were free from suffering caused by obsession. ${ }^{300}$ Therefore he decided to oppress Michaels, claiming that it

${ }^{300}$ As discussed in the beginning of the chapter, the same Michaels would play the role of a man obsessed with his rematch with The Undertaker in 2010, attesting to the arbitral nature of the story world of the WWE. 
would ease his suffering. McMahon's speech described the process in which an obsessive disciplined capitalist had mental suffering and ceased to be a disciplined capitalist anymore; he was occupied with his resentment against others' "obsession-free" state of mind.

As an original and innovative villain, Mr. McMahon has illuminated the wicked nature of contemporary capitalism that forces disciplined subjects into obsessive states of mind. He has also personified the WWE's exposure of its own brutal nature as a capitalist enterprise. In most of the fictional storylines of the WWE, Mr. McMahon ends up being humiliated by rivals, suggesting that oppressive capitalists will eventually receive what they deserve. In fact, about two months after the speech, at WrestleMania XXII, Michaels defeated Mr. McMahon in the most spectacular way possible. The obsessive, evil capitalist (who had lost his sight as a capitalist) was once again proved to be ruined.

However, the moral of the story has been entirely opposite at the nonfictional level. Mr. McMahon has been among the most valuable talents of the WWE, and has greatly contributed to the domination of the WWE in the business. Also, all of the defeats and humiliations that Mr. McMahon goes through bring Vince McMahon further fame as a distinguished capitalist and extraordinary performer. ${ }^{301}$ Therefore, the fictional self-criticism of the WWE through Mr. McMahon character validates Andrejevic's observation regarding the dominance of "debunked" capitalism in contemporary popular culture. As Andrejevic notes, cynical consumers of popular culture support the rule of capitalism even though they are aware of the disturbing nature of capitalism. Therefore, today, popular culture industries do not hesitate to expose their own contrivance, brutality, and wickedness and turn these features into premier commodities of their

\footnotetext{
${ }^{301}$ As discussed in chapter 2, fans love to boo and jeer the fictional Mr. McMahon character, while paying great respect to Vince McMahon as the real-life owner of the WWE. When Mr. McMahon enters into the ring, some of the WWE fans weave their hands to jokingly demonstrate their worship to him.
} 
own. Such self-exposure only caters to savvy and cynical consumers' desire to see through the true colors of the industries, and bring further prosperity to them. Likewise, the WWE's selfreferential portrait of its own brutality through the Mr. McMahon character greatly attracts today's informed fans, who yearn for the further behind-the-scene truth of the industry. His success is the epitome of the dominance of contemporary capitalism and culture industries, of which oppressive nature has already been exposed.

\section{Over-the-Top matches, Obsession, and the WWE's Mew Masculine Aesthetic}

Starting the mid to late 1990s, the WWE, as well as other organizations, developed a new style of presenting and performing matches. The company has increasingly featured long, grueling, over-the-top matches where wrestlers would keep fighting until the critical limit. ${ }^{302}$ To date, the new style has become the most valuable commodity of the WWE; now the company features over-the-top matches as the main attraction of every big event.

The narratives of over-the-top matches always center around wrestlers' obsessive state of mind; in these matches, wrestlers demonstrate obsessive will to win or to perform extremely dangerous moves while their bodies are suffering increasingly serious damage. Therefore, these matches occupy a significant, in fact central, part in the current dominance of obsession in the WWE, and address the problem of modern disciplined subjects. More concretely, obsession of wrestlers expressed in over-the-top matches is that of disciplined competitors who cannot but follow their inner urges to compete at all costs.

Like other expressions of obsession in contemporary WWE wrestling, over-the-top matches are to be viewed as both postmodern and hypermodern texts. These matches describe

\footnotetext{
${ }^{302}$ A 60-minitue "Iron-man" match between Shawn Michaels and Bret Hart in 1996 is to be considered the origin of such over-the-top matches.
} 
the process in which wrestlers who cannot help but keep competing gradually exhaust themselves. In doing so, over-the-top matches suggest that if disciplined competitors are absolutely faithful to their inner urges that are interjected by disciplinary power, competitors will eventually reach their breaking points. In other words, these matches address the contradiction in the construction of modern disciplined subject, when the subjects' inner urges are intensified and become unstoppable.

Over-the-top matches are also to be viewed as the fictional reenactment of real problems that were concealed in the 1980 s. We have seen that in the 1980 s many wrestlers as disciplined laborers secretly exhausted their bodies and minds, as they constantly urged themselves to make their own bodies as profitable commodities as possible. In the late $90 \mathrm{~s}$, as these concealed problems came to be revealed in some of nonfictional narratives of professional wrestling, the WWE began to trace the problems in fictional, over-the-top matches; the real-life exhaustion of disciplined laborers was transposed to the fictional self-destruction of obsessive, disciplined competitors.

When being fictionalized, the self-destruction of obsessive, disciplined subjects turns into the object of utter celebration. Every time wrestlers exhibit their obsessive will to fight or perform high-risk moves, the crowd fervently cheer for them. In these matches, fans often ardently praise and appreciate both wrestlers regardless of they play babyface (hero) or heel (villain). That is, an obsessive mind of a wrestler is one of the privileged states in the contemporary WWE, which overcomes usual moral orders of wrestling storyline.

This does not mean that in over-the-top matches fans do not see obsessive wrestlers as real-life disciplined laborers. In fact, the fans' respect for wrestlers as disciplined laborers was the major cause of the transgression of moral orders and the celebration of obsessive wrestlers. In 
these matches, in expressing their enthusiastic praise for wrestlers, the live crowd frequently give collective chants such as "This is Awesome!" and "Holy Shit!” These chants, which give an extremely positive evaluation of wrestler's performance, reflect fans' recognition of real-life danger, damage, courage, hard work, skills, and discipline involved in the performance. In the age when behind the scene reality and severity of professional wrestling are well known, fans praise wrestlers not only as fictional characters, but also as real-life performers. Fans pay respects to wrestlers as disciplined laborers who are willing to make their bodies valuable commodities by taking risks, suffering damages, and working hard. ${ }^{303}$

The duel glorification of wrestlers' obsessive state of mind (from both fictional and nonfictional perspectives) signals the transformation in the dominant masculine aesthetic of the postmodern WWE. The excessive energy of hyper-masculinity in the 1980s has waned. Instead, what was hidden behind glimmering surfaces of hyper-masculinity has emerged. Now, the exhausted bodies and minds of obsessive, disciplined wrestlers embody the new postmodern masculine aesthetic of WWE wrestling. The WWE has exposed the previously concealed dark reality, turning it into the ultimate object of glorification and fascination. In this sense, the "Randy the Ram" character in the film The Wrestler discussed in the beginning of this dissertation is a truly faithful and excellent reflection of the new masculine aesthetic of the WWE. In Randy, battered bodies and minds of the former superstars in the 1980s, and obsessive and self-destructive inner states of wrestlers in over-the-top matches after the late 1990s are fused into one.

\footnotetext{
${ }^{303}$ The success of Mick Foley’s autobiography Have a Nice Day! discussed in chapter 2 epitomized fans' respect for wrestlers as obsessed real-life performers. In this book, in the form of nonfictional narrative about himself a human being, Foley powerfully described his extremely dangerous performance in the ring.
} 
The transformation in the WWE's masculine aesthetic demands wrestling scholars to update the existent theory of postmodern culture, such as Jameson's. Jameson considers the predominance of surface appearances and the weakling sense of inner subjectivity a major trait of postmodern culture, a trait certainly fit to professional wrestling in the 1980s. However, today's popularity of over-the-top matches demonstrates that the expression of the WWE has turned inward. Now, through the spectacular presentation of intense physical performance, WWE wrestling has come to express inner obsessive state of mind of disciplined wrestlers as both characters (competitors) and performers (laborers). ${ }^{304}$ In other words, by exposing and dramatizing its own serious problems, the WWE caters to fans' desire for more intense and real experience. Like contemporary reality television viewers observed by Andrejevic, wrestling fans attempt to squeeze intense pain out of obsessive wrestlers performance, and experience "a bit of authenticity—of 'real' emotion.", 305

Over-the-top Matches, Capitalism, and the Postmodern Dilemma of the WWE

Over-the-top matches should not only be viewed as the representation of concealed issues in the past, but also be considered the reflection of profound problems in cotemporary capitalism and a serious dilemma that the WWE faces. As discussed earlier, one of the major attractions of over-the-top matches lies in the real-life fact that wrestlers put their bodies "on the line." ${ }^{306}$ Fans avidly consume real-life pain, physical damage, and the exhausting performance of wrestlers.

\footnotetext{
${ }^{304} \mathrm{Mr}$. McMahon's expression of his mental sufferings in his speech to Michaels discussed earlier in this chapter also reflects the WWE's new emphasis on inner states of mind.

${ }^{305}$ Andrejevic, Reality TV, 207.

${ }^{306}$ In fact, in a "fatal four way ladder tag match," one of the extremely dangerous and painful matches where wrestlers jumped down from the top of huge ladders or hit their bodes on ladders, held in December 2006, the WWE superstar Joey Mercury legitimately injured in a sensational fashion. He was struck with a ladder in the face very hard, breaking his nose, bleeding profusely.
} 
This, along with Andrejevic's observation of the increasingly torturous contents of todays' reality television, suggests that in contemporary popular culture the experience of intense pain and the sighting of the destruction of humans are among the most valuable commodities. Now, the laws of capitalist competition demand the WWE to manufacture and sell human pain and destruction by endangering bodies of wrestlers. In the case of WWE wrestling, which commodifies real live human bodies, the disruptive nature of capitalism calls for the literal disruption of live humans. However, after the abuse of wrestlers bodies and minds in the 1980s was exposed, the WWE is also compelled to protect wrestlers bodies, which are both materials and commodities of the company, in order to maintain its profit and reputation,

This dilemma can also be viewed as the contradiction of the disciplinary power that surrounds the WWE and its wrestlers. As a disciplinary institution under capitalism, the WWE produces wresters as disciplined laborers who constantly urge themselves to make their bodies the most profitable commodities. Now, in doing so, the WWE has to force wrestlers to accomplish two conflicting missions: to produce as profitable match as possible by taking significant amounts of physical risk, and not to inflict fatal damages to their and their colleagues' bodies. Obsessed wrestlers featured in over-the-top matches are a symptom of contradictions in contemporary capitalist society and culture. The contradictions emerge as the intensified competition under capitalism incessantly drives disciplinary institutions to constantly produce obsessive laborers.

In responding to the dilemma, the current WWE has encouraged wrestlers to find ways to reduce real physical risk involved as best as they can while performing over-the-top matches. As a result, wrestlers have come to attempt to tell dramas during the match using so called ringpsychology (the ability to control the crowd's emotion at will by giving facial expressions, 
frequently communicating with them, effectively using routine moves, etc.) without relying too much on high-risk moves. The match between Michaels and The Undertaker discussed earlier was one of the most sophisticated answers to the postmodern dilemma. The match presented a superb fictional story of the self-destruction of Michaels as an obsessed competitor to satisfy viewers. It accomplished this task by using his real-life retirement as an enhancement to the drama, and without causing serious injury. At the same time, the match also told a related, but contrasting story at the nonfictional level. It proudly presented Michael's glorious retirement, his ultimate autonomy against the inhumanity of capitalism. Using multiple levels of storytelling, this match fulfilled capitalism's demand to commodify the exhaustion of human bodies, while also claiming that the WWE and its wrestlers were capable of protecting themselves against the ferociousness of contemporary capitalist culture.

Now WWE wrestling tends to premier new forms of expression, storytelling, and aesthetics through over-the-top matches, the company's most valuable product. These matches illuminate contradictions of capitalism and disciplined bodies and minds in new and sensational ways, while offering intense viewing experience and pleasure. At 2011's WrestleMania, the WWE produced another compelling over-the-top match that deserved close attention. The match was in fact a virtual sequel of the previous years' Michaels-Undertaker match. HHH (pronounced "Triple H"), Michaels' long-time best friend, and another legendary superstar of the late 1990s, challenged The Undertaker in a "no-holds-barred" match, where the usage of any foreign object was allowed. In this case, the no-rule rules did not deny "fair" competition. During the build up of the match, both wrestlers showed great respect to each other, suggesting that they would compete under their own concept of fairness. They agreed on no-holds-barred rules in 
order to ensure that both could fully unleash their competitiveness, and there would be "no regrets, no excuses," in the words of The Undertaker.

In the match, The Undertaker played the role that Michaels played the previous year; he was entirely beaten up by HHH in an all-out, exhaustive battle. Recognizing that the battered opponent still had not given up, HHH smashed The Undertaker on the back with a steal chair numerous times. Then he yelled at the opponent to stay down, But the Undertaker wouldn't listen and staggered to his feet. With a determined look, HHH swung the chair downward to the head of The Undertaker with full strength to knock him down, the move that the WWE had banned - an actual order to wrestlers as performers, not a "storyline" ban —in order to reduce concussion problems among wrestlers. Even this move failed to finish the match; $\mathrm{HHH}$ eventually found that that the laying Undertaker was still wriggling his limbs and struggling to sit up. As announcers pointed out that HHH looked distressed, he walked to The Undertaker and once again yelled at the opponent, "Stay down! Just die! Stay...down! What's wrong with you?" The Undertaker again ignored him. After further failed attempts to talk The Undertaker into giving up, $\mathrm{HHH}$ once again made up his mind, lifted the opponent upside down for tombstone piledriver, the move by which The Undertaker finished Michaels. As the announcer yelled "No, no, no! Come on! This is too much!" HHH declared, "It's over," and executed the move, dropping the opponent's head to the mat. HHH went for the three-count pinfall, but the Undertaker rose one of his shoulders a moment before the third count, making the crowd hysterical with excitement. While the astonished announcers were yelling, "What did we just see?" "He's not human!," HHH showed a terrified look and crawled backward to the edge of the ring, looking at The Undertaker in disbelief. "This is awesome!" chant broke out from the crowd. HHH eventually gained his composure, and tried to wreck the head of the lying Undertaker with 
a sledgehammer, his signature weapon. However, as he was about to swing the weapon down, The Undertaker suddenly moved and caught him with Hell's Gate, a choking submission hold that he usually saved for the last moment. After a long struggle to escape from the hold, HHH feebly tapped The Undertaker's shoulder to submit. The bell rang to signal The Undertaker's victory as the crowd roared. Both wrestlers could not move for some time. HHH eventually got up and totteringly walked out of the ring. The Undertaker collapsed outside the ring and was carried out by the cart, while the crowd was changing his name to show their appreciation. The next day, the WWE quietly announced on its website that the two wrestlers were fined due to the violation of the company's policy, namely, HHH's chair shot to The Undertaker's head. The two veterans deliberately broke the policy in order to perform a compelling match.

Two large points are to be made to explain the significance and originality of this match as a new expression in postmodern contexts. First, like the previous years' Michaels-Undertaker match, $\mathrm{HHH}$ and The Undertaker addressed problems that concerned modern disciplined subjects, capitalism, and professional wrestling at the levels of both fiction and nonfiction. However, the match did the job in quite different ways than the previous year.

At the level of fictional storyline, by highlighting the contrasting states of mind of two wrestlers as disciplined competitors, the HHH-Undertaker match broke new ground in the aesthetic of over-the-top match. That is, this match not only emphasized the physical pain of a wrestler (The Undertaker) who was ready to destroy his own body, but also extensively featured the perspectives of a wrestler $(\mathrm{HHH})$ who had to destroy the body of an already broken down opponent. Through HHH's distressed expressions and desperate attempts to talk The Undertaker into quitting, and this match invited viewers to experience emotional conflict and pain of a disciplined subject, who could not help but follow his inner urges and inflict fatal damage to the 
opponent as long as the opponent refused to quit. In doing so, the match stressed the unbreakable authority of the coercion from disciplinary power, evoking a homosocial emotional bonding between the two subjects who could not free themselves from the coercion. The fictional storytelling of this match powerfully and melodramatically illuminated the constraining force and contradiction involved in the construction of modern disciplined subjects.

In contrast, HHH's chair shot to the head of The Undertaker had significant and a quite different implications at the nonfictional level, as it overtly violated the real-life rule implemented by the WWE. By performing the chair shot "spot" (move), the two wrestlers illuminated the difficulty of the WWE's dilemma from the perspective of wrestlers. We have seen that now wrestlers as disciplined laborers are compelled to meet two contradictory demands: to take significant amounts of physical risk and produce the most profitable match as they can, and not to cause significant damage on their and their colleagues' bodies. The forbidden chair shot to the head during the match was to be viewed as the two wrestlers' demonstration of their own way to manage the dilemma. In order to perform a more compelling and profitable match, $\mathrm{HHH}$ and The Undertaker exposed their own bodies to a higher risk than the WWE allowed. In other words, in order to show their own way of responding to conflicting demands of capitalist system, the two disciplined laborers (HHH and The Undertaker) had to transgress the rule implemented by the disciplinary institution (the WWE) that trained them.

Here, the chair shot in this match suggested the complication of Foucault's view regarding the nature of discipline as a "counter-law." Foucault argued that discipline would confirm the "non-reversible subordination of one group of people by another," ${ }^{307}$ which would include the relationship between managers of disciplinary institutions and disciplined subjects.

\footnotetext{
${ }^{307}$ Foucault, Discipline and Punish, 222-3.
} 
Discipline would allow the former to exert coercion over the latter, even by transgressing the egalitarian law of modern society. However, in this case, it was managers of a disciplinary institution (the WWE) that were faced with a dilemma and implemented the law that aimed at protecting the well-being of disciplined subjects (wrestlers), the law that would restrain its own disciplinary power in terms of producing the most profitable commodities. Nevertheless, the same disciplinary power had two disciplined subjects (HHH and The Undertaker) who were facing the same dilemma transgress the law enforced by their disciplinary institution, risking their own bodies. The dangerous and sensational transgression by the two veterans, and the complication of Foucault's theory of discipline suggested by it demonstrated that there was no final answer in resolving the dilemma of disciplinary power that the WWE and its wresters faced.

In novel and bold ways, the HHH-Undertaker match illuminated contradictions of modern disciplined subjects and contemporary popular culture. Ultimately the WWE ended up glorifying the wrestlers who lived the contradictions. The fictional narrative of the match ultimately ended up with a miraculous victory of The Undertaker, whose body was entirely destroyed by the opponent. In the real-life business after the match, while rather quietly fining the two for the chair shot, the WWE repeatedly stressed the greatness of the match, and decided to feature a rematch between the two in the following year's WrestleMania. In this sense, the WWE rather sustain the contradictions of modern disciplined subjects as the largest source of profit of its own. This match is considered another case where a culture industry thrives by exposing its own problems to informed, cynical consumers who love to know the problems and keep supporting the industry. Viewed from another angle, however, the HHH-Undertaker match 
exemplified that some of fine popular entertainments develop critical views to themself and the system they belong to in the course of the creation of the most profitable, desired products.

The second point that proved the originality and significance of the match lay in HHH's horrified look and act when The Undertaker raised his shoulder after receiving what should have been fatal damage. This scene was the expression of the most intense experience that was ardently desired in the postmodern age. Here, Jameson's argument of the postmodern sublime mentioned earlier is suggestive for understanding radical effects and the uniqueness of the scene. Like Jameson's notion of the sublime, HHH's expression of terror indicated (exaggeratedly) that he just experienced something that was beyond his understanding or imagination. It is certainly open to interpretation whether or not this scene represented another coming of The Undertaker's obsessive will to keep fighting. ${ }^{308}$ However, in this case, I would like to follow Jameson and view that $\mathrm{HHH}$ touched something bigger than obsession, or something came after human obsession ceased to exist: sheer unexplainable force, or the other, of which we could only catch a glimpse. $^{309}$

However, there is a significant difference between Jameson's postmodern sublime and HHH's experience of terror. Jameson argues that postmodern sublime is the glimpse of enormous power, or the second nature of the contemporary age: "the whole new decentered

\footnotetext{
${ }^{308}$ It is certainly tempting to interpret this as another expression of The Undertaker's obsessive will. In fact, after the moment of astonishment, the play-by-play announcer of the match told that it was The Undertaker's "will" and "passion" that kept him going. Also HHH appeared in Raw in the next night, and gave a similar thought. In addressing the fact that he could not finish The Undertaker, HHH said he was still figuring out what drove The Undertaker going. But he finally concluded that it was "just a will power" and The Undertaker was after all, a human being and not the possessor of some supernatural power (The Undertaker's "dead man" character has a strong affinity with the supernatural or the force from the other world, which constitutes another interpretative possibility for his miraculous comeback against HHH.) However, such views are afterthoughts, or hindsight attempts to make sense of the uncanny experience and their correctness is not guaranteed. The only sure thing is that HHH was terrified at that moment because he toughed something utterly unexplainable and his frames of interpretation collapsed.

${ }^{309}$ Jameson, Postmodernism, 34-5.
} 
global network of the third age of capital itself." ${ }^{\prime 310}$ The descriptions of technological devices such as TV and computer in powerful postmodern texts provide such experience. In contrast, what HHH experienced had nothing to do with developed capitalism or advanced technology. The other (or "this other thing" to again borrow from Jameson) in professional wrestling only concerned the act of physical fighting; it momentarily emerged through the unexplainable fighting back move of The Undertaker, who should have been entirely destroyed.

This reasoning suggests the claimed autonomy of the professional wrestling ring. According to Jameson, the postmodern sublime was the experience of the enormous force of contemporary capitalism. Obviously, in terms of the reality of the wrestling business, the same capitalist force regulates the world of professional wrestling. The business reality and the logic of capitalism even frequently intrude the fictional narrative of contemporary WWE wrestling. Nevertheless, the fictional storytelling of the HHH-Undertaker match made a "purist" or "fundamentalist" claim. It asserted that the sublime force in the ring of professional wrestling only concerns physical act of fighting, however often the logic of capitalism invaded into the ring.

As discussed earlier, WrestleMania is the company's the largest spectacle extravaganza that prominently celebrates the commodification of culture. During the featured event of this capitalist spectacle (that is, from within the capitalist system), HHH-The Undertaker match fictionally, and only momentarily, created the most intense, sublime site of physical fighting that was uncontaminated by capitalism. In a sense, like the previous years' Michaels-The Undertaker match, this match claimed the autonomy of professional wrestling against the omnipotent power of capitalism. But it took entirely different path in doing so. As discussed in the two previous

\footnotetext{
${ }^{310}$ Ibid., 38.
} 
chapters, today's informed fans of the WWE well recognize the manufactured nature of WWE wrestling, and how the logic of capitalism saturates it. Nevertheless, like cynical reality television viewers described by Andrejevic, they enthusiastically appreciate the experience of a capitalism free Utopia of fighting manufactured by the WWE. The WWE's offering of extremely intense, painful, and awe-inspiring experience to cynical yet avid fans exemplifies the latest phase of postmodern popular culture. 


\section{Conclusion}

Contemporary WWE wrestling faces challenges and difficulties. The essential attraction of professional wrestling lies in the fact that it stylizes and commercializes live human bodies. Intensified competition of contemporary capitalist society inevitably imposes the strain on wrestlers; it demands wrestlers to constantly stylize their bodies to give intense, damaging performances and maintain extremely impressive appearances. The WWE now finds itself in a dilemma. It needs to exploit wrestlers bodies, while also protecting the well-being of wrestlers, who are its laborers and commodities. The changing state of fans poses challenges to the WWE, too. It has become increasingly difficult for wrestling organizations to impress today's informed fans using usual fictional storylines and characters. Fans have seen enough of repeated patterns and devious practices employed by the WWE. They are well aware of the WWE's oftendeceptive intentions and will not easily be in the palms of wrestlers.

All three chapters of this dissertation discussed how the WWE attempts to survive and thrive against these challenges. Chapter 1, through John Cena's farewell speech, considered the process in which the WWE momentarily realized the state of total control - a perfect harmony between producers' intentions and consumers' reactions - with fans who were well aware of how the WWE wanted them to react, and not always willing to react accordingly. By inserting a wellscripted, seemingly nonfictional narrative into its usual fictional narratives, the WWE successfully tempted fans to temporarily allow themselves to succumb to the pleasure of being controlled. These fans demonstrated a negative version of cynicism discussed by Žižek, as they dared to be obedient and experience the sense of total unity, while knowing that such a unity would be broken in a moment. Chapter 2 extensively discussed significances of nonfictional 
narratives, which the WWE introduced in the late 1990s. In the period when increasing numbers of fans began to seek access to inside information of professional wrestling, the WWE revealed that there were real discipline, respect, pain, and human beings behind the fictional world of absurdity. In doing so, it officially introduced fans a new way of experiencing verisimilitude in WWE wrestling and of being mesmerized by it. Chapter 3 examined the WWE's most popular product: over-the-top matches where obsessed wrestlers would keep fighting to the point of destroying their own bodies. These matches were to be considered a new type of postmodern and hypermodern expression, in the sense that they described the inner obsessive state of wrestlers as modern disciplined competitors, who could not help but follow their urges to keep fighting until they exhausted. In these matches, fans praised obsessive wrestlers also as real-life disciplined laborers, who were willing to make themselves valuable commodities by taking significant amounts of risk and damage. Over-the-top matches offered viewers much coveted experience of intense pain and emotion, while illuminating contradictions of contemporary capitalism and popular culture, where the destruction of humans had become the most valuable commodity. Through these matches, the WWE also often claimed its autonomy against the ferociousness of capitalism.

All of these efforts by the WWE include the blurring of boundaries between the fictional and nonfictional in times when the usual fictional narratives of wrestling have lost its force to keep attracting fans. These efforts are also to find ways to commercialize and sell the experience of real pain and emotion to contemporary fans who are well aware of the manufactured nature of professional wrestling and the profit-seeking nature of the wrestling industry. When the WWE beautifully succeeds in these efforts, the show will be a hive of excitement, where an enthusiastic crowd eats up everything that wrestlers do. In such moments of intense pleasure and emotion, 
WWE wrestling also calls for the refinement and updating of existing cultural theories, illuminating problems and contradictions of itself and the system it belongs to.

Now, several popular culture products employ similar strategies to thrive. As Andrejevic argues, many reality television programs provide intense and brutal experience of realness to audiences who are well aware of the programs' contrived nature. Mixed Martial Arts, the emerging fighting sport, also offers the most "real" form of fighting, where fighters are presented as the ultimate version of modern disciplined sportsmen. ${ }^{311}$ What we have observed in WWE wrestling constitutes a part of a larger trend in contemporary popular culture.

Professional wrestling is a rich and complex cultural phenomenon that demands more scholarly attention. It is my hope that this dissertation contributes to the understanding of this popular entertainment spectacle and leads to further work in the study of contemporary culture.

${ }^{311}$ For a detailed examination of the representation of realness in mixed martial arts, see my "Real Fighting: The Emergence and Reemergence of the Ultimate Fighting Championship as Reality Entertainment" (unpublished manuscript, 2012). 


\section{Bibliography}

“Company Overview.” WWE Corporate. http://corporate.wwe.com/company/overview.jsp (accessed April 1, 2012).

"Former Talent Rehabilitation Assistance." WWE Corporate.

http://corporate.wwe.com/news/rehabilitation/summary.jsp (accessed April 1, 2012).

“Live and Televised Entertainment." WWE Corporate.

http://corporate.wwe.com/company/events.jsp (accessed April 1, 2012).

“Overview.” WWE Parents. http://corporate.wwe.com/parents/overview.jsp (accessed April 1, 2012).

"Survivor Series PPV Reax \#1: 'I Enjoyed the Three-hour Old School Raw More than Tonight's PPV."” PWTORCH VIP Website [Membership Website]. 2010.

http://www.pwtorch.com/members/artman/publish/Torch_Feedback_14/article_47470.sht $\mathrm{ml}$ (accessed April 1, 2012).

"Talent Life Skills." WWE Corporate. http://corporate.wwe.com/company/talent_life_skills.jsp (accessed April 1, 2012).

“Talent Wellness Program Summary.” WWE Corporate. http://corporate.wwe.com/company/wellness/talent_wellness.jsp (accessed April 1, 2012).

"What is "WWE style."” In Pro Wrestling: WWE LurKerFAQs. 2011. http://www.lurkerfaqs.com/posts/view/222733 (accessed April 1, 2012).

"WWE Raw Reax \#1: The Miz Cashing in MITB, John Cena's Acting, TLC Look-ahead, Creative Hitting their Stride?” PWTORCH VIP Website [Membership Website]. 2010. http://www.pwtorch.com/members/artman/publish/Torch_Feedback_14/article_47500.sht $\mathrm{ml}$ (accessed April 1, 2012).

"WWE Raw Reax \#2: Strong Opinions for \& against Miz Becoming New WWE Champion, Review of King of the Ring Qualifying Matches." PWTORCH VIP Website [Membership Website]. 2010.

http://www.pwtorch.com/members/artman/publish/Torch_Feedback_14/article_47504.sht ml (accessed April 1, 2012).

Adams, Charles S. "Myth and Ritual in Professional Wrestling." In From Season to Season: Sports as American Religion, edited by Joseph L Price, 203-211, Macon: Mercer University Press, 2001. 
Adelman, Melvin L. A Sporting Time: New York City and the Rise of Modern Athletics, 1820-70. Urbana: University of Illinois Press, 1986.

Adorno, Theodor W. "On the Fetish Character in Music and the Regression of Listening." In The Culture Industry: Selected Essays on Mass Culture, edited by J.M. Berstein, 29-60. London: Routledge, 2001.

Andrejevic, Mark. Reality TV: The Work of Being Watched. Lanham MD: Rowman \& Littlefield, 2003.

Ang, Ien. Watching Dallas: Soap Opera and the Melodramatic Imagination. London: Methuen, 1985.

Assael, Shaun, and Mike Mooneyham. Sex, Lies, and Headlocks: The Real Story of Vince McMahon and the World Wrestling Federation. New York: Crown Publishers, 2002.

Ball, Michael R. Professional Wrestling as Ritual Drama in American Popular Culture. Lewiston: Edwin Mellon Press, 1990.

Barthes, Roland. "The World of Wrestling." In Mythologies, translated by Annette Lavers, 1525. New York: Hill and Wang, 1972.

Battema, Douglas, and Philip Sewell. "Trading in Masculinity: Muscles, Money, and Market Discourse in the WWF." In Steel Chair to the Head: The Pleasure and Pain of Professional Wrestling, edited by Nicholas Sammond, 269-294. Durham: Duke University Press, 2005.

Beekman, Scott M. Ringside: A History of Professional Wrestling in America. Westport, CT: Praeger Publishers, 2006.

Benjamin, Walter. "The Work of Art in the Age of Mechanical Reproduction." In Illuminations: Essays and Reflections, edited by Hannah Ardent, translated by Harry Zohn, 217-251. New York: Schocken Books, 1969.

Billington, Tom. Pure Dynamite: The Price You Pay for Wrestling Stardom. Ontario: Winding Stair Press, 2001.

Bischoff, Eric. "Eric Bischoff on ECW, Wrestling Media, WCW.” Interview by Wade Keller. Pro Wrestling Torch 278 (1994), 9.

Budd, Mike, Robert M. Entman, and Clay Steinman. "The Affirmative Character of U.S. Cultural Studies.” Critical Studies in Mass Communication 7, no. 2 (1990): 169-184.

Campbell, John W. "Professional Wrestling: Why the Bad Guy Wins." Journal of Popular Culture 19 (1996): 127-132. 
Cornette, Jim. "Jim Cornette's Opinion on the Torch and Wrestling Press." Interview by Wade Keller. Pro Wrestling Torch 243 (1993), 7-8.

Craven, Gerald, and Richard Moseley. "Actors on the Canvas Stage: The Dramatic Conventions of Professional Wrestling." Journal of Popular Culture 4 (1972): 326-336.

Culler, Jonathan. Structuralist Poetics: Structuralism, Linguistics, and the Study of Literature. Ithaca: Cornell University Press, 1975.

Davis, Lennard J. Obsession: A History. Chicago: University of Chicago Press, 2008.

Dell, Chad. "Researching Historical Broadcast Audiences: Female Fandom of Professional Wrestling, 1945-1960.” PhD diss., University of Wisconsin-Madison. 1997.

Douglas, Edward. "Mickey Rourke Piledrives The Wrestler.” 2008. http://www.comingsoon.net/news/movienews.php?id=51289 (accessed April 1, 2012).

Elias, Norbert, and Eric Dunning. Quest for Excitement: Sport and Leisure in the Civilizing Process. Oxford: Basil Blackwell, 1986.

Feigenbaum, Aaron D. "Professional Wrestling, Sports Entertainment, and the Liminal Experience in American Culture." PhD diss., University of Florida. 2000.

Fiske, John. Television Culture. London: Routledge, 1987.

---. "Postmodernism and Television." In Mass Media and Society, edited by James Curran and Michael Gurevitch, 55-67. London, Edward Arnold, 1991.

Foley, Mick. Have a Nice Day!: A Tale of Blood and Sweatsocks. New York: Reganbooks, 1999.

---. "The Wrestler is Good: A Three-time WWE Champion Explains What Darren Aronofksy's Pro-wrestling Movie Gets Right.” 2008.

http://www.slate.com/articles/news_and_politics/life_and_art/2008/12/the_wrestler_is_g ood.single.html (accessed April 1, 2012).

Foucault, Michel. Discipline and Punish: The Birth of the Prison. Translated by Alan Sheridan. New York: Vintage Books, 1995.

Gilroy, Paul. The Black Atlantic: Modernity and Double-Consciousness. Cambridge, MA.: Harvard University Press 1993.

Glynn, Kevin. Tabloid Culture: Trash Taste, Popular Power, and the Transformation of American Television. Durham: Duke University Press, 2000. 
Griffin, Marcus. Fall Guys: The Barnums of Bounce. Top Quality Wrestling. http://tqw.comeze.com/Fall\%20Guys.pdf (accessed April 1, 2012). Originally published in Chicago: The Reilly and Lee Company, 1937.

Guttmann, Allen. From Ritual to Record: The Nature of Modern Sports. New York: Columbia University Press, 1978.

Habermas, Jürgen. "Modernity: An Incomplete Project.” In The Anti-aesthetic: Essays on Postmodern Culture, edited by Hal Foster, 3-15. Washington: Bay Press, 1983.

---. The Theory of Communicative Action, Volume 1: Reason and the Rationalization of Society. Boston: Beacon Press, 1985.

Hall, Stuart. "Encoding/decoding," In Culture, Media, and Language: Working Papers in Cultural Studies 1972-1979. Edited by Stuart Hall, Dorothy Hobson, Andrew Lowe, and Paul Wills, 128-39. London: Hutchinson, 1980.

Hart, Bret. Forward to Tributes II: Remembering More of the World's Greatest Professional Wrestlers. by Dave Meltzer, vii-ix. Champaign, IL: Sports Publishing L.L.C., 2004.

---. Hitman: My Real Life in the Cartoon World of Wrestling. New York: Grand Central Publishing, 2007.

---. “The Hitman versus 'The Wrestler.'” 2009. http://www2.macleans.ca/2009/02/16/thehitman-versus-'the-wrestler'/ (accessed April 1, 2012).

Harvey, David. The Condition of Postmodernity: An Enquiry into the Origins of Cultural Change. Cambridge: Blackwell, 1990.

Henricks, Thomas. "Professional Wrestling as Moral Order." Sociological Inquiry 44, no. 3 (1974): 177-188.

Hoffman, Jeane. "Thesz Sez Age of Gimmicks in Wrestling Will Soon be Over." Los Angeles Times (1923-Current File), May 20, 1952. C3, http://search.proquest.com/docview/166298048?accountid=10141.

Holt, Richard. Sport and the British: A Modern History. Oxford: Clarendon Press, 1989.

Horiuchi, Isamu. "Real Fighting: The Emergence and Reemergence of the Ultimate Fighting Championship as Reality Entertainment.” Unpublished manuscript. 2012.

Horkheimer, Max, and Theodor W. Adorno. Dialectic of Enlightenment: Philosophical Fragments. Edited by Gunzelin Schmid Noerr. Translated by Edmund Jephcott. Stanford: Stanford University Press, 2002. 
Jameson, Fredric. Postmodernism, or, the Cultural Logic of Late Capitalism. Durham: Duke University Press, 1991.

Jenkins, Henry. "'Never Trust a Snake': WWE Wrestling as Masculine Melodrama.” In Out of Bounds: Sports, Media and the Politics of Identity, edited by Aaron Baker and Todd Boyd, 48-78. Bloomington: Indiana University Press, 1997.

---. "Star Trek Rerun, Reread, Rewritten: Fan Writing as Textual Poaching." In Fans, Bloggers, and Gamers: Exploring Participatory Culture, 37-60. New York: New York University Press, 2006. Originally Published in Critical Studies in Mass Communication 5, no. 2 (1988): 85-107.

---. The Wow Climax: Tracing the Emotional Impact of Popular Culture. New York: New York University Press, 2007.

Jenkins IV, Henry. “Afterword, Part II: Growing up and Growing More Risqué.” In Steel Chair to the Head: The Pleasure and Pain of Professional Wrestling, edited by Nicholas Sammond. 317-342. Durham: Duke University Press, 2005.

Jericho, Chris, and Peter T. Fornatale. Undisputed: How to Become the World Champion in 1372 Easy Steps. New York: Grand Central Publishing, 2011.

Kerr, Peter. "Now It Can Be Told: Pro Wrestlers Are Just Having Fun: It's Out Now: Wrestling Is All in Fun." New York Times (1923-Current file). Feb 10, 1989. http://search.proquest.com/docview/110196575?accountid=10141

Kobayashi, Masayuki. "Puroresu Shakaigaku he no Shoutai: Ideology and Texture (An Introduction to the Sociology of Professional Wrestling: Ideology and Texture)." Gendai Shiso (Modern Thought) 30-3 (2002): 97-110.

Krips, Henry. “A Mass Media Cure for Auschwitz: Adorno, Kafka and Žižek.” International Journal of Žižek Studies 1, no. 4 (2007): 1-21.

Leverrette, Mark. Professional Wrestling, the Myth, the Mat, and American Popular Culture. Lewiston: Edwin Mellen Press, 2003.

Lincoln, Bruce. Discourse and the Construction of Society. Oxford: Oxford University Press, 1989.

Lyotard, Jean-François. The Postmodern Condition: A Report on Knowledge. Translated by Geoff Bennington and Brian Massumi. Minneapolis: University of Minnesota Press, 1984.

Maguire, Brendan, and John F. Wozniak. "Racial and Ethnic Stereotypes in Professional Wrestling.” Social Justice Journal 24, no. 3 (1987): 261-273. 
Mazer, Sharon. Professional Wrestling: Sports and Spectacle. Jackson: University Press of Mississippi, 1998.

Meltzer, Dave. Wrestling Observer Newsletter. Feb. 20, 1989.

---. Wrestling Observer Newsletter. May 11, 1998.

---. Wrestling Observer Newsletter. March 17, 2003.

---. Wrestling Observer Newsletter. March 24, 2003.

---. Wrestling Observer Newsletter. March 7, 2005.

---. Wrestling Observer Newsletter. July 19, 2007.

---. Wrestling Observer Newsletter. Nov. 29, 2010.

---. Wrestling Observer Newsletter. Dec. 6, 2010.

---. Wrestling Observer Newsletter. Jan. 31, 2011.

Migliore, Sam. "Professional Wrestling: Moral Commentary Through Ritual Metaphor." Journal of Ritual Studies 7 (1993): 65-84.

Mitchell, Bruce. “PPV Roundtable.” Pro Wrestling Torch 1179 (2010), 14.

---. “WRESTLEMANIA 26 PPV Roundtable.” Pro Wrestling Torch 1140/1141 (2010), 8.

Morton, Gerald W., and George M. O'Brien. Wrestling to Rasslin: Ancient Sport to American Spectacle. Bowling Green: Bowling Green State University Popular Press, 1985.

Negus, Keith. "The Production of Culture." In Production of Culture/Cultures of Production, edited by Paul du Gay, 67-104. London: Sage, 1997.

Nichols, Bill. Representing Reality: Issues and Concepts in Documentary. Bloomington: Indiana University Press, 1991.

Nonini, Donald M., and Akiko Arlene Teraoka. "Class Struggle in the Squared Circle: Professional Wrestling as a Working-Class Sport." In The Politics of Culture and Creativity: A Critique of Civilization, edited by Christine Ward Gailey, 147-168. Gainsville: University of Florida Press, 1992.

Piermarini, John. "TORCH TALK with John Piermarini Part 2: Detailed Account of Writing for Vince McMahon, Working under Brian Gewirtz, Why He Left WWE.” Interview by Wade Keller, Pro Wrestling Torch. 1191 (2011), 1, 13-14. 
Randazzo V, Matthew. Ring of Hell: The Story of Chris Benoit \& the Fall of the Pro Wrestling Industry. Beverly Hills: Phoenix Books, 2008.

Rivlin, Christopher. "Aronofsky Looks over a Wrestler's shoulder for his Latest Endeavor." 2008. http://www.tuftsdaily.com/arts/aronofsky-looks-over-a-wrestler-s-shoulder-for-hislatest-endeavour-1.1048903 - .T5JNxBxbx_U (accessed April 1, 2012).

Sammond, Nicholas. "Introduction: A Brief and Unnecessary Defense of Professional Wrestling." In Steel Chair to the Head: The Pleasure and Pain of Professional Wrestling, edited by Nicholas Sammond, 1-21. Durham: Duke University Press, 2005.

Saunders, Terry M. "Play, Performance and Professional Wrestling: An Examination of a Modern Day Spectacle of Absurdity." PhD diss., University of California, Los Angeles. 1998.

Stallybrass, Peter, and Allon White. The Politics and Poetics of Transgression. Ithaca: Cornell University Press, 1986.

The Phantom of the Ring. "Unreal Stories." http://www.wrestlingperspective.com/UnrealVideo.html (accessed April 1, 2012).

Thesz, Lou, and Kit Bauman. Hooker: An Authentic Wrestler's Adventures Inside the Bizarre World of Professional Wrestling. Edited by Mike Chapman. Seattle: Wrestling Channel Press, 2000.

Tranter, Neil. Sport, Economy, and Society in Britain 1750-1914. Cambridge: Cambridge University Press, 1998.

Waltman, Sean. "When Jericho Came to the WWF, He Didn't Get it Yet." Interview by Wade Keller. Pro Wrestling Torch. 726 (2002), 9-12.

Webley, Irene A. "Professional Wrestling: The world of Roland Barthes Revisited." Semiotica 58 (1986): 59-81.

Weisberg, Dan. "Wrestling with the Audience: Fan Culture on the Internet." PhD diss., Northwestern University. 2005.

Žižek, Slavoj. The Sublime Object of Ideology. London: Verso, 1989. 